4open 2019, 2, 9

(c) B.L.D.M. Brücher and I.S. Jamall, Published by EDP Sciences 2019

https://doi.org/10.1051/fopen/2018008

\title{
Eicosanoids in carcinogenesis
}

\author{
Björn L.D.M. Brücher ${ }^{1,2,3, *}$, Ijaz S. Jamall ${ }^{1,2,4}$ \\ 1 Theodor-Billroth-Academy ${ }^{\circledR}$, Germany, USA \\ 2 INCORE, International Consortium of Research Excellence of the Theodor-Billroth-Academy ${ }^{\circledR}$, Germany, USA \\ 3 Department of Surgery, Carl-Thiem-Klinikum, Cottbus, Germany \\ ${ }^{4}$ Risk-Based Decisions Inc., Sacramento, CA, USA
}

Received 21 March 2018, Accepted 16 December 2018

\begin{abstract}
Inflammation is the body's reaction to pathogenic (biological or chemical) stimuli and covers a burgeoning list of compounds and pathways that act in concert to maintain the health of the organism. Eicosanoids and related fatty acid derivatives can be formed from arachidonic acid and other polyenoic fatty acids via the cyclooxygenase and lipoxygenase pathways generating a variety of pro- and anti-inflammatory mediators, such as prostaglandins, leukotrienes, lipoxins, resolvins and others. The cytochrome P450 pathway leads to the formation of hydroxy fatty acids, such as 20-hydroxyeicosatetraenoic acid, and epoxy eicosanoids. Free radical reactions induced by reactive oxygen and/or nitrogen free radical species lead to oxygenated lipids such as isoprostanes or isolevuglandins which also exhibit pro-inflammatory activities. Eicosanoids and their metabolites play fundamental endocrine, autocrine and paracrine roles in both physiological and pathological signaling in various diseases. These molecules induce various unsaturated fatty acid dependent signaling pathways that influence crosstalk, alter cell-cell interactions, and result in a wide spectrum of cellular dysfunctions including those of the tissue microenvironment. Although the complete role of eicosanoids, including that of the recently elucidated anti-inflammatory specialized pro-resolving lipid mediators (SPMs), e.g. lipoxins, resolvins, protectins and maresins, is not completely understood, the result of unremitting chronic inflammation is fostering early stages of carcinogenesis. Chronic inflammation facilitates the transition from a normal cell to a cancerous one. The disruption of homeostasis across a wide, but identifiable, swath of diverse molecular pathways creates a micromilieu which constitutes an early and necessary step in the 6 -step sequence of carcinogenesis for the vast majority of cancers, termed "sporadic cancers".
\end{abstract}

Keywords: 20-HETE, Cancer, Carcinogenesis, Cell transition, Chronic inflammation, Cyclooxygenase, Cox, EET, Eicosanoids, Epidemiology, Epigenetics, Fibrosis, Genomics, Leukotrienes, microRNA, Mutation, Pathogenesis, Precancerous niche, Proteomics, Reactive oxygen species, ROS, Somatic mutation

\section{Introduction}

The term eicosanoids comes from the Ancient Greek term 'Eik ${ }^{\prime} o \sigma \iota$ ' (eikosi) meaning twenty. A chain of 20 polyunsaturated fatty acids (PUFA) is found in every mammalian cell with 20 carbon atoms and 4 double bonds in the cis-position also known as arachidonic acids (AA) and named all-cis-5,8,11,14-eicosatetraenoic acid [1]. $\mathrm{C}_{20} \mathrm{H}_{32} \mathrm{O}_{2}, 20: 4(\omega-6)$ is the chemical formular for omega-6 ( $\omega-6)$ PUFA in which 20:4 refers to its 20 carbon atom chain with four double bonds and $\omega-6$ refers to the position of the first double bond from the last, omega carbon atom. AA are found in animal and human tissue, in plants, and in food [1-6]. AA are esterified to membrane phospholipids. We now recognize their

\footnotetext{
*Corresponding author: b-bruecher@gmx . de
}

importance "for normal cellular membrane fluidity, but also as a substrate for numerous enzymatic transformations that form biologically active lipid mediators, such as prostaglandins, leukotrienes, epoxyeicosatetraenoic acids, and endocannabinoids" [5].

Although scientists investigated neutral fats, such as glycerins and phospholipids, as far back as in the 19th century [7-10 reviewed in 11-13], significant progress began in the early days of X-ray crystallography [14 reviewed in 5]. Fish oil studies took place between 1899 and 1906 [15-17], and the Japanese chemist, Mitsumaru Tsujimoto (1877-1940), described how the addition of bromine could result in products of PUFA which could then be crystalized [17]. The British physiologist, Sir Percival Hartley (1881-1957), was the first to isolate and purify AA and understood that these fatty acids had four double bonds [18 reviewed in 5,19]. 

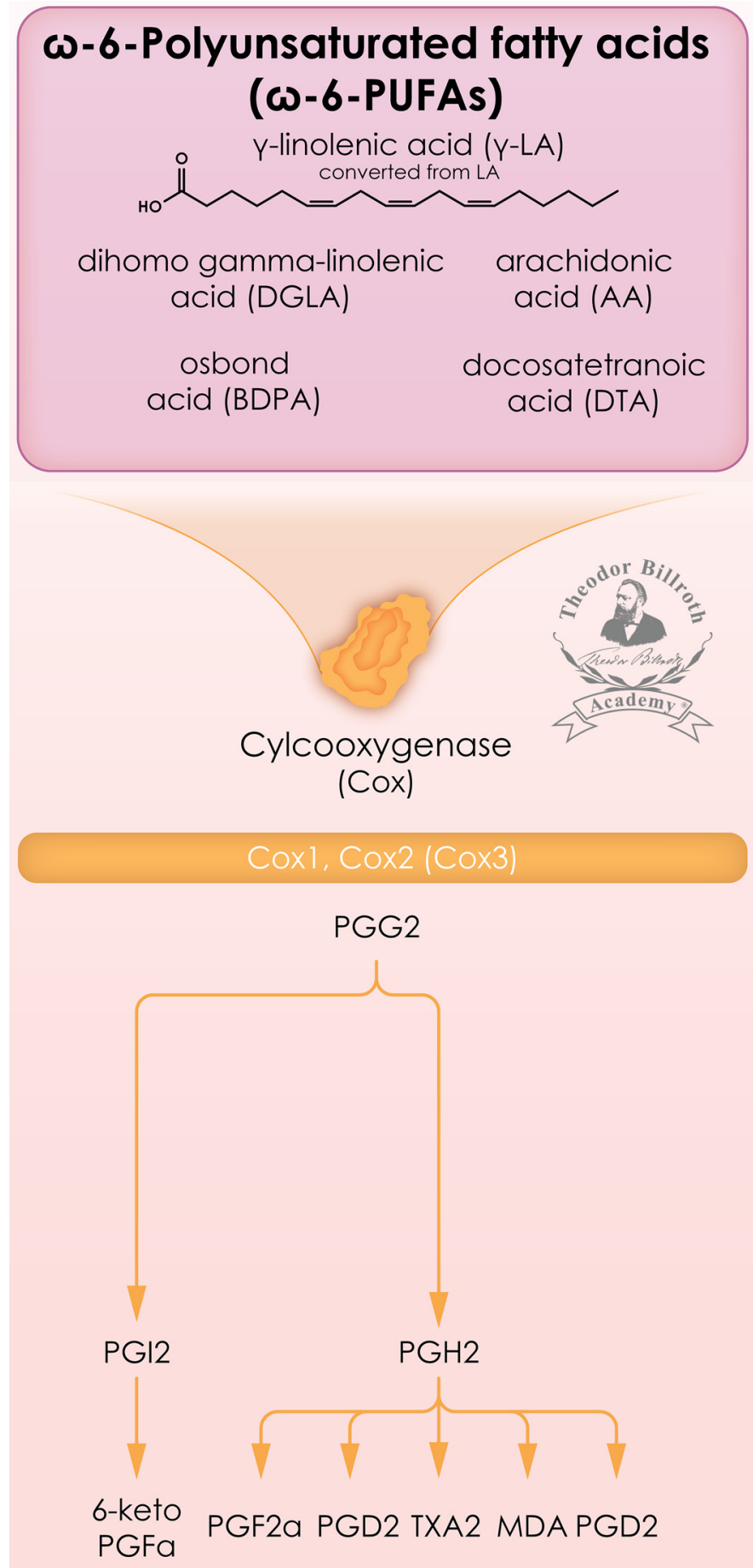

\section{pro-inflammatory}

Fig. 1. Cyclooxygenase (Cox) pathway of eicosanoid metabolism and its relevance in inflammation. Nomenclature: Simplified scheme of the cyclooxygenase pathway (COX) leading to the formation of pro-inflammatory prostaglandins. The nomenclature common abbreviations are bold, followed by the common trivial names (if available) and (if available) by the name in accordance to the International Union of Pure and Applied Chemistry (IUPAC): (-6-6-PUF As N-6 polyunsaturated fatty acid; LA linoleic acid, cis, cis9,12-octadecadienoic acid; LA is not a direct substrate of prostaglandins - this occurs after metabolism to $\gamma$-LA; therefore LA here is in brackets; $\boldsymbol{\gamma}$-LA gamma linolenic acid; DGLA dihomo gamma-linolenic acid, (8Z,11Z,14Z)-8,11,14-Icosatrienoic acid; AA archidonic acid, (5Z,8Z,11Z,14Z)-5,8,11,14-eicosatetraenoic acid; DTA docosatetranoic acid, (7Z,10Z,13Z,16Z)-7,10,13,16-docosatetraenoic acid; BDPA osbond acid, (All-Z)-4,7,10,13,16-docosapentaenoic acid; Cox-1 cyclooxygenase 1; Cox-2 cyclooxygenase 2; Cox-3 splice variant and isoform of Cox-2, (therefore in brackets); PGG2 prostaglandin G2, (Z)-7-[(1S,4R,5R,6R)-5-[(E,3S)-3hydroperoxyoct-1-enyl]-2,3-dioxabicyclo[2.2.1]heptan-6-yl]hept-5-enoic acid; PGI2 prostaglandin I2, prostacyclin I2, (5Z)-5- 
The German chemical engineer, Julius Isidor Lewkowitsch (1857-1913), moved to England in 1887 and in 1913 coined the term "arachidonic acid" for those fatty acids which had been described earlier by Sir Hartley [20].

It was observed that the application of human seminal fluid induced uterine contractions [21 reviewed in 22], which later was identified as due to lipophilic compounds [23]. Von Euler thought that such compounds were produced by the prostate and therefore named these as prostaglandins (PGs) [24]. There is an alternative reason for the name of PGs, which is the 5-membered prostane ring in its structure. It was Karl Sune Detlof Bergström (1916-2004) and Jan Sjövall who showed that PGs come from seminal vesicles and isolated PG E (PGE) and PG F2alpha (PGF2 $\alpha)[25]$. Two independent groups showed that PGs are derived from essential fatty acids [26,27]. Sir John Robert Vane (1927-2004) showed that PG synthesis could be inhibited by aspirin and aspirin-like drugs [28]. In 1982, Vane and Bergström received the Nobel Prize for the discoveries of PGs, and Samuelsson for the discoveries of leukotrienes.

Due to their complexity, the following discussion of eicosanoids contains their pathways of cyclooxygenases (Cox), lipoxygenase (ALOX), cytochrome P450 (CYP) and reactive oxygen species (ROS) and/or reactive nitrogen species (RNS), followed by unsaturated fatty acids and the recently discovered specialized antiinflammatory lipid mediators (SPMs).

\section{Eicosanoids}

Eicosanoids contain signal-mediating molecules such as PGs, prostacyclines, thromboxanes (TXAs), leukotrienes (LTs), and related fatty acid derivatives which are integrated into the phospholipids of the cellular membranes formed from PUFA, especially the AA and other polyenioic fatty acids through four pathways $[1,6]$ namely:

- the Cox pathway (Cox) (Fig. 1) leads to the formation of pro- and anti-inflammatory PGs [29-33],

- the LOX (ALOX) pathway (Fig. 2) leads to the formation of pro- and anti-inflammatory mediators, [34-38],

- the CYP pathway (Fig. 3) leads to the formation of hydroxy fatty acids (20-HETE) and epoxy eicosanoids [39-44] and
- free radical reactions induced by ROS and/or RNS lead to oxygenated lipids such as isoprostanes or isolevuglandins which exhibit pro-inflammatory activities [45-51].

For some time, eicosanoids have been known to be associated with diarrhea [52] and inflammation [53], and it was known that exogenous AA resulted in PGE synthesis [54]. Furthermore, that PGE was produced by mast cells $[55,56]$, polymorphonuclear leukocytes [57], and macrophages [58]. Once the inflammatory effect of PGs were identified [59,60], contradictory findings were reported which suggested that PGs act as a turn-on/off mediator relevant for homoestasis [61,62] and that PGs were not accumulated but instead were newly synthesized [56].

One key checkpoint of AA metabolism is phospholipase A2 (PLA2); this enzyme was first isolated and purified from the venom of Vipera berus in 1971 [63]. Later the purification, sequencing and cloning of the first human non-pancreatic form obtained from synovial arthritic knee fluid (a point of inflammation) was identified $[64,65]$. A PLA2 superfamily has since been recognized [66].

The substrate for Cox, ALOX and CYP to generate eicosanoids are the AA. PLA2 in the cytosol is a key control checkpoint for inflammation and acts by hydrolyzing AA from membrane phospholipids [67]. The crystalline structure of human pancreatic PLA2 was determined [68] including its anti-bacterial and anti-viral functions $[69,70]$. PLA2s are expressed by macrophages, monocytes, T cells, mast cells, and neutrophils [71] and we know that the PLA2 in the cytoplasm responsible for the production of lipid mediators in human macrophages is cytosolic PLA2-alpha [72 reviewed in 66]. PLA2 knockdown in mice results in less PG synthesis, decreased inflammation, and decreased cancer development [73]. The anti-inflammatory effect of zinc is thought to be mediated by inhibition of PLA2 [74].

RAF proto-oncogene serine/mitogen-activated protein kinase kinase 1,2/threonine-protein kinase/extracellular signal-regulated kinase (Raf1/MEK1,2/Erk1,2) is activated by protein kinase $\mathrm{C}$ (PKC) activators such as phorbol esters but after stimulation of Erk2 phosphorylation, e.g., endotoxin. This pathway is only partially inhibited showing that there is a PKC independent pathway involved in E2k2 phosphorylation. The authors showed that using the selective inhibitor bis-indolylmaleimide (BIM) inhibited arachidonate metabolites from activated macrophages and that PKC-dependent

[(3aR,4R,5R,6aS)-5-hydroxy-4-[(E,3S)-3-hydroxyoct-1-enyl]-3,3a,4,5,6,6a-hexahydrocyclopenta[b]furan-2-ylidene]pentanoic acid; 6-keto-PGF1 $\boldsymbol{\alpha}$ 6-keto-prostaglandin F1alpha, 7-[(1R,2R,3R,5S)-3,5-dihydroxy-2-[(E,3S)-3-hydroxyoct-1-enyl]cyclopentyl]-6-oxoheptanoic acid; PGH2 prostaglandin H2, (Z)-7-[(1S,4R,5R,6R)-5-[(E,3S)-3-hydroxyoct-1-enyl]-2,3-dioxabicyclo[2.2.1]heptan-6-yl] hept-5-enoic acid; PGFF2 $\boldsymbol{\alpha}$ prostaglandine F2 alpha, (Z)-7-[(1R,2R,3R,5S)-3,5-dihydroxy-2-[(E,3S)-3-hydroxyoct-1-enyl]cyclopentyl]hept-5-enoic acid; PGD2 prostaglandin D2, (Z)-7-[(1R,2R,5S)-5-hydroxy-2-[(E,3S)-3-hydroxyoct-1-enyl]-3-oxocyclopentyl] hept-5-enoic acid; PGE2 prostaglandin E2, (Z)-7-[(1R,2R,3R)-3-hydroxy-2-[(E,3S)-3-hydroxyoct-1-enyl]-5-oxocyclopentyl]hept-5enoic acid; TXA2 thromboxane A2, (Z)-7-[(1S,2S,3R,5S)-3-[(E,3S)-3-hydroxyoct-1-enyl]-4,6-dioxabicyclo[3.1.1]heptan-2-yl]hept-5enoic acid; MDA malondialdehyde, propanedial. 


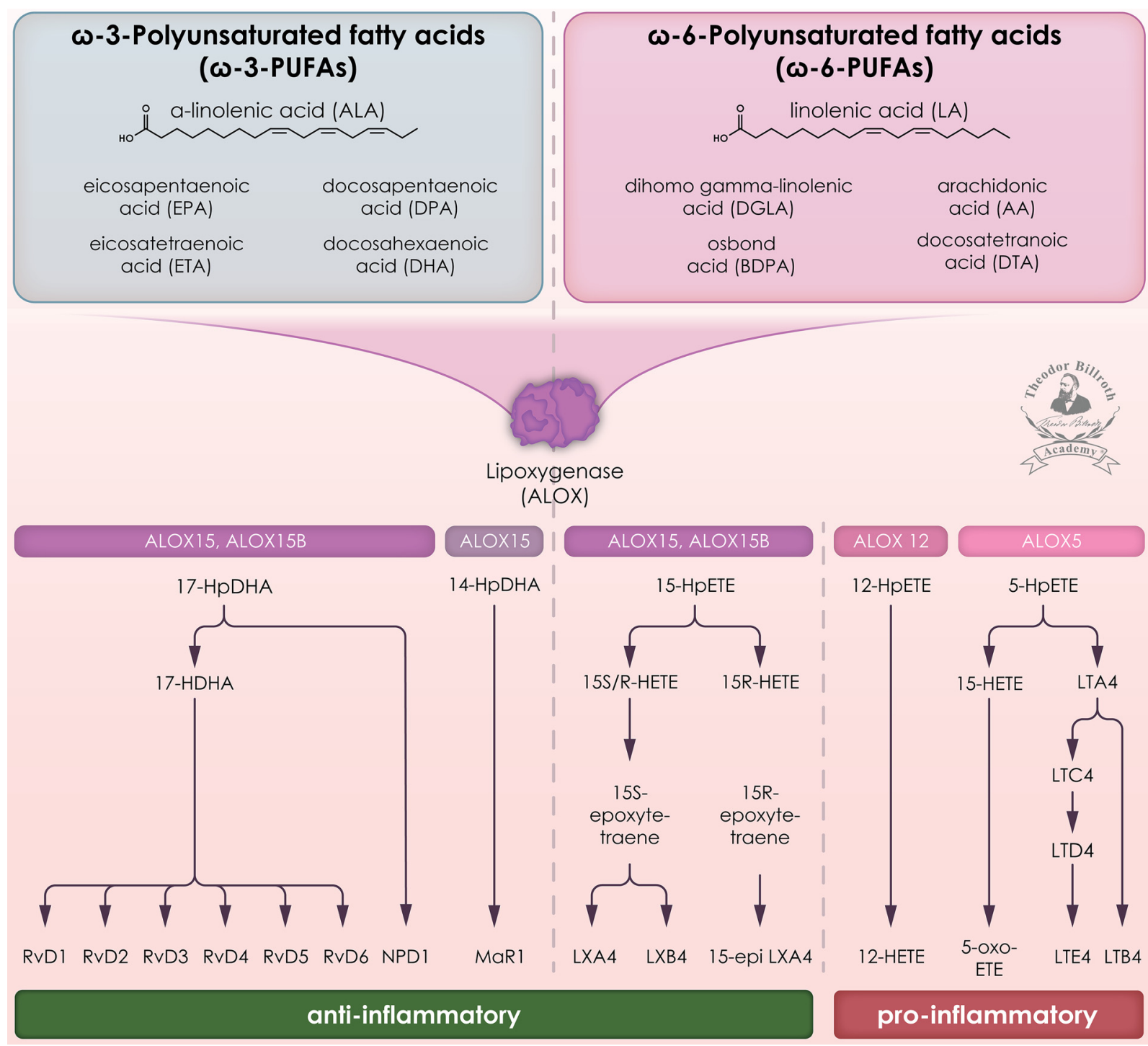

Fig. 2. Lipoxygenase (ALOX) pathway of eicosanoid metabolism and its relevance in inflammation. Nomenclature: Simplified scheme of polyenioic fatty acid metabolism via the lipoxygenase (ALOX) pathway, leading to the formation of anti- and proinflammatory mediators. Common abbreviations are bold, followed by the common trivial names (if available) and (if available) by the name in accordance to the International Union of Pure and Applied Chemistry (IUPAC): $\boldsymbol{\omega}-\mathbf{3 - P U F A s ~ N - 3 ~ p o l y u n s a t u r a t e d ~ f a t t y ~}$ acid; ALA $\alpha$-linolenic acid, (9Z,12Z,15Z)-octadeca-9,12,15-trienoic acid; ETA eicosatetraenoic acid, all-cis-8,11,14,17-eicosatetraenoic acid; EPA eicosapentaenoic acid, (5Z,8Z,11Z,14Z,17Z)-eicosa- 5,8,11,14,17-pentenoic acid; DPA docosapentaenoic acid, 7,10,13,16,19-docosapentaenoic acid; DHA docosahexaenoic acid, (4Z,7Z,10Z,13Z,16Z,19Z)-docosa-4,7,10,13,16,19-hexaenoic acid; (w-6-PUF As N-6 polyunsaturated fatty acid; LA linoleic acid, cis, cis-9,12-octadecadienoic acid; DGLA dihomo gamma-linolenic acid, (8Z,11Z,14Z)-8,11,14-Icosatrienoic acid; AA archidonic acid, (5Z,8Z,11Z,14Z)-5,8,11,14-eicosatetraenoic acid; DTA docosatetranoic acid, (7Z,10Z,13Z,16Z)-7,10,13,16-docosatetraenoic acid; BDPA osbond acid, (All-Z)-4,7,10,13,16docosapentaenoic acid; ALOX lipoxygenase, arachidonate lipoxygenase; ALOX15 15-lipoxygenase, 15-LOX, 15-LOX-1, arachidonate 15-lipoxygenase; ALOX15B 15-lipoxygenase type II, 15-LOX-2, arachidonate 15-lipoxygenase type B; ALOX12 12-lipoxygenase, 12-LOX, 12S-LOX, arachidonate 12-lipoxygenase 12S type; ALOX5 5- lipoxygenase, 5-LOX, arachidonate 5-lipoxygenase; 17-HpDHA 17S-hydroperoxy-4Z,7Z,10Z,13Z,15E,19Z-docosahexaenoic acid; 17-HDHA 17S-hydroxy4Z,7Z,10Z,13Z,15E,19Z-docosahexaenoic acid; RvD1 resolvin D1, (4Z,7S,8R,9E,11E,13Z,15E,17S,19Z)-7,8,17-trihydroxydocosa4,9,11,13,15,19-hexaenoic acid; RvD2 resolvin D2, (4Z,7S,8E,10Z,12E,14E,16R,17S,19Z)-7,16,17-trihydroxydocosa-4,8,10,12,14,19hexaenoic acid; RvD3 resolvin D3, (4S,5E,7E,9E,13Z,15E,17R,19Z)-4,11,17-trihydroxydocosa-5,7,9,13,15,19-hexaenoic acid; RvD4 resolvin D4, (4S,6E,8E,10E,13E,15Z,17S,19Z)-4,5,17-trihydroxydocosa-6,8,10,13,15,19-hexaenoic acid; RvD5 resolvin D5, (5Z,7S,8E,10Z,13Z,15E,17S,19Z)-7,17-dihydroxydocosa-5,8,10,13,15,19-hexaenoic acid; RvD6 resolvin D6, (4S,5E,7Z,10Z,13Z,15E,17S,19Z)-4,17-dihydroxydocosa-5,7,10,13,15,19-hexaenoic acid; NPD1 neuroprotectin D1, protectin D1, (4Z,7Z,10R,11E,13E,15Z,17S,19Z)-10,17-dihydroxydocosa-4,7,11,13,15,19-hexaenoic acid; 14-HpDHA 14-hydro(peroxy)-docosahexaenoic acid, 4-[(1E,3E,5E,7E,9E)-nonadeca-1,3,5,7,9-pentaenyl]dioxete-3-carboxylic acid; MaR1 maresin 1, (4Z,7R,8E,10E,12Z,14S,16Z,19Z)-7,14-dihydroxydocosa-4,8,10,12,16,19-hexaenoic acid; 15-HpETE 15-hydroperoxy-eicosatetraenoic acid, (5Z,8Z,11Z,13E)-15-hydroperoxyicosa-5,8,11,13-tetraenoic acid; 15S/R-HETE 15S-HETE (5Z,8Z,11Z,13E,15S)-15- 
Erk2-phosphorylation by the benzamide derivative JM34, which inhibits tumor necrosis factor alpha $(\mathrm{TNF} \alpha)$ from macrophages, and is based on its inhibitory effect on PLA2 activation [75].

\section{Cyclooxygenase (Cox) pathway and pro- and anti-inflammatory Prostaglandins (PGs) (Fig. 1)}

Increased cyclooxygenase 2 (Cox-2) in human colorectal adenomas and adenocarcinomas was first reported in 1994 [76] followed by the association of Cox-2 with chronic inflammation and colorectal cancer (CRC) [77-79]. The degree of malignancy in lung cancer is directly correlated with Cox-2 expression [80]. Co-localization of HBx with the inner mitochondrial cytochrome c oxidase protein COXIII in liver cancer cells upregulates Cox-2 with consecutive ROS-induced cell growth [81].

It is known that PGs have multiple effects and are involved in inflammatory diseases such as rheumathoid arthritis, asthma, cardiovascular diseases, and cancer [22,82-89].

There is an association of cyclic adenosine $3^{\prime}, 5^{\prime}$ monophosphate (cAMP) and PGs. cAMP was shown to be activated or abnormally regulated in neoplasia [90,91] but its impact in cancer is controversial as it was suggested cAMP has an inverse correlation with tumor growth [92] or is involved in hormone-induced tumor growth arrest [93], compared to the interrelationship between cAMP and $3^{\prime}, 5^{\prime}$-cyclic guanosine monophosphate (cGMP) [94].

Mouse-derived fibroblasts transformed by the oncogenic polyomavirus, simian virus (SV40), resulted in constant cAMP activity. On the other hand, SV40transformed rat fibroblasts show decreased cAMP levels. Stimulating cAMP with PGs revealed that this phenomenon depends on prostaglandin E2 (PGE2). PGF2 $\alpha$ and prostaglandin B1 (PGB1) were more effective as compared to prostaglandin A2 (PGA2) [95]. These experiments are important in that they reveal that $\mathrm{PGs}$ have different effects and that the same experiment in different species may produce different results.
PGs can be produced by tumors [96,97] and it was shown that PGs activate cAMP [98]. It has long been suspected that PGs and cAMP are involved in cell growth and cancer development [99] but this seems to be dependent on which specific PG is involved. PGF1alpha (PGF1a) and PGF2alpha (PGF2a) do not increase cAMP but 2-acetylaminofluorene (AAF)-induced cancer is associated with increased prostaglandin E1 (PGE1) [100].

The two Cox isoforms, cyclooxygenase 1 (Cox-1) and Cox-2 utilize AA liberated from membrane phospholipids and catalyze the conversion of AA to prostanoids. A splice variant of Cox-1, is cyclooxygenase 3 (Cox-3; also called Cox-1b or Cox-1 variant) [101]. Inflammation-induced Cox-2 is regulated by cytokines through macrophage activation [102] while Cox-1 is expressed constitutively [103]. Cox-2 is repressed physiologically by $1 \alpha, 25(\mathrm{OH}) 2-$ cholecalciferol (equivalent to $1 \alpha, 25(\mathrm{OH}) 2$ vitamin D3, $1,25(\mathrm{OH}) 2 \mathrm{D} 3$, calcitriol), which is the active form of vitamin D [104] and by glucocorticosteroids [105].

Cox-2 mRNA and protein suppression by calcitriol leads to an increase of the PG catabolyzing enzyme, 15-hydroxyprostaglandin dehydrogenase, which in turn decreases levels of PGs and inflammatory cytokines [106]. The bioxygenase activity of Cox catalyzes the addition of two oxygens to AA producing an unstable cyclic hydroperoxide, prostaglandin G2 (PGG2), which is then reduced by Cox peroxidase activity to an endoperoxide, prostaglandin $\mathrm{H} 2$ (PGH2). PGH2 is converted by various routes to prostaglandins (e.g. PGE2), prostacyclin, and thromboxane A2 (TXA2) [107,108 reviewed in 101].

In K562 human leukemia cells, PGE2 activates $\mathrm{Ca} 2^{+}$permeable transient receptor potential cation 7 (TRPC7) channels which can trigger apoptosis [109]. NAD- and $\mathrm{NADP}$ - radicals triggered by Cox peroxidase activity generate superoxide $(\mathrm{O} 2 \cdot-)$ [107 reviewed in 101]. Exogenous PGE2 in human patellar tendon fibroblasts (HPTFs) induce cell death and autophagy in a dosedependent manner and mechanical stretching stimulates PGE2 resulting in cell death. In contrast, the Cox inhibitors, indomethacin and celecoxib, block PGE2 and reduce stretching-induced autophagy [110]. Lipopolysaccharide (LPS), TNF $\alpha$, interleukin-1-alpha (IL-1 $\alpha$ ), and

hydroxyicosa-5,8,11,13-tetraenoic acid; 15(R)-HETE lacks a bit of the activity attributed to their S stereoisomers of 15(S)-HETE; 15S-epoxy-tetraene 5,6-15S-HETE， 4-[(2S,3S)-3-[(1E,3E,5Z,7E,9S)-9-hydroxytetradeca-1,3,5,7-tetraenyl]oxiran-2-yl]butanoic acid; 15R-epoxy-tetraene lacks a bit of the activity attributed to their S stereoisomers of 15S-epoxy-tetraene; LXA4 lipoxin A4, (5S,6R,7E,9E,11Z,13E,15S)-5,6,15-trihydroxyicosa-7,9,11,13-tetraenoic acid; LXB4 lipoxin B4, (5S,6E,8Z,10E,12E,14R,15S)5,14,15-trihydroxyicosa-6,8,10,12-tetraenoic acid; 15-epi-LXA4 (5R,6R,7E,9E,11Z,13E,15R)-5,6,15-trihydroxyicosa-7,9,11,13tetraenoic acid; 12-HpETE 12-hydroperoxyicosa-5,8,10,14-tetraenoic acid; 12-HETE (5E,8Z,10Z,14Z)-12-hydroxyicosa5,8,10,14-tetraenoic acid; 5-HpETE (6E,8Z,11Z,14Z)-5-hydroperoxyicosa-6,8,11,14-tetraenoic acid; 15-HETE (5Z,8Z,11Z,13E)15-hydroxyicosa-5,8,11,13-tetraenoic acid; 5-oxo-ETE (6E,8Z,11Z,14Z)-5-oxoicosa-6,8,11,14-tetraenoic acid; LTA4 leukotriene A4, 4-[(2S,3S)-3-[(1E,3E,5Z,8Z)-tetradeca-1,3,5,8-tetraenyl]oxiran-2-yl]butanoic acid; LTC4 leukotriene C4, (5S,6R,7E,9E,11Z,14Z)-6[(2R)-2-[[(4S)-4-amino-4-carboxybutanoyl]amino]-3-(carboxymethylamino)-3-oxopropyl]sulfanyl-5-hydroxyicosa-7,9,11,14-tetraenoic acid; LTD4 leukotriene D4, (5S,6R,7E,9E,11Z,14Z)-6-[(2R)-2-amino-3-(carboxymethylamino)-3-oxopropyl]sulfanyl-5-hydroxyicosa7,9,11,14-tetraenoic acid; LTE4 leukotriene E4, (5S,6R,7E,9E,11Z,14Z)-6-[(2R)-2-amino-2-carboxyethyl]sulfanyl-5-hydroxyicosa7,9,11,14-tetraenoic acid; LTB4 leukotriene B4, (5S,6Z,8E,10E,12R,14Z)-5,12-dihydroxyicosa-6,8,10,14-tetraenoic acid. 

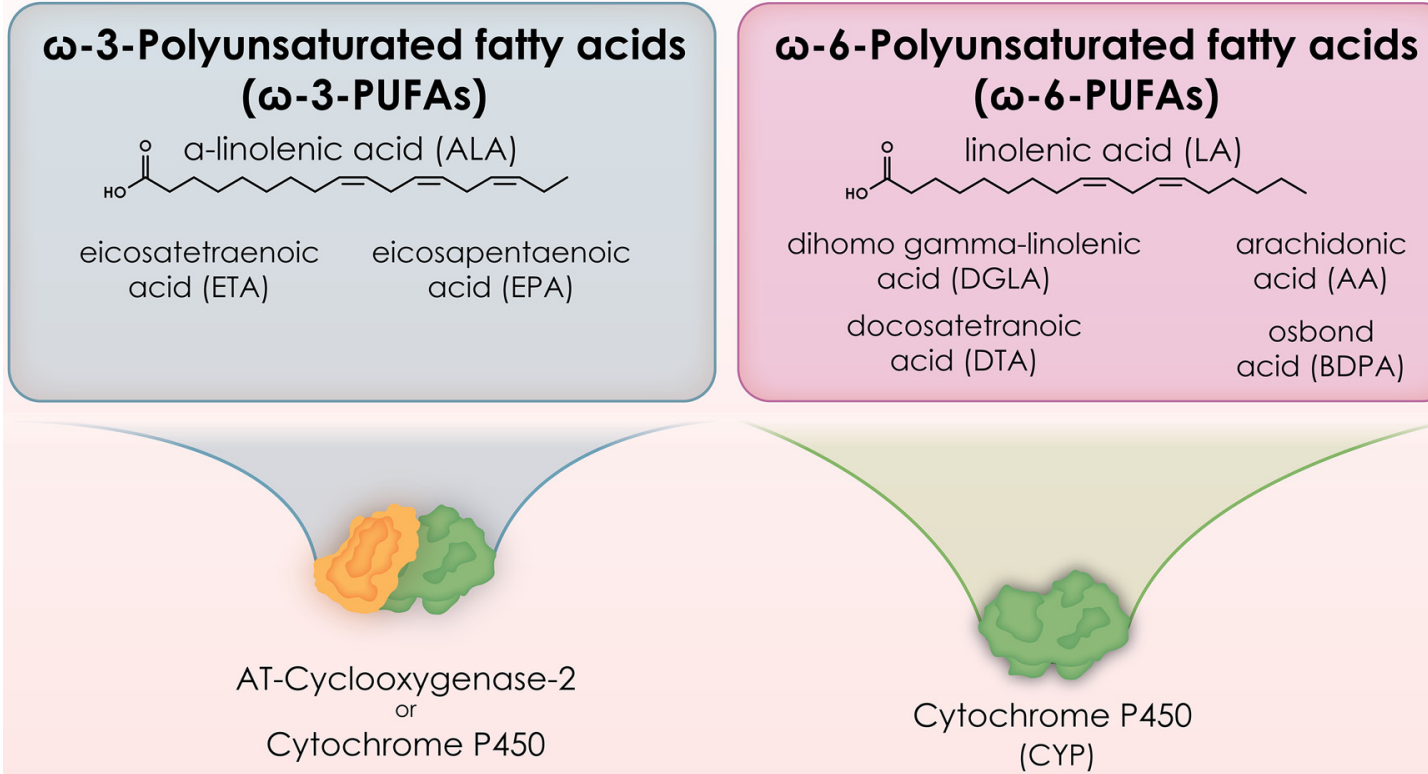
dihomo gamma-linolenic arachidonic acid (DGLA) acid (AA)
docosatetranoic acid (DTA) osbond
acid (BDPA)

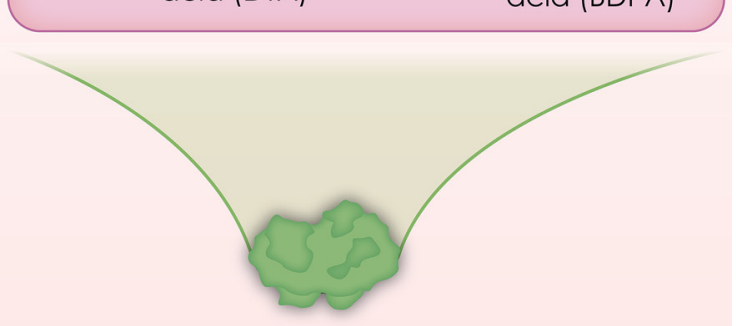

Cytochrome P450 (CYP)
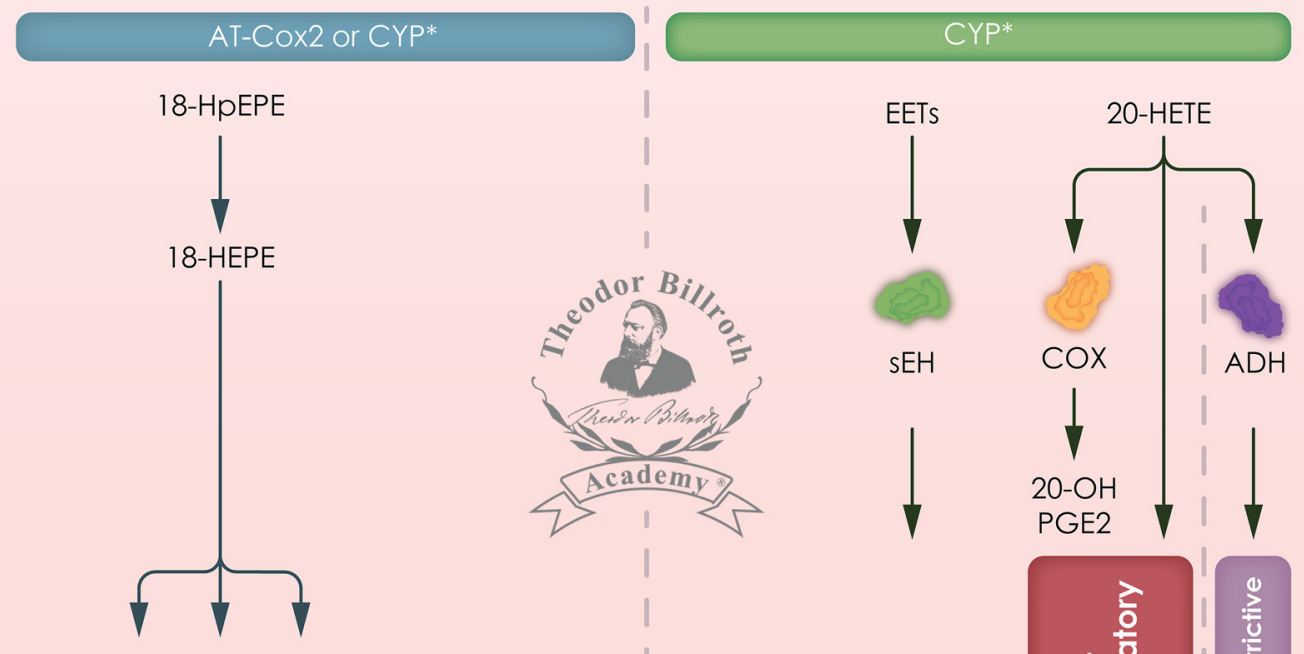

RVEI RVE2 RVE3

\section{anti-inflammatory}

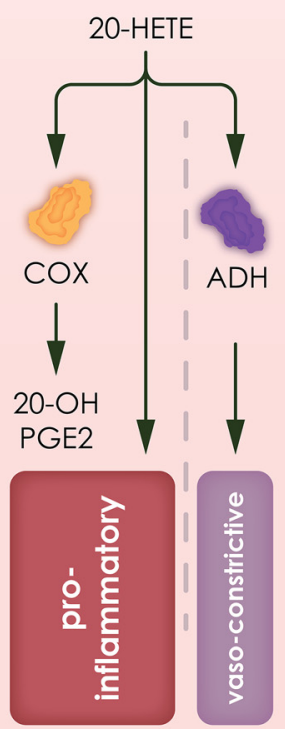

Fig. 3. Cytochrome P450 (CYP) pathway of eicosanoid metabolism and its relevance in inflammation. Nomenclature: Simplified scheme of polyenioic fatty acid metabolism via the cytochrome P450 (CYP) pathway leading to the formation of anti- and proinflammatory mediators. Common abbreviations are bold, followed by the common trivial names (if available) and (if available) by the name in accordance to the International Union of Pure and Applied Chemistry (IUPAC): $\boldsymbol{\omega}-\mathbf{3 - P U F A s ~ N - 3 ~ p o l y u n s a t u r a t e d ~ f a t t y ~}$ acid; ALA $\alpha$-linolenic acid, (9Z,12Z,15Z)-octadeca-9,12,15-trienoic acid; ETA eicosatetraenoic acid, all-cis-8,11,14,17-eicosatetraenoic acid; EPA eicosapentaenoic acid, (5Z,8Z,11Z,14Z,17Z)-eicosa- 5,8,11,14,17-pentenoic acid; DPA docosapentaenoic acid, 7,10,13,16,19-docosapentaenoic acid; DHA docosahexaenoic acid, (4Z,7Z,10Z,13Z,16Z,19Z)-docosa-4,7,10,13,16,19-hexaenoic acid; (-6-PUFAs N-6 polyunsaturated fatty acid; LA linoleic acid, cis, cis-9,12-octadecadienoic acid; DGLA dihomo gamma-linolenic acid, (8Z,11Z,14Z)-8,11,14-Icosatrienoic acid; AA archidonic acid, (5Z,8Z,11Z,14Z)-5,8,11,14-eicosatetraenoic acid; DTA docosatetranoic acid, (7Z,10Z,13Z,16Z)-7,10,13,16-docosatetraenoic acid; BDPA osbond acid, (All-Z)-4,7,10,13,16docosapentaenoic acid; AT-Cox2 aspirin-triggered cyclooxygenase 2; CYP* cytochrome P450 isoforms; 18-HpEPE 18-hydroxyeicosapentaenoic acid, 18-hydroxyicosa-2,4,6,8,10-pentaenoic acid; 18-HEPE (5Z,8Z,11Z,14Z,16E)-18-hydroxyicosa5,8,11,14,16-pentaenoic acid; RvE1 resolvin E1, (5S,6Z,8E,10E,12R,14Z,16E,18R)-5,12,18-trihydroxyicosa-6,8,10,14,16-pentaenoic acid; RvE2 resolvin E2, (5S,6E,8Z,11Z,14Z,16E,18R)-5,18-dihydroxyicosa-6,8,11,14,16-pentaenoic acid; RvE3 resolvin E3, (5Z,8Z,11Z,13E,15E,18S)-17,18-dihydroxyicosa-5,8,11,13,15-pentaenoic acid; Cox cyclooxygenase; 20-HETE 20-hydroxyeicosatetraenoic acid, (5Z,8Z,11Z,14Z)-20-hydroxyicosa-5,8,11,14-tetraenoic acid; 20-OH-PGE2 20-hydroxy prostaglandin E2; 20-COOH-HETE 20-carboxy-hydroxyeicosatetraenoic acid; EETs epoxyeicosatrienoic acid; sEH soluble epoxide hydrolase; DHETs dihydroxyeicosatrienoic acids. 
nitric oxide (NO) donor (NONOate) increases acute and or chronic inflammation in both in vivo and in vitro in bovines with enhanced PGE2, PGF2 $\alpha$, leukotriene B4 (LTB4), and leukotriene C4 (LTC4) [111,112]. Cox-1 expressions is increased at the mRNA level with prostaglandin $\mathrm{E}$ synthase (PGES) and transforming growth factor beta 1 (TGF- $\beta 1$ ) in small bowel cancers [113].

Lysophosphatidic acid (LPA) stimulates PGE2 production in stromal cells via the induction of prostaglandinendoperoxide synthase 2 (PTGS2) and PGES mRNA expression in bovine endometrium [114] and through activating its $\mathrm{G}$ protein-coupled receptors (LPAR 1-6) directly influences aspects of endometriosis and reproductive tissue associated tumors [115]. PGE2 generated by Cox-2 in mice can protect beta-cells from apoptosis [116].

Another Cox isoform, Cox-3, is under investigation and not completely elucidated. It was first disovered in 1989 and found primarily to be expressed in the cerebral cortex and the heart [117]. We now know that Cox-3 is also found in the kidney and aorta [118]. Cox-3 is encoded by the same gene as Cox-1 with a difference of one intron and is under investigation [119]: Cox-3 derives from Cox- 1 and is a smaller protein which is why it is also named partial Cox-1 (pCox-1), pCox-1 protein or Cox variant Cox-1V1. It is selectively inhibited by acetaminophen, phenacetin, antipyrine, and dipyrone, as well as by some non-steroidal anti-inflammatory drugs (NSAIDs) and useful in treating pain and fever. It shares all the catalytic features and important structural features of Cox- 1 and -2 and its inhibition results in decreases of PGE2. Cox-3 may be involved in the regulation of body temperature [120-122]. Cox-3 assays using an anti-Cox-3 polyclonal sera pCox-1a was shown to have a little lower weight compared to Cox-3 $(65 \mathrm{kD})$ [Fig. 1 of 123]. NSAIDs inhibit PG synthesis and thereby function as anti-inflammatories and analgesics [124].

Acetaminophen $\left(\right.$ Paracetamol $^{\circledR}$ ) was synthesized 1878 [125] and is included as a NSAID. It is interesting that it was reported not to reduce inflammation or inhibit platelet aggregation and does not prolong bleeding time nor does it induce bleeding or ulceration [126] but it inhibits Cox-3 with a decrease in body temperature [122]. Cox-3 is highly expressed in cerebral endothelial cells and decreases PGE2 [127]. Cox-3 inhibition in rats increases PGE2, prostaglandin I2 (PGI2, prostacyclin), and TXA2 levels in rats in both inflammed and non-inflammed tissues suggesting that Cox-1 and Cox-2 are more specific and effective in terms of prostanoid synthesis of PGE2, PGI2, and TXA2 as compared to Cox-3. Furthermore, Cox-3 results in the augmentation of the vasodilatory activity of bradykinin by modifying Cox-1 and Cox-2 [128].

Dipyrone (Metamizole ${ }^{\circledR}$ ) inhibits Cox-3 more effectively than Cox-1 and Cox-2 and this effect is concentration dependent in that high levels (IC50 >1000 $\mu \mathrm{M}$ ) inhibit all three isoforms, moderate levels (IC50: $350 \mu \mathrm{M}$ ) inhibt Cox-1 and Cox-3 and low levels (IC50: $52 \mu \mathrm{M}$ ) inhibit only Cox-3 [120 reviewed in 129,130]. It was suggested "that Cox inhibition achieved with dipyrone may be responsible for the augmentation of the smooth-muscle relaxing effects of the angiotensin-converting enzymes (ACEs) inhibitor losartan or lisinopril' while the combination of dipyrone with losartan inhibited phenylephrine (Phe), potassium chloride ( $\mathrm{KCl}$ ), and angiotensin II (Ang II) induced contractions compared to combined dipyrone with lisinopril inhibiting Phe and Ang II-induced contractions [130].

All Cox enzymes (Cox-1, Cox-2 and Cox-3) have been found to be expressed in glioblastoma and normal brain tissues but Cox-3 expression was significant higher in cancerous versus normal tissues [131]. Inhibiting Cox-3 with acetaminophen decreased glioblastoma tumor size by $71 \%$ in a rat model and by $43 \%$ using indomethacin. The exact molecular mechanisms still are unresolved. However, evidence such as epidemiology, molecular, genetic, polymorphisms, epigenetics, or proteomic Cox-3 research is warranted as information abouts its catalytic activity and signaling influence and crosstalk remains largely unknown.

Aspirin has long been known to be anti-inflammatory, anti-pyretic, and analgesic but this goes back to the knowledge of the salicytes as the medicine of the early ages used in a powder from the bark of the willow tree to treat fevers and pain [132]. Aspirin was produced in 1853 by the French chemist, Charles Frédéric Gerhardt (1816-1856) [133] and the isolation of acetylsalicyclic acid (ASA) in pure form occurred in 1897 by Felix Hoffmann (18681946). The laboratory manager, Arthur Eichengrün (1867-1949), claimed that he had advised his co-worker Hoffmann to produce esters of salicyclic acid [134], but Eichengrün was a German Jew and was arrested by the Nazis in 1943 and imprisoned in the Konzentrationslager Theresienstadt; after Eichengrün survived the KZ, he was confident enough to publish his claim in 1949 which was at first ignored. The British chemist, Walter Sneader, investigated the case during the 90 s and came to the conclusion that attributing the discovery and first isolation of aspirin to the German chemist Felix Hoffmann (1868-1946) in 1897 had been wrong which was denied by Bayer [132,135-137].

Aspirin affects the PG pathway by suppressing the production of PGs and TXAs through acetylation of a serine-rest of Cox-1 through prostaglandine-H2-synthasis-1 (PTGS1) and Cox-2 through PTGS2, discovered by British pharmacologist, Sir John Robert Vane (19272004) in 1971 [28]. For this he was awarded the Nobel Prize in 1982.

Salicylic acid (SA) has different effects in animal models and in the human body: (1) PG pathway, (2) formation of NO- radicals with decrease of leucocyte adhesion [138] (3) thrombocyte adhesion, (4) signaling through nuclear factor kappa-light-chain-enhancer of activated B cells (NF- $\mathrm{KB}$ ) pathway [139], and (5) uncoupling of phosphorylation in mitochondria [140].

Because of the inflammation-carcinogenesis association, aspirin data show an anticancer effect on overall cancer reduction [141-145]. Aspirin is effective in CRC [146-150] and may explain why it has an effect as a 
neoadjuvant to radiochemotherapy in rectal cancer [151]. Aspirin was shown to be effective in the precancerous adenomatosis polyposis coli or APC [152] and in terms of adenoma prior to CRC [153]. Effective aspirin use against cancers had been shown in ovarian [154,155], stomach [156-158], pancreas [159,160], hepatocellular carcinoma (HCC) [161], breast [162,163], prostate [164-166], melanoma [167] and mesothelioma [168]. Furthermore, aspirin seems to be effective in inflammatory diseases such as Alzheimer's [169] as well as in obesity, as morbid obesity increased cancer risk was reduced in those patients taking aspirin [170].

However, the mechanistic signaling pathways of aspirin are still under investigation [171]. Aspirin is absorbed in high-pH environments $(\mathrm{pH}$ of proximal colon $5-8.0)$ [172,173].

A meta-analysis of 5648 patients from 29 studies revealed that an overexpression of Cox- 2 correlated with recurrence and survival in CRC. The analysis was judged to have contradictory findings in terms of survival and recurrence and, therefore, it was not recommended until recently to use Cox-2 as a prognostic biomarker for CRC patients [149]. For completeness, some authors advise caution with regard to bleeding complications [159].

Additional insights on the role of Cox pathways in cancer come from the following findings: (1) when TGF- $\beta 1$ was applied to human lung cancer A549 cells, it induced a downregulation of Cox-2 which resulted in a decrease of PGE2; (2) the researchers administered PGE2 or PGE2 receptor agonists, and found that it suppressed TGF- $\beta 1$ induced actin remodeling [174] and PGE-2 inhibited the transition of a normal cell to a cancerous cell [175]. On the other hand, the continuous activation of macrophages led to interleukin 6 (IL-6)-induced increases in Cox-2 expression and serum PGE2 levels (Cox-2/PGE2 pathway), thus facilitating cell transition and metastasis in lung cancer [176]. The fact that increased levels of TNF $\alpha$ and IL-6 in patients in various stages of chronic kidney disease reflects an ongoing chronic inflammatory state [177] and highlights the importance of maintaining Cox homeostasis. This observation may explain why a continuous activation of T-cells with triggering of neutrophils, macrophages, and their cytokine release may be of greater consequence than previously thought. Excellent reviews about the different opinions on Cox isoenzymes, in vivo PGs, PGE2, PGI2, prostaglandin D2 (PGD2) and PGF2 $\alpha$, and the diversity of receptor subtypes (EP1-EP4) are available [178,179].

\section{Lipoxygenase (ALOX) pathway (Fig. 2)}

The ALOX enzymes are another important class within AA metabolism. The abbreviation LOX here should not be mistaken for the 2 nd available abbreviation of lysyl oxidase which constitutes a completely different enzyme. The various LOXs convert "arachidonic, linoleic, and other polyunsaturated fatty acids into biologically active metabolites that influence cell signaling, structure, and metabolism" [180 reviewed in 181]. The following
LOXs are known such as arachidonate 5-lipoxygenase (5-LOX, ALOX5), 12-lipoxygenase (12-LOX, ALOX12, 12S-LOX), 15-LOXa, and 15-LOXb, respectively [79].

Various hydroxyeicosatetraeonic acid (HETE) metabolites are formed via the lipoxygenase pathway, such as 5-hydroxyeicosatetraenoic acid (5-HETE), the reaction intermediate 5-hydroperoxy eicosatetraenoic acid (5-HpETE), 5-oxo-eicosatetraenoic acid (5-oxo-ETE), 8-hydroxyeicosatetraenoic acid (8-HETE), 12-hydroxyeicosatetraenoic acid (12-HETE), 15-hydroxyeicosatetraenoic acid (15-HETE) as well as the LTs, such as LTB4, LTC4, leukotriene D4 (LTD4) and leukotriene E4 (LTE4) [182]. The prostate, lung, colorectal, and ovarian cancer (PLCO) screening trial was a nested case-control study (157 cases/156 matched controls) that analyzed the prediagnostic serum levels of $31 \mathrm{AA} /$ linoleic acid/alphalinoleic acid metabolites with risk of developing ovarian cancer and found the following results to be positively associated with ovarian cancer: the identification riskrelated fatty acid metabolites such as 8-HETE, 12,13-Dihydroxyoctadec-9-enoic acid (12,13-DHOME), 13-hydroxyoctadecadienoic acid (13-HODE) and 9-hydroxyoctadecadienoic acid (9-HODE) [154].

\section{Leukotrienes}

Under the influence of mast cells, the expression of ALOX in immune cells such as leukocytes, eosinophils, basophils, neutrophils, macrophages, and platelets is activated resulting into the release of leukotrienes (LTs) from these cell types [183]. LTs are brokers of the inflammatory immune response and are found in body fluids. Cysteinyl LTs (CysLTs) that involve the amino acid cysteine in their structure include LTC4, LTD4, LTE4 and LTF4, LTB4, LTG4 and leukotriene 5 (LTB5) [184]. LTB5 is the LTB4 equivalent formed from eicosapentaenoc acid and its chemotactic activity is several orders of magnitude lower than that of LTB4 [185].

The LT receptor slow reacting substance (SRS) of anaphylaxis antagonist FPL-55712 was found to be much more effective in inhibiting LTE4 and LTF4 compared to LTC4 and LTD4 [186] which raises the question if there are different bioactivities and if the concentrations in biological samples as well as bioactivity might be poorly understood.

As part of the immune response, LTs chemically attract T-cells $[187,188]$. Consequently, LTs have been linked to conditions associated with an inflammatory response such as asthma and allergy [189,190], neurological diseases including dementia [191], stroke, and ischemic events [192,193], multiple sclerosis [194,195] and cancer [196-198].

The association of various leukotrienes and cancers such as lung, esophageal and prostate cancer had been reported in detail [reviewed in 182]. However, the cysteinyl leukotrienes LTC4, LTD4 and LTE4 induce various effects, such as cell recruitment, muscle contraction and vessel dilatation and permeability, and 5-LO signaling can 
induce increased LTs synthesis especially by leukocyte recruitment. The released exosomes with LTB4 can even create a gradient with additional para- and autocrine neutrophile stimulation and chemoattractivity.

The disruption of homeostatic mechanisms by LTs alters the tumor microenvironment and facilitates the progression of cancer [182] but it is important to note that immune cells can play dual roles both producing immunosuppressive and inflammatory regulatory mediators [199]. Especially the interaction of the immune systems with its various cell types needs to be further elucidated as Cox-2 inhibition can result into LTB4 increase [reviewed in 182]. The homeostasis of Cox-2 versus 5-LO seems to be of importance if cell proliferation is effectively or ineffectively inhibited. For this, the various ALOX enzymes are likely to be important.

\section{Various LOX enzymes}

Until now, our knowledge about the detailed biological functions of LOXs isoforms is limited [37], and known arachidonate LOXs contain arachidonate 5-lipoxygenase (5-LOX, ALOX5, 15-LO-1, 15-LOX-1), 12-LOX, arachidonate 12-lipoxygenase type II (ALOX12B, 12R-LOX), arachidonate 15-lipoxygenase (ALOX15), and ALOX15 type II (ALOX15B) [200].

5 -LOX is upregulated in cancers of the lung [201], esophagus [202], colon [203], pancreas [204-206] prostate $[207,208]$, breast [209], brain and promyelitic leukemic HL-60 cells [210], and in osteosarcoma [211] and mesothelioma [212]. 5-LOX is also found to be downregulated in colon adenoma of familial adenomatous polyposis (FAP) patients versus non-cancer colorectal mucosa [213]. 5-LOX derived from mast cells promote in the APC $(\Delta 468)$ murine model of colon polyposis triggers polyposis [214]. The inhibition of 5-LOX in a mouse breast cancer model revealed the opposite: abrogation of neutrophil pro-metastatic activity resulted in reduced metastasis [215]. We assume that these contradictory data may be a result of differences in expressed metabolites such as e.g. 5-HpETE and 5-HETE.

Increased expression of Cox-2 and ALOX5 are reported in lung cancer and knocking-out 5-LOX resulted into progression [216]. In this regard 5-LOX blockade resulted in an increase of apoptosis [200]. 5-LOX was shown to be higher expressed in HCC versus normal liver tissues and inhibiting 5-LOX induces apoptosis and blocks cancer progression [217]. A 22-fold elevated expression of 15-lipoxygenase-2 in ovarian cancer compared to normal ovarian tissue was observed and 15-lipoxygenase- 2 was augmented [218]. Increased 5-LOX metabolites enhanced $\mathrm{TNF} \alpha$ and heparin-binding epidermal growth factor-like growth factor (HB-EGF) through upregulation of matrixmetalloproteinase 7 (MMP-7) which was associated with increased tumor-associated macrophages infiltration [219]. 5-LOX was also increased in brain cancer [210], thyroid cancer together with promotion of metalloproteinase 9 (MMP-9) [220].
Procarcinogenic LOXs include 5-, 8-lipoxygenase (8-LOX), and 12-LOX while 15-lipoxygenase-1 (15LOX-1) and possibly 15-lipoxygenase-2 (15-LOX-2) which was previously thought to be anticarcinogenic [221]. 15-LOX-1 is decreased in esophageal cancer but applying the Cox-2 inhibitor SC-236 to gastric cancer cells induced apoptosis without affecting Cox-1, Cox-2, 5-LOX and 12-LOX. Thus, the upregulation of 15-LOX-1 may be developed as a therapeutic target in the future [222]. NSAIDs can induce apoptosis in colon cancer cells through 15-LOX-1 upregulation in the absence of Cox-2 [181,221]. TGF- $\beta 1$ induces SMAD4/4 with consequent increase of the 5-LOX promoter activity followed with upregulated 5-LOX expression [223] building yet another bridge to chronic inflammation during carcinogenesis via the lipooxygeanse signaling pathways.

Chronic cystitis showed slight increases of 5-LOX and 12-LOX versus marked increase in bladder cancer tissues and inhibition of lipoxygenase resulted into "chromatin condensation, cellular shrinkage, small membrane bound bodies (apoptotic bodies) and cytoplasmic condensation" [224]. This effect was also shown in bladder cancer cells in vitro [225]. In canine osteosarcoma cells 5-LOX was upregulated in about $65 \%$ in the cytoplasm, cell culture and xenograft model and application of the canine 5 -lipoxygenase inhibitor tepoxalin diminished xenograft tumor growth together with cell proliferation in mice [226].

Applying the thromboxane synthetase and 5-lipoxygenase inhibitor ketoconazole versus placebo into melanoma cell incubated mice showed significantly reduced incidence of metastasis and tumor mass with better survival in the ketoconazole-treated mice compared to placebo [227]. Recently CarbORev-5901 as a new carborane-based inhibitor of the 5-LOX was reported to be more stable and effective in melanoma and colon cancer cell lines was reported [228], but investigations in various cancers so far missing. It seems that 5 -LOX is also constitutively highly expressed in patients with idiopathic pulmonary fibrosis [229].

It was suggested that Cox-2 is responsible for the regulation of the lipid metabolism [230]. This goes in line with the findings that inhibiting 5-LOX and Cox-2 blocks colon cancer proliferation, migration, as well as invasion in vitro [231]. This may explain why NSAID intake might result in some $50 \%$ reduction of the relative CRC risk [232,233] as the combined Cox-1 and Cox-2 activity is increased in CRC [234]. The non-enteroendocrine "tuft cells" which are referred to chemosensory cells showed mainly Cox-1 overexpression while Cox-2 was primarily found in absorptive cells and are "rather constitute a distinct entity with transcription factor requirements for differentiation that differ from those of enterocytes, enteroendocrine, Paneth, and goblet cells" [supplemental material Fig. S1A not shown here by 235 and reviewed by 234]. Tuft cells first were reported in 1956 in rat trachea and mouse gastrointestinal tract [236,237 reviewed in 235].

Inhibiting 5-LOX and the 5-lipoxygenase-activating protein (FLAP) by the tobacco carcinogen, 4-methylni- 
trosamino-1-(3-pyridyl)-1-butanone suppresses carcinogenesis [238] and modulating LOX by clearly defining proand anti-carcinogenic effects depend on which metabolite is used and may be an option in anticancer treatment [181]. Receptors for LTB4 are upregulated in gastric cancer but 5 -LOX does not appear to be involved in gastric [239] or in colon carcinogenesis in rodents [240] which may explain why 5 -LOX is not widely observed in carcinogenesis or it may well be that 5-LOX itself may have its own homeostasis maintenance pathway. Furthermore, antiHelicobacter therapy by Tanshinone IIA from Salvia miltiorrhiza Bge resulted in lower chronic inflammation and 5-LOX [241]. 15-LOX suppresses colitis associated colon cancer by inhibiting IL-6/signal transducers and activators of transcription (STAT3) signaling [242]. Therefore antagonizing 5-LOX and/or promoting 15LOX is thought being effective as a future anti-cancer therapy. However, recent experiments with 15-LOX1 knockout mice suggested that this enzyme exhibits a proinflammatory role in the dextrane sodium sulfate induced mouse colitis model. In fact, these knockout mice were strongly protected from inflammatory symptoms [243].

\section{Cytochrome P450 pathway (CYP) and hydroxy fatty acids (20-HETE) (Fig. 3)}

The CYP signaling pathway in AA metabolism involves the $\omega$-hydroxylases and epoxygenases: " $\omega$-hydroxylases convert AA into hydroxyeicosatetraenoic acids (HETEs) and epoxygenases which converts it to epoxyeicosatrienoic acids (EETs)" [79].

\section{0-hydroxyeicosatetraenoic acid (20-HETE)}

Another underappreciated product of PUFA metabolism rin the context of eicosanoids is the (CYP) metabolite, 20-HETE [244], which has been in cardiovascular diseases [245] and cancers [246,247]. Downregulation of 20-HETE decreases proliferation in renal cancer cells [248], and enzymes that catalyze the formation of 20-HETE, such as cytochrome P450 4A/F $(\mathrm{CYP} 4 \mathrm{~A} / \mathrm{F})$ are found in higher concentrations in ovarian cancer than in normal tissues [249]. Cytochrome P450 2J2 (CYP2J2) is highly expressed in hematologic malignant diseases and promotes tumor cell growth [250]. Future research on the metabolism of 20-HETE and its biosynthesizing cytochromes might demonstrate specifically how 20-HETE contributes to carcinogenesis. 20-HETE increases ACE mRNA, protein through NF-кB [251].

\section{Epoxyeicosatrienoic acids (EETs)}

Another group of products of eicosanoid metabolism are the cytochrome P-450 metabolites, the EETs [252]. Cytochrome P450 2C (CYP2C) and cytochrome P450 2J (CYP2J) are CYPs epoxygenases that metabolize AA to biologically active EETs (5,6-EET, 8,9-EET, 11,12-EET, and 14,15-EET), which in turn, are further "metabolized to less active dihydroxyeicosatrienoic acids (DHETs) by soluble epoxide hydrolase (sEH)" [253].

The idea of using EETs in anticancer therapy emerged in the late 1980s [254,255]. An elevated CYP2J2 expression has been reported in esophageal, liver, breast, lung, and colorectal organs [250,256 reviewed in 253]. Markers such as these eicosanoids could serve as targets in cancer therapy [257]. The potential for such a use was demonstrated by the inhibition of sEH, which decreased NF-кB, TGF- $\beta 1 /$ Smad3, and inflammatory signaling pathways, together with activating peroxisome proliferator-activated receptor (PPAR) isoforms with consequent treating effectively renal interstitial fibrogenesis in obstructive nephropathy in mice [258].

Cytochrome P450 3A4 (CYP3A4) expression promotes STAT3-mediated breast cancer cell growth via 14,15-EET [259]. EET analogs and sEH inhibitors are thought to have application in multiple diseases [260], such as Parkinson's [261], renal interstitial fibrosis in obstructive nephropathy [258], marrow or cord blood transplantation [262], inflammatory bowel disease-associated cancer [263], and other cancers [264,265].

Elastase (ELA) is known to be induced by bacteria and regulates fibrosis and $\mathrm{PG}$ output; ELA-inhibition is assumed to reduce "mare endometrial fibrosis by stimulating the production of anti-fibrotic PGE2 and inhibiting pro-fibrotic PGF2 $\alpha$ " [266]. In the rabbit, 5,6-EET stimulates endogenous PGE2 synthesis [267].

11,12-EET triggers hematopoietic stem and progenitor cells (HSPCs) in zebra fish via the activator protein 1 (AP-1) and runt-related transcription factor 1 (RUNX1) transcription, independent of any hemogenic endothelium need for phosphatidylinositide 3-kinase (PI3K) pathway activation [262]. Dual inhibition with RAF-1 and sEH with trans-4-\{4-[3-(4-chloro-3-trifluoromethyl-phenyl)ureido]-cyclohexyloxy $\}$-pyridine-2-carboxylic acid methylamide (t-CUPM) was reported to be of potential use in preventing chronic pancreatitis and in ameliorating pancreatic cancer [268]. Greater 14,15-epoxyeicosatrienoic acid levels were reported in breast cancer tissue than in noncancerous tissue [265].

EETs are rapidly metabolized, short-lived signaling molecules produced by various cell types and investigated and reported as potential targets for treating inflammation and cancer [269]. Lipid hydroperoxides (LOOHs), with Vitamin C as a regulator, seem to be necessary for EET formation [270]. On the other hand, EETs have been seen as a double-edged sword in cardiovascular diseases and cancer concerning the use of anti-EET drugs [253]. The anti-inflammatory effects of soluble sEH inhibitors appear to be independent of leukocyte recruitment [271].

The CYP allele CYP3A7*1C is associated with adverse outcomes in chronic lymphocytic leukemia (CLL), breast cancer, and lung cancer [272]. CYP3A4, found mainly in liver and intestine, binds to N1-hexyl-N5benzyl-biguanide (HBB) inhibiting the CYP3A4 AA epoxygenase activity that suppress intra-tumoral mechanistic target of rapamycin (mTOR) [273]. CYP2J2 metabolizes AA to anti-flammatory, -fibrotic and 
-oxidant 5,6-, 8,9-, 11,12-, and 14,15-EETs [274-279] resulting in a decrease of IL- $1 \beta$, IL- 8 , TNF- $\alpha$, sP- and sEselectin together with decreased NF-кB p65 activation and degradation of $\mathrm{I} \kappa \mathrm{B} \alpha$ which may be mediated though peroxisome proliferator-activated receptor gamma (PPAR $\gamma$ ) activation [280,281].

Furthermore, the epoxygenase-dependent metabolite, 11,12-EET, inhibits epithelial Na channels $(\mathrm{ENaC})$ in the rat renal cortical region [282] (renal tubular epithelial cells) which is dependent on Cox activity and cell polarity [283].

Another bridge to chronic inflammation was recently shown. sEH plays a significant role in neurological diseases such as Parkinson or dementia [284] but also triggers obesity induced chronic colonic inflammation [285]. The importance of the research of LOXs may be recognized as most recently endogeneous nitro-fatty acids (NFAs) were identified as potential future new well tolerated chemotherapeutic drug candidates [286].

\section{Reactive oxygen and nitrogen species induced formation of EETs and oxygenated lipids}

The free radical story $[287,288]$ started by the Swedish student John Rhodin in 1954 who reported in his doctorate microbodies [289], which afterwards were "mistakenly suggested ....that they were precursors to mitochondria" [290 reviewed in 291-293]. In 1966, these microbodies were described as peroxysomes by the British born Belgian biochemist Christian de Duve (1917-2013) [294]. At that time De Duve already had discovered new organelles and had termed lysosomes and endosomes; he also discovered important processes, such as autophagy, endocytosis and exocytosis [293].

McCord and Fridovich created an inactive metal-free apoenzyme and adding copper resulted into some $80 \%$ recovery from dismutase activity; they reported superoxide dismutase (SOD) catalyzing "the dismutation or disproportionation of superoxide free radical anions" of the superoxide $\left(\mathrm{O}_{2}{ }^{-}\right)$radical into both molecular oxygen $\left(\mathrm{O}_{2}\right)$ and hydrogen peroxide $\left(\mathrm{H}_{2} \mathrm{O}_{2}\right): \mathrm{O}_{2}{ }^{-}+\mathrm{O}_{2}{ }^{-}+2 \mathrm{H}^{+} \rightarrow$ $\mathrm{O}_{2}+\mathrm{H}_{2} \mathrm{O}_{2}[295,296]$. Saito et al. investigated SOD in erythrocytes without finding a difference between young and elderly subjects [297]. Peroxisomes from fungi and plants contain antibiotics [298], toxins [299], and signaling molecules [300 reviewed in 292], and liver peroxiosomes are involved in beta-oxidation of rare fatty acids [301-304].

Today, three SOD families are known in regard to the metal cofactor and protein: (1) copper-zinc-SOD (Cu-ZnSOD) in eukaryotes (animals/humans, plants, fungus) found in cytosol, peroxisomes, or chloroplast, (2) ironSOD (Fe-SOD) or manganese-SOD (Mn-SOD) which are found in peroxisomes and mitochondria in prokaryotes (archaea and bacteria) and plants (Fe-SOD) or in humans (Mn-SOD) and (3) nickel-SOD (Ni-SOD) in prokaryotes [305]. There are not just intra- and intersubunit motions within the different subdomains of SOD known but there also seems to be an intersubunit information exchange [306].

\section{Reactive oxygen (ROS) and reactive nitrogen species (RNS)}

Reactive oxygen species (ROS) "are a family of molecules that are continuously generated, transformed and consumed in all living organisms as a consequence of aerobic life" $[101,307,308]$ meaning ROS are naturally a metabolism product relevant for homeostasis, physiology as well as for so-called oxidative stress, a term coined by Sies in 1985 [309 reviewed in 310,311]. ROS include nonradical derivatives of singulet oxygen (1O2), $\mathrm{H}_{2} \mathrm{O}_{2}$ and ozone $\left(\mathrm{O}_{3}\right)$, and oxygen radicals such as hydroxyl radical $(\mathrm{OH})$, and superoxide $(\mathrm{O} 2 \cdot-)$. When ROS and RNS react with unsaturated lipids, lipid hydroperoxides are formated, which can damage biomembranes and or inactivate proteins. The major source of ROS in most mammalian cells is the respiratory chain of the mitochondria and about $1-2 \%$ of the daliy oxygen consumption is converted to ROS (incomplete reduction of oxygen during cellular respiration). 1-2\% does not really seems a lot but considering the fact thast a normal humen being consumes about $450 \mathrm{l}$ of oxygen per day, a large number of ROS are normally produced. Luckily, most of these potentially damaging chemicals are readily detoxified by the antioxidative defense system. In addition, other ROS and RNS sources are the nicotinamide adenine dinucleotide phosphate (NADPH) oxidase (Nox) and xanthine oxidase (XO). Accumulation of ROS is prevented by SOD, which rapidly convert in the cytosol cytosolic and in the mitochondrial intermembrane space superoxide dismutase 1 (SOD1). Superoxide dismutase 2 (SOD2) is located in the mitochondrial matrix and contributes to detoxifying superoxide produced during cellular respiration [312314]. As pointed out, "accumulation of superoxide is more associated with oxidative stress than redox signaling" [315].

Reactive nitrogen species (RNS) are antimicrobial molecules; they are mainly generated by phagocytic cells and involve nitric oxide (NO), with its derivative peroxynitrite $\left(\mathrm{ONOO}^{-}\right)$, nitrogen dioxide $\left(\mathrm{NO}_{2}^{-}\right)$, dinitrogen trioxide $\left(\mathrm{N}_{2} \mathrm{O}_{3}\right)$, nitrous acid $\left(\mathrm{HNO}_{2}\right)$, and others $[316,317]$. Both, ROS and RNS can modulate regulatory proteins and are linked to each other in plants and animals/humans inducing consequent signaling [316,318].

ROS is also involved in autophagy and the major source regulating ROS is superoxide $\left(\mathrm{O}_{2}{ }^{-}\right)$[319]. Mitochondrial ROS metabolism is needed for normal kRAS associated cancer cell proliferation [320]. AA metabolites such as 5-LOX and Cox can induce ROS through Nox stimulation [321 reviewed in 322].

ROS have various physiological and pathophysiological damaging properties next to evolution and are an essential consecutive part of signaling for various physiologies as cellular adhesion, signaling and migration, apoptosis, lipid metabolism, stem cell differentiation, immune response, and sport, and during aerobic and 
anaerobic respiration as well as pathologies, such as e.g. acute and chronic inflammation, atherosclerosis, renal diseases, arthritis, cardiovascular and neurodegenerative diseases, ageing, cancer [reviewed in $315,323,324$ ]. ROS levels are increased by ultraviolet (UV) radiation, cigarette smoking, and alcohol consumption. They are also elevated in infections and after an ischemia-reperfusion (I/R) injury. It has been suggested that the homeostasis of ROS production versus the capacity to detoxify rapidly is what determines the degree of oxidative stress at any given time in a tissue or organ [101]. In synovial fibroblasts, ROS promote the phosphorylation of mitogen-activated protein kinases (MAPKs) and NF-кB through the activation of transforming growth factor betaactivated kinase 1 (TAK1), and lead to an increased expression of Cox-2 and PGE2 [325]. Further, even PGs induce Cox-2 expression [326].

Abnormal ROS levels can result in MAPK and PI3K signaling with STAT3 activation and phosphorylation of SNAIL with E-Cadherin suppression and a loss of cell polarity [327]. A chronic increase in ROS by macrophages increases levels of $\mathrm{C}-\mathrm{X}-\mathrm{C}$ chemokine receptor type 4 (CXCR4) and trigger the transition of a normal cell to a cancer cell [328]. It seems that under physiological conditions, a Cox- and -ROS homeostasis exists. Both Cox-1 and Cox-2 are expressed in normal human gastric mucosa and in gastric ulcers; they are increased by an $H$. pylori infection, but Cox- 1 alone can increase gastric PGE2 production [329]. H. pyloriinfected gastric epithelium co-express gastrin, its receptors, cholecystokinin B receptor (CCK(B)-R), Cox-2, and prostaglandin [330]. The continuous stimulation of Cox-2 and NF- $\mathrm{KB}$ signaling results in a persistent increase of inflammatory cytokines such as $\mathrm{TNF} \alpha$ and IL-6, as well as ROS and nitrogen-free radical species [331]. Skin samples from patients with chronologically aged and photoaged skin showed greater Cox-2 expression in keratinocytes and fibroblasts compared to that observed in younger individuals [332].

Since a multi-billion market grew promising the health effects of antioxidants and creating a global dietary supplements industry that is expected to grow in the U.S. alone to some $\$ 220$ billion by 2022 [333]. The detailed understanding of the ROS complexity may not be as easy as earning money through the sale of antioxidants.

Applying the cytochrome c peroxidase assay to measure the rates of free $\mathrm{H}_{2} \mathrm{O}_{2}$ with a cytosolic steadystate concentration and a rate of $90 \mathrm{nmol} / \mathrm{l} / \mathrm{min} /$ wet weight of liver revealed that "some (40-80\%) of the H202 generated in the peroxisomes is destroyed inside the organelle, and that the remaining 20-60\% diffuses to the surrounding medium" [334]. Half-life times (T1/2) of ROS are short contain in between $<$ nanoseconds to seconds [335 reviewed in 336]: the very reactive $\mathrm{OH}$ radical has a $\mathrm{T} 1 / 2$ of approximately $10^{-9} \mathrm{~s}$ [337] compared to $\mathrm{O}_{2}^{-}$and $\mathrm{H}_{2} \mathrm{O}_{2}$ in between $10^{-6} \mathrm{~s}$ and $10^{-5} \mathrm{~s}$ [338] respectively [reviewed in 339]. There is hope using low level magnetic field to modulate cellular produced $\mathrm{H}_{2} \mathrm{O}_{2}$ [336].

\section{Unsaturated fatty acids (PUFAs)}

Unsaturated fatty acids are associated with the Cox and LOX pathways. PUFAs are essential and have to ingested by external sources (food). They are associated with inflammation and cancer; the main two PUFAs families are metabolized through $6 \Delta$ desaturase, elongase, $5 \Delta$ desaturase, and $4 \Delta$ desaturase; those deriving from $\alpha$-linolenic acid (ALA) result into eicosapentaenoic acid (EPA), docosapentaenoic acid (DPA) and docosahexaenoic acid (DHA) and are named family of omega-3 (n-3) PUFAs ( $\omega-3$ PUFAs) and are less inflammatory. In contrast, those deriving from linoleic acid (LA) result in gamma-linolenic acid (GLA), di-homo-gamma-linolenic acid (DGLA), AA, docosatetraenoic and docosapentaenoic acid and are part of the family of omega- 6 (n-6) PUFAs ( $\omega-6$ PUFAs). The last (most far away from the carboxylic group) carbon-carbon double bond is found in the $\omega-6$ position. $\omega-6$ PUFAs are more pro-inflammatory while $\omega-3$ PUFAs with the carbon-carbon double bond in the $\omega-3$ position have more anti-inflammatory effects [340-344]. The third fatty acids family involves the nonessential monounsaturated fatt acid omega-9 (n-9), $\omega-9$ MUFAs with the carbon-carbon double bond in the $\omega-9$ position [345,346]. $\omega-9$ MUFAs induce fatty acid oxidation and are associated with a greater anti-inflammatory effect in a sepsis model [347], but showed direct associations with mortality within the Cardiovascular Health Study [348]. Furthermore, "high $\omega-9: \omega-6$ ratio and low $\omega-6: \omega-3$ ratio significantly reduced inflammatory response in rats submitted to dental extraction" [349].

$\omega-3$ PUFAs are anti-inflammatory. Their metabolism via the Cox / lipooxygenase pathway induce the formation of prostaglandin D3 (PGD3), prostaglandin F3alpha (PGF3 $\alpha$ ), prostaglandin I3 (PGI3), thromboxane A3 (TXA3), and LTs such as leukotriene A5 (LTA5), leukotriene B5 (LTB5), leukotriene C5 (LTC5) and and leukotriene D5 (LTD5). $\omega-6$ PUFAs induce more proinflammatory effects triggering the biosynthesis of the 2series of prostaglandins which comprises prostaglandin E2 (PGE2), prostaglandin F2alpha (PGF2 $\alpha$ ), PGD2, TXA2, and LTs LTB4, LTC4, LTD4 and LTE4.

The association of PUFAs with AA metabolism and Cox metabolism and inflammatory/anti-inflammatory effects and cancer/anti-cancer effects provides in vitro and in vivo evidence, that $\omega-6$ PUFAs stimulate cancers of the oral cavity [350], gastric [351,352], colon [353-355], liver $[356,357]$, prostate $[358,359]$, breast [360-364], endometrium [365], pancreas [366,367], bladder [368], urethial [369], lung [370], and melanoma cell growth [371-374] compared to $\omega-3$ PUFAs suppressing it. This is in accordance with our understanding of precancerous lesions [375-379].

As PUFAs are directly associated with various signaling pathways and crosstalk in chronic inflammation, obesity, and the microbiome, these topics are reviewed separately within this Special Issue.

Due to the above studies, the involvement of PGE2, and LTB4 involvement through Cox-1, Cox-2 and 5-LOX 
are thought to have a pro-carcinogenesis effects via inflammation [341,366,380]. Cox-2, PGE2 and EP2 and EP4 receptors stimulating pancreatic cancer cell growth while $\omega$-3 PUFAs e.g. $\omega$-3 PUFAs downregulates MMP-9 [381] and PGE2 by competitive effect in the AA metabolism [382], and has anti-inflammatory effects [383]. Granulocyte-macrophage CSF colony stimulating factor (CSF) (gm-CSF) induce PLA2 activity with PLA2 protein and consequent trigger rat alveolar macrophages (but not peritoneal macrophages or peripheral blood monocytes) to generate LTB4 as well as the 5-lipoxygenase products LTC, and 5-HETE [384 reviewed in 385].

\section{Specialized pro-resolving lipid mediators (SPMs) (Figs. 2-4)}

A new class of lipid mediators derived from AA and other polyenoic fatty acids are the family of specialized pro-resolving mediators (SPM). These signaling molecules are biosynthesized from AA and other frequently occurring polyenoic fatty acids (DHA, EPA) and function as counterregulators of pro-inflammatory stimuli inducing the resolution of inflammation [386-397]. This class of mediators involves lipoxins (LXs), resolvins (RVs), protectins (PDs) and maresins (MaRs); SPMs have distinct cellular and sometimes transcellular pathways of biosynthesis and they have been suggested to be quick at the resolution of inflammation. LXs derive from $\omega-6$ PUFAs and Rvs, PDs and MaRs from $\omega-3$ PUFAs [387-391,393,395,396,398-400 reviewed in 397-405].

Although not entirely clear at the present, the newly discovered anti-inflammatory and pro-resolving eicosanoids, such as lipoxins, resolvins, maresins and protectins could be one reason why multiple inflammatory changes in the tumor microenvironment directly results in a remodeled ECM. Furthermore, it could explain why the disruption of the homeostasis between anti- and proinflammatory mediators is needed, although there are additional pieces of missing information such as the period of time how long the disruption has to occur with regard to various pathogenic stimuli until a normal to cancer cell transition can occur.

\section{Lipoxins (LXs)}

LXs are metabolites of $\omega-6$ PUFAs. They are formed from AA, which are converted to its 14,15-epoxide and this reaction might be catalyzed by an arachidonic acid 15lipoxygenating enzyme - such as ALOX12, ALOX15, aspirin-treated Cox-2, and CYPs - to di-hydroxyeicosatetraenoates. This dihydroxy derivative may then be oxidized by an arachidonic acid 5-lipoxygenating enzmye (ALOX5) to a trihydroxy compound, which is called lipoxin B4 (LXB4) [5S,14R,15S-trihydroxy$6 E, 8 Z, 10 E, 12 E$-eicosatetraenoic acid]. This compound carries three hydroxyl residues and four double bonds. An alternative of lipoxin formation is when an arachidonic acid 5-lipoxygenatinhg enzyme converts arachidonic acid to its 5,6-epoxide. This intermediate is subsequently hydrolyzed to the 5,6-diol and finally oxygenated at C15 by an arachidonic acid 15-lipoxygenating enzyme. In this case LXA4 (5S,6R,15S-trihysroxy-7E,9E,11Z,13E-eicosatetraenoic acid) is formed. Both lipoxin isomers have a 15-epi-equivalent which differs from the structure of LXA4 and LXB4 by having adverse chirality at C15 (15R). These 15-epi-LX-isomers are formed via the catalytic activity of aspirin treated Cox-2 (instead of a 15-lipoxygenating LOX) and thus, they are sometímes called aspirin-triggert lipoxins. LXs are rapidly inactivated e.g. in monocytes by dehydrogenases $[406,407]$. The 15-LOX derived precursor molecule for LX biosynthesis, 15-S-hydroperoxyeicosatetraenoic acid (15-(S)-HpETE) is an active form of 15-HETE having 15(S)-configuration; it also functions as LTs antagonists [408]. Anti-inflammatory lipids such as LXA4 [408], RVs, PDs and MaRs [409], may function as a sentinel against a pathogenic stimulus and cytokinetriggered inflammatory overreaction. LXA4 together with LXB4 can inhibit LT-triggered polymorphonuclear neutrophils (PMN) [410]. It had been suggested that "PGs, LXA4, resolvins, protectins, maresins, and LTs modulate macrophage phenotype and function" [385].

\section{Resolvins (RVs)}

The name Resolvins denates from "resolution phase interaction products" which limit neutrophil infiltration as well as chemokines and cytokines effects [411]. These metabolites are formed from $\omega-3$ PUFAs. EPA derived resolvins are E-series resolvins such as resolvin E1, resolvin E2, and resolvin E3 with [412]. DHA-derived resolvins are counted among the D-series of resolvins, such as resolvin D1 (RvD1) [413-416], resolvin D2 (RvD2) [415-418], and resolvin D5 (RvD5) [419].

Resolvins carry various chiral centers and thus this family of proresolving mediators also involves epimers. An important signaling pathway from aspirin was discovered in 1995: aspirin, a Cox-isoforms inhibitor that acetylates Cox-2, induces the synthesis of "aspirin-triggered" proresolving mediators in humans, including 15-epi-lipoxin A4. This metabolite stimulates phagocytosis of apoptotic inflammatory cells, which is required for cleaning up the battlefield of inflammation [386,420-423]. The formation of 15R-hydroxy products by acetylated Cox-2, which is named "aspirin-triggered cyclooxygenase 2" (AT-Cox-2) can also be catalyzed by microsomal, mitochondrial, or bacterial enzymes CYPs with the following products: aspirin-induced epimers of resolving D3, 17R-D series resolvins (RVs) and docosatriene (DTs) which are denoted aspirin-triggered resolvins (ATRvDs) and aspirin-triggered DTs (ATDTs) [396,411,424,425].

RvD1 is anti-inflammatory and regulates human polymorphonuclear leukocyte transendothelial migration and its epimer, aspirin-triggered form (ATRvD1) 17-oxoRvD1, is much more resistant against rapid inactivation [414]. RvD2 downregulates leukocyte-endothelial interactions in vivo via adhesion receptor expression modulation [417]. RvD3 and its aspirin-triggered 17R-epimer 


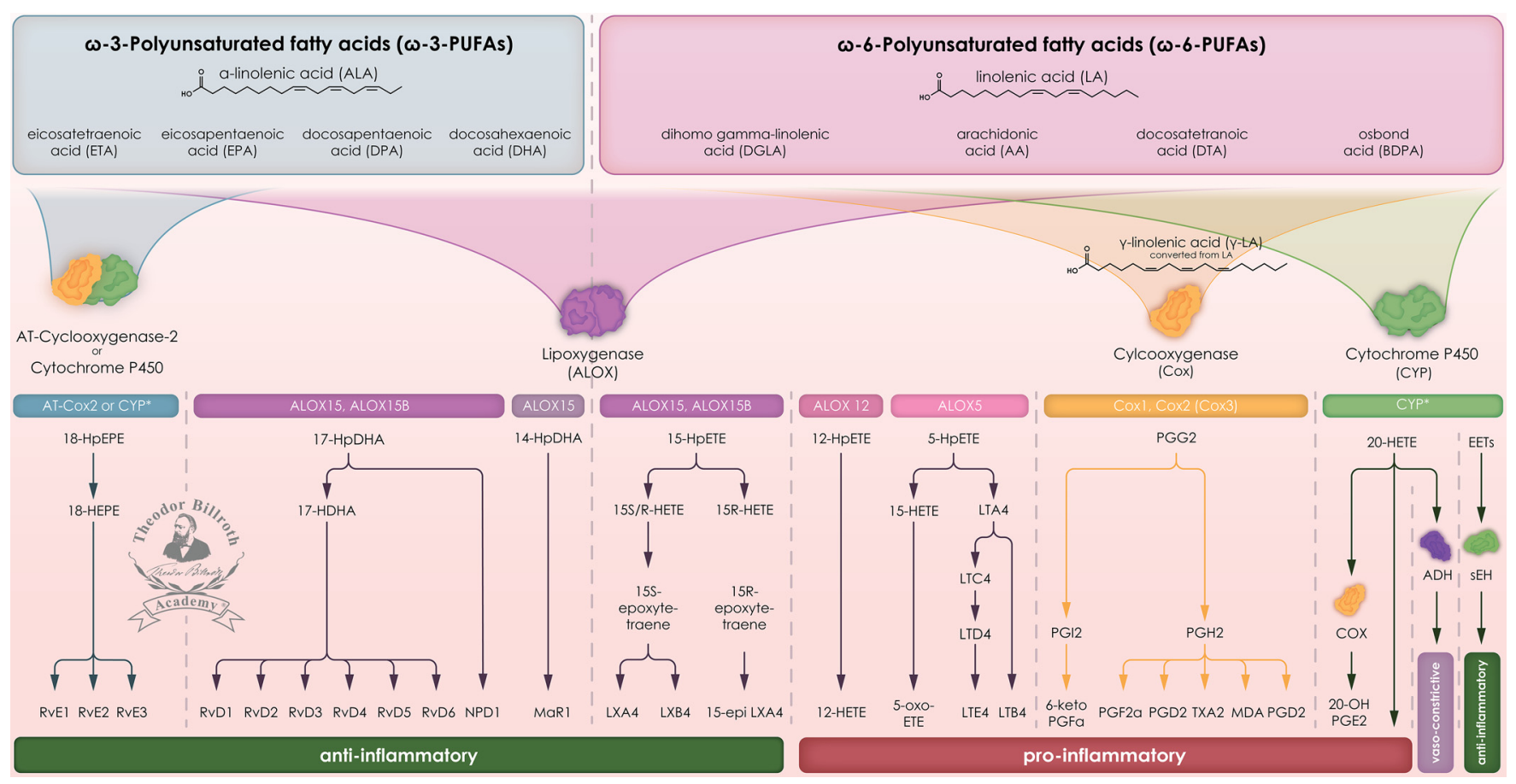

Fig. 4. Eicosanoid metabolism and its relevance in inflammation. Nomenclature: Simplified scheme of the eicosanoid metabolism with formation from polyunsaturated fatty acids, including cyclooxygenase (Cox), lipoxygenase (ALOX), and cytochrome p450 (CYP) pathways with the formation of anti- and pro-inflammatory regulatory mediators. Common abbreviations are bold, followed by the common trivial names (if available) and (if available) by the name in accordance to the International Union of Pure and Applied Chemistry (IUPAC): $\boldsymbol{\omega}$-3-PUFAs N-3 polyunsaturated fatty acid; ALA $\boldsymbol{\alpha}$-linolenic acid, (9Z,12Z,15Z)-octadeca-9,12,15-trienoic acid; ETA eicosatetraenoic acid, all-cis-8,11,14,17-eicosatetraenoic acid; EPA eicosapentaenoic acid, (5Z,8Z,11Z,14Z,17Z)-eicosa5,8,11,14,17-pentenoic acid; DPA docosapentaenoic acid, 7,10,13,16,19-docosapentaenoic acid; DHA docosahexaenoic acid, (4Z,7Z,10Z,13Z,16Z,19Z)-docosa-4,7,10,13,16,19-hexaenoic acid; $\boldsymbol{\omega}$-6-PUF As N-6 polyunsaturated fatty acid; LA linoleic acid, cis, cis-9,12-octadecadienoic acid; DGLA dihomo gamma-linolenic acid, (8Z,11Z,14Z)-8,11,14-Icosatrienoic acid; AA archidonic acid, (5Z,8Z,11Z,14Z)-5,8,11,14-eicosatetraenoic acid; DTA docosatetranoic acid, (7Z,10Z,13Z,16Z)-7,10,13,16-docosatetraenoic acid; BDPA osbond acid, (All-Z)-4,7,10,13,16-docosapentaenoic acid; AT-Cox2 aspirin-triggered cyclooxygenase 2; CYP* cytochrome P450 isoforms; 18-HpEPE 18-hydroxyeicosapentaenoic acid, 18-hydroxyicosa-2,4,6,8,10-pentaenoic acid; 18-HEPE (5Z,8Z,11Z,14Z,16E)-18-hydroxyicosa-5,8,11,14,16-pentaenoic acid; RvE1 resolvin E1, (5S,6Z,8E,10E,12R,14Z,16E,18R)-5,12,18trihydroxyicosa-6,8,10,14,16-pentaenoic acid; RvE2 resolvin E2, (5S,6E,8Z,11Z,14Z,16E,18R)-5,18-dihydroxyicosa-6,8,11,14,16pentaenoic acid; RvE3 resolvin E3, (5Z,8Z,11Z,13E,15E,18S)-17,18-dihydroxyicosa-5,8,11,13,15-pentaenoic acid; Cox cyclooxygenase; ALOX lipoxygenase, arachidonate lipoxygenase; ALOX15 15-lipoxygenase, 15-LOX, 15-LOX-1, arachidonate 15-lipoxygenase; ALOX15B 15-lipoxygenase type II, 15-LOX-2, arachidonate 15-lipoxygenase type B; ALOX12 12-lipoxygenase, 12-LOX, 12S-LOX, arachidonate 12-lipoxygenase 12S type; ALOX5 5- lipoxygenase, 5-LOX, arachidonate 5-lipoxygenase; 17-HpDHA 17S-hydroperoxy-4Z,7Z,10Z,13Z,15E,19Z-docosahexaenoic acid; 17-HDHA 17S-hydroxy-4Z,7Z,10Z,13Z,15E,19Zdocosahexaenoic acid; RvD1 resolvin D1, (4Z,7S,8R,9E,11E,13Z,15E,17S,19Z)-7,8,17-trihydroxydocosa-4,9,11,13,15,19-hexaenoic acid; RvD2 resolvin D2, (4Z,7S,8E,10Z,12E,14E,16R,17S,19Z)-7,16,17-trihydroxydocosa-4,8,10,12,14,19-hexaenoic acid; RvD3 resolvin D3, (4S,5E,7E,9E,13Z,15E,17R,19Z)-4,11,17-trihydroxydocosa-5,7,9,13,15,19-hexaenoic acid; RvD4 resolvin D4, (4S,6E,8E,10E,13E,15Z,17S,19Z)-4,5,17-trihydroxydocosa-6,8,10,13,15,19-hexaenoic acid; RvD5 resolvin D5, (5Z,7S,8E,10Z,13Z,15E,17S,19Z)-7,17-dihydroxydocosa-5,8,10,13,15,19-hexaenoic acid; RvD6 resolvin D6, (4S,5E,7Z,10Z,13Z,15E,17S,19Z)-4,17dihydroxydocosa-5,7,10,13,15,19-hexaenoic acid; NPD1 neuroprotectin D1, protectin D1, (4Z,7Z,10R,11E,13E,15Z,17S,19Z)-10,17dihydroxydocosa-4,7,11,13,15,19-hexaenoic acid; 14-HpDHA 14-hydro(peroxy)-docosahexaenoic acid, 4-[(1E,3E,5E,7E,9E)-nonadeca-1,3,5,7,9-pentaenyl|dioxete-3-carboxylic acid; MaR1 maresin 1, (4Z,7R,8E,10E,12Z,14S,16Z,19Z)-7,14-dihydroxydocosa4,8,10,12,16,19-hexaenoic acid; 15-HpETE 15-hydroperoxy-eicosatetraenoic acid, (5Z,8Z,11Z,13E)-15-hydroperoxyicosa-5,8,11,13tetraenoic acid; 15S/R-HETE 15S-HETE (5Z,8Z,11Z,13E,15S)-15-hydroxyicosa-5,8,11,13-tetraenoic acid; 15S-epoxy-tetraene 5,6-15S-HETE, 4-[(2S,3S)-3-[(1E,3E,5Z,7E,9S)-9-hydroxytetradeca-1,3,5,7-tetraenyl]oxiran-2-yl]butanoic acid; 15R-epoxy-tetraene lacks a bit of the activity attributed to their S stereoisomers of 15S-epoxy-tetraene; 15R-epoxy-tetraene lacks a bit of the activity attributed to their $\mathrm{S}$ stereoisomers of 15S-epoxy-tetraene; LXA4 lipoxin A4, (5S,6R,7E,9E,11Z,13E,15S)-5,6,15trihydroxyicosa-7,9,11,13-tetraenoic acid; LXB4 lipoxin B4, (5S,6E,8Z,10E,12E,14R,15S)-5,14,15-trihydroxyicosa-6,8,10,12-tetraenoic acid; 15-epi-LXA4 (5R,6R,7E,9E,11Z,13E,15R)-5,6,15-trihydroxyicosa-7,9,11,13-tetraenoic acid; 12-HpETE 12-hydroperoxyicosa-5,8,10,14-tetraenoic acid; 12-HETE (5E,8Z,10Z,14Z)-12-hydroxyicosa-5,8,10,14-tetraenoic acid; 5-HpETE (6E,8Z,11Z,14Z)-5-hydroperoxyicosa-6,8,11,14-tetraenoic acid; 15-HETE (5Z,8Z,11Z,13E)-15-hydroxyicosa-5,8,11,13-tetraenoic acid; 5-oxo-ETE (6E,8Z,11Z,14Z)-5-oxoicosa-6,8,11,14-tetraenoic acid; LTA4 leukotriene A4, 4-[(2S,3S)-3-[(1E,3E,5Z,8Z)tetradeca-1,3,5,8-tetraenyl]oxiran-2-yl]butanoic acid; LTC4 leukotriene C4, (5S,6R,7E,9E,11Z,14Z)-6-[(2R)-2-[[(4S)-4-amino-4carboxybutanoyl]amino]-3-(carboxymethylamino)-3-oxopropyl]sulfanyl-5-hydroxyicosa-7,9,11,14-tetraenoic acid; LTD4 leuko- 
(ATRvD3) appear in the late phase of inflammation regulating neutrophils, mediators and enhancing phagocytosis and efferocytosis, which contain the removal of dying apoptotic cells by phagocytosis $[389,396,405]$.

\section{Protectins (PDs)}

Protectin D1 (PD1) is termed neuroprotection D1 (NPD1) when described in the central nerve system and will be here named NPD1 to avoid confusion; NPD1 derives from DHA lipooxygenation through 15-LOX metabolism and reported to be neuroprotective $[426,427]$. Bcl-2 proteins such as Bcl-2 and BclxL are increased by NPD1 with a decrease of pro-apoptotic bcl-2associated X protein (Bax, bcl-2-like protein) and Bcl-2associated death promoter (BAD) expression together with inhibition of interleukin 1-beta (IL-1 $\beta$ ) induced Cox2 expression and it is thought that PLA2 releases a DHA precursor [426]. NPD1 was found to be generated by LOXdependent $\mathrm{T}$ helper type 2-skewed peripheral blood mononuclear cells, and inhibits secretion of $\mathrm{TNF} \alpha$, interferon gamma (IFN $\gamma$ ), promotes apoptosis and blocks even T cell migration [428]. NPD1 "reduces infiltrating leukocytes and blocked TLR-mediated activation of macrophages" and alleviates kidney injury [429].

NPD1 protects against inflammation promoting wound healing [430] and is also found in neutrophils [413,431], and decreases inflammation and hyperresponsiveness in asthma [432]. The dihydroxy-containing DHA derivative NPD1 decreases proaptotic protein and stimulates antiapoptotic Bcl-2 protein, protects against oxidative stress and inhibits mitochondrial cytochrome c activated caspase- 3 and by this it's induced cleavage and inhibits inflammatory IL-1 $\beta$ induced Cox-2 expression [427]. NPD1 selectively "enhances neuronal differentiation, an action not shared by eicosanoids, such as LTB4 or leukotriene C4" [433] and suppresses "Abeta42-triggered activation of proinflammatory genes while upregulating the antiapoptotic genes encoding Bcl-2, Bcl-xl, and Bfl-1(A1)" and is suggested to be effective in neurodegenerative diseases and spinal cord injuries [434].

Aspirin-triggered NPD1 (AT-NPD1) reduced neutrophil infiltration in an inflammatory bowel mouse model $[395,435]$ and aspirin-triggered LXA4 (ATLXA4) suppressed proinflammatory cytokines and chemokines [393]. The NPD1 isomer PDX inhibits blood platelets aggregation [436].

\section{Maresins (MaRs)}

Maresin 1 (MaR1) was reported as a new 7,14dihydroxydocosa-4Z,8,10,12,16Z,19Z-hexaenoic acid SMPs derived from DHA through 12 -LOX by macrophages involved in resolution of inflammation and coined Maresin (macrophage mediator in resolving inflammation) [437]. MaR1 is produced by macrophages, leukocytes and platelets [438] and has anti-inflammatory effects [439].

Two synthesized diastereomers blocked neutrophil infiltration in an acute peritonitis model [440]. MaR1 reduces neutrophil infiltration in peritonitis, reduces chemotaxis and enhances efferocytosis of apoptotic neutrophils with increased effectiveness compared to RvD. Investigating planaria flatworm infections (of the class Turbellaria) reported that MaR1 increased stimulation of tissue regeneration including shortening the regeneration time interval. MaR1 showed potent inflammatory analgesic effects with an IC50 of $0.49 \pm 0.2 \mathrm{nM}$ and by this reduced chemotherapy induced (vincristineinitiated) neuropathic pain [441]; an anti-neuropathic pain amelioration was recently reproduced [442]. Further, 13S,14S-epoxy-maresin was reported as precursor of MaR1 converted by macrophages inhibiting LTA4 and 12-LOX promoting phenotype change of M1 into M2 macrophages [443].

Leukotriene $\mathrm{C} 4$ synthase (LTC4S) and glutathione S-transferase Mu 4 (GSTM4) catalyze the formation of the synthesized epoxide intermediate maresin conjugates in

triene D4, (5S,6R,7E,9E,11Z,14Z)-6-[(2R)-2-amino-3-(carboxymethylamino)-3-oxopropyl]sulfanyl-5-hydroxyicosa-7,9,11,14-tetraenoic acid; LTE4 leukotriene E4, (5S,6R,7E,9E,11Z,14Z)-6-[(2R)-2-amino-2-carboxyethyl]sulfanyl-5-hydroxyicosa-7,9,11,14-tetraenoic acid; LTB4 leukotriene B4, (5S,6Z,8E,10E,12R,14Z)-5,12-dihydroxyicosa-6,8,10,14-tetraenoic acid; LA linoleic acid, cis, cis9,12 -octadecadienoic acid; LA is not a direct substrate of prostaglandins - this occurs after metabolism to $\gamma$-LA; therefore LA here is in brackets; $\boldsymbol{\gamma}$-LA gamma linolenic acid; Cox-1 cyclooxygenase 1; Cox-2 cyclooxygenase 2; Cox-3 splice variant and isoform of Cox-2; (therefore in brackets); PGG2 prostaglandin G2, (Z)-7-[(1S,4R,5R,6R)-5-[(E,3S)-3-hydroperoxyoct-1-enyl]-2,3-dioxabicyclo[2.2.1] heptan-6-yl]hept-5-enoic acid; PGI2 prostaglandin I2, prostacyclin I2, (5Z)-5-[(3aR,4R,5R,6aS)-5-hydroxy-4-[(E,3S)-3-hydroxyoct1-enyl]-3,3a,4,5,6,6a-hexahydrocyclopenta[b]furan-2-ylidene|pentanoic acid; 6-keto-PGF1 $\alpha$ 6-keto-prostaglandin F1alpha, 7[(1R,2R,3R,5S)-3,5-dihydroxy-2-[(E,3S)-3-hydroxyoct-1-enyl]cyclopentyl]-6-oxoheptanoic acid; PGH2 prostaglandin H2, (Z)-7[(1S,4R,5R,6R)-5-[(E,3S)-3-hydroxyoct-1-enyl]-2,3-dioxabicyclo[2.2.1]heptan-6-yl]hept-5-enoic acid; PGFF2 $\boldsymbol{\alpha}$ prostaglandine F2 alpha, (Z)-7-[(1R,2R,3R,5S)-3,5-dihydroxy-2-[(E,3S)-3-hydroxyoct-1-enyl]cyclopentyl]hept-5-enoic acid; PGD2 prostaglandin D2, (Z)-7-[(1R,2R,5S)-5-hydroxy-2-[(E,3S)-3-hydroxyoct-1-enyl]-3-oxocyclopentyl]hept-5-enoic acid; PGE2 prostaglandin E2, (Z)-7[(1R,2R,3R)-3-hydroxy-2-[(E,3S)-3-hydroxyoct-1-enyl]-5-oxocyclopentyl|hept-5-enoic acid; TXA2 thromboxane A2, (Z)-7[(1S,2S,3R,5S)-3-[(E,3S)-3-hydroxyoct-1-enyl]-4,6-dioxabicyclo[3.1.1]heptan-2-yl]hept-5-enoic acid; MDA malondialdehyde, propanedial; Cox cyclooxygenase; Cox cyclooxygenase; 20-HETE 20-hydroxyeicosatetraenoic acid, (5Z,8Z,11Z,14Z)-20-hydroxyicosa5,8,11,14-tetraenoic acid; 20-OH-PGE2 20-hydroxy prostaglandin E2; ADH alcohol dehydrogenase; 20-COOH-HETE 20-carboxy-hydroxyeicosatetraenoic acid; EETs epoxyeicosatrienoic acid; sEH soluble epoxide hydrolase; DHETs dihydroxyeicosatrienoic acids. 
tissue regeneration 1 (MCTR1), which is converted by gamma-glutamyltransferase (GGT) to MaR conjugates in tissue regeneration 2 (MCTR2), followed by conversion to MaR conjugates in tissue regeneration 3 (MCTR3) by a dipeptidase which increases our understanding of tissue repair and regeneration [444]. This may provide a deeper understanding why carbon tetrachloride-induced liver injury can be alleviated by MaR1 [445]. Furthermore, MaR1 reduces inflammation response of bronchial epithelial cells to organic dust [446], and inhibits the NF-кB pathway in a mouse colitis model decreasing IL- $1 \beta$, TNF- $\alpha$, IL-6, and INF- $\gamma$ production [447]. Aggressive periodontitis leukocytes are effectively inhibited by MaR1 [448]. MaR1 administration inhibits TGF- $\beta 1$ in fibroblasts [449] and consequent epithelial-to-mesenchymal cell transition in vitro, and attenuates bleomycin-induced pulmonary fibrosis [450]. Vascular endothelial hyperplasia in mice was attenuated by RvD2 and MaR1 [451].

Maresin 2 (MaR2, 13R,14S-diHDHA) also has antiinflammatory effects but this is less potent compared to MaR1 [452]. RVD1, RVD2 and MaR1 each decrease TNF $\alpha$, IL-1 $\beta$, IL- 8 together with upregulated phosphorylation and activation of protein kinase B (Akt, PBK), serine/threonine-protein kinase 1 (SGK1) and cAMP response element binding protein (CREB, CREB-1) and the antiflammatory glycogen synthase kinase $3 \beta$ (GSK3 $\beta$ ) but not MAPK-related molecules [453].

\section{Summary (Fig. 4)}

Eicosanoids "like PGs, lipoxins and leukotrienes play essential roles in maintenance of mucosal integrity" and "can become major drivers of inflammatory processes" [454]. Otherwise the inevitable ageing process may be delayed by changing the homeostasis by calorie restriction, exercise, and parabiosis through growth differentiation factor-11 (GDF-11) and AA anti-inflammatory metabolites such as LXA4, RvDs, PvDs and MaRs increase $\mathrm{NO}$, hydrogen sulfide $\left(\mathrm{H}_{2} \mathrm{~S}\right)$, and carbon monoxide $(\mathrm{CO})$ with suppressing $\mathrm{NF}-\mathrm{kB}$ and alter mTOR [385].

Kaposi's sarcoma-associated herpesvirus (KSHV) decreased anti-inflammatory LXA4 in host cells; using de novo KSHV-infected endothelial cells in vitro Kaposi's sarcoma and primary effusion lymphoma models with lipoxin and epilipoxin decreased NF-кB, AKT, ERK1/2, Cox-2, and 5-LOX [455]. Otherwise, Cox-2 is also "constitutively expressed, in the absence of overt inflammation, with a specific tissue distribution that includes the kidney, gastrointestinal tract, brain, and thymus" and this is "independent of commensal microorganisms and not associated with activity of the inflammatory transcription factor $N F-\kappa B "$ [456].

Influencing the disruption of homeostasis depends, amongst other things, on the local balance of eicosanoide pro- and anti-inflammation mediators: ionophore stimulated lymphocytes, monocytes, and basophils together with synthetic LTB4 induced in vitro chemotaxis of fibroblasts but applied LTB4 $10^{-8}$ concentrations result into optical migration while higher concentrations have an inhibitory effect [457]. Triggering a fibrotic tissue process by the sulfidopeptide LT stimulated fibroblasts only when simultaneously PG synthesis was suppressed by indomethacin [458]. Detailed knowledge of various pathways with its functional implications is needed and "... metabolic network by using systems biology approaches, should be strongly encouraged' [459]. Furthermore, this needs to include reaction specifity information of regulatory mediators impacting the biological activity of various enzymes and poteins including its dynamic changes [460-463].

Furthermore, important consequences of homeostasis disruption influencing the preparation of the precancerous niche (PCN) in this Special Issue "Disruption of signaling homeostasis induced crosstalk in the carcinogenesis paradigm Epistemology of the origin of cancer" include undervalued ubiquitous proteins [464], various pathogenic stimulus evoking chronic inflammation [465], remodeled fibrosis by chronic inflammation [466], the microbiome and morbi obesity [467] and PCN induced chronic cellmatrix stress with normal to cancer cell transition [468].

Eicosanoids are hydrophobic hormone-like substances built from PUFAs that play important roles in maintaining physiological levels of inflammation and signaling pathways. Disruption of this delicate homeostasis can create not just persistent inflammation but, with ROS and RNS species, trigger fibrosis and cell transition leading to cancer. Where do we stand today? The available evidence in regard to eicosanoids has been provided. However, not everything is well understood. The data suggest that eicosanoids are not always deleterious as there are newly elucidated anti-inflammatory and pro-resolving eicosanoids (lipoxins, resolvins, maresins, and protectins) which counteract the inflammatory reaction that are important for homeostasis. Until now this mystery, especially with the detailed biological roles of such mediators in cancer and carcinogenesis and associated inflammation are not well understood [469-472].

Eicosanoids are derived from fatty acids which explain the necessity to discuss the microbiome and morbid obesity for understanding the "Disruption of signaling homeostasis induced crosstalk in the carcinogenesis paradigm Epistemology of the origin of cancer". The disruption of homeostasis across a wide, but identifiable, swath of diverse molecular pathways creates a micromilieu which constitutes an early and necessary step during the 6step sequence of carcinogenesis for the vast majority of cancers, termed "sporadic cancers" because their etiology is not understood [473,474].

\section{Nomenclature}

$\begin{array}{ll}\text { 1O2 } & \text { Singlet oxygen } \\ 5,6 \text {-EET } & 5,6 \text {-Epoxyeicosatrienoic acid } \\ 5 \text {-HETE } & \text { 5-Hydroxyeicosatetraenoic acid } \\ 5 \text {-HpETE } & \begin{array}{l}5 \text {-Hydroperoxide intermediate } \\ \text { arachidonic acid }\end{array}\end{array}$




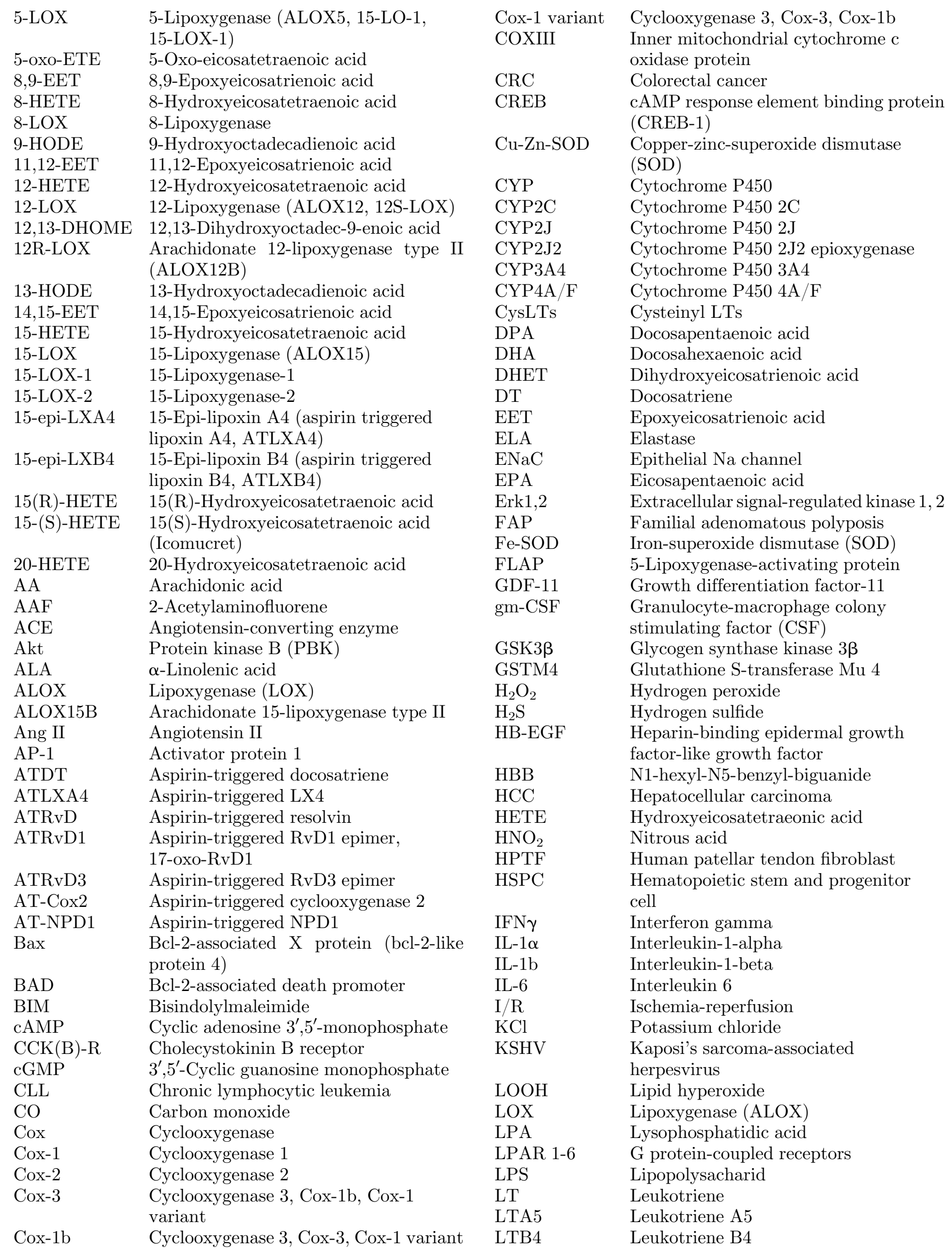




LTB5
LTC4
LTC5
LTC4S
LTD4
LTD5
LTE4
LX

LXA4

LXB4

MAPK

MaR

MaR1

MaR2

MCTR1

MCTR2

MCTR3

MEK1,2

MMP-7

MMP-9

Mn-SOD

mTOR

$\mathrm{N}_{2} \mathrm{O}_{3}$

NADPH

$\mathrm{NF}-\kappa \mathrm{B}$

NFA

Ni-SOD

$\mathrm{NO}$

$\mathrm{NO}_{2}{ }^{-}$

NONOate

Nox

NPD1

NSAID

$\omega-3$ PUFA

$\omega-6$ PUFA

๘-9 PUFA

$\mathrm{O}_{2}$

$\mathrm{O}_{2}$

$\mathrm{O}_{3}$

$\mathrm{ONOO}^{-}$

PBK

pCox-

PD
Leukotriene B5

Leukotriene C4

Leukotriene C5

Leukotriene C4 synthase

Leukotriene D4

Leukotriene D5

Leukotriene E4

Lipoxin

Lipoxin A4, 5S,6R,15S-trihydroxy-

7E,9E,11Z,13E-eicosatetraenoic acid

Lipoxin B4, 5S,14R,15S-trihydroxy-

6E,8Z,10E,12E-eicosatetraenoic

acid

Mitogen-activated protein kinase

Maresin

Maresin 1

Maresin 2

Maresin conjugates in tissue

regeneration 1

Maresin conjugates in tissue

regeneration 2

Maresin conjugates in tissue

regeneration 3

Mitogen-activated protein kinase kinase 1,2

Matrixmetalloproteinase 7

Matrixmetalloproteinase 9

Manganese-superoxide dismutase

(SOD)

Rapamycin

Dinitrogen trioxide

Nicotinamide adenine dinucleotide

phosphate

Nuclear factor kappa-light-chain-

enhancer of activated B cells

Nitro-fatty acid

Nickel-superoxide dismutase (SOD)

Nitric oxide

Nitrogen dioxide

Nitric oxide (NO) donor

Nicotinamide adenine dinucleotide

phosphate (NADPH) oxidase

Neuroprotectin D1 (PD1,protectin D1)

Non-steroidal anti-inflammatory

drug

Omega-3 (n-3) polyunsaturated fatty acid

Omega-6 (n-6) polyunsaturated fatty acid

Omega-9 (n-9) polyunsaturated fatty acid

Oxygen

Superoxide

Ozone

Peroxynitrite

Protein kinase B (Akt)

Partial Cox-1, pCox-1 protein or Cox variant Cox-1V1

Protectin
PD1

PDX

PG

PGB1

PGD2

PDG3

PGE

PGE1

PGE2

PGES

PGF1a

PGF2a

PGF3a

PGG2

PGH2

PGI2

PGI3

Phe

PI3K

PKC

PLA2

PLCO

PMN

PPAR

PPAR $\gamma$

PTGS2

PUFA

Raf1

RNS

ROS

RUNX1

RV

$\mathrm{SA}$

sEH

SGK1

SOD

SOD1

SOD2

SPM

STAT3

SV40

t-CUPM

TAK1

TGF- $\beta 1$

TNFa

TRPC7
Protectin D1 (neuroprotectin D1, NPD1)

NPD1 isomer (10(S),17(S)-dihydroxydocosahexa-4Z,7Z,11E,13Z,15E,19Z-

enoic acid)

Prostaglandin

Prostaglandin B1

Prostaglandin D2

Prostaglandin D3

Prostaglandin E

Prostaglandin E1

Prostaglandin E2

Prostaglandin E synthase

Prostaglandin F1alpha

Prostaglandin F2alpha

Prostaglandin F3alpha

Prostaglandin G2

Prostaglandin $\mathrm{H} 2$

Prostaglandin I2, prostacyclin

Prostaglandin I3

Phenylephrine

Phosphatidylinositide 3-kinase

Protein kinase $\mathrm{C}$

Phospholipase A2

Prostate, lung, colorectal, and ovarian cancer screening trial

Polymorphonuclear neutrophil

Peroxisome proliferator-activated receptor

Peroxisome proliferator-activated receptor gamma

Prostaglandin-endoperoxide synthase 2

Polyunsaturated fatty acids

RAF proto-oncogene serine/threonineprotein kinase

Reactive nitrogen species

Reactive oxygen species

Runt-related transcription factor 1

Resolvin

Salicylic acid

Soluble epoxide hydrolase

Serine/threonine-protein kinase 1

Superoxide dismutase

Superoxide dismutase 1

Superoxide dismutase 2

Specialized pro-resolving lipid mediator

Signal transducers and activators of transcription

Polyomavirus simian virus

Trans-4-\{4-[3-(4-chloro-3-trifluoromethyl-phenyl)-ureido]-cyclohexy-

loxy\}-pyridine-2-carboxylic acid

methylamide

Transforming growth factor betaactivated kinase 1

Transforming growth factor beta 1

Tumor necrosis factor a

Transient receptor potential cation 7 channel 
TXA

TXA1

TXA2

TXA3

UV

$\mathrm{XO}$
Thromboxane

Thromboxane A1

Thromboxane A2

Thromboxane A3

Ultraviolet

Xanthine oxidase

\section{Acknowledgements}

The manuscripts of this Special Issue were supported by the Theodor-Billroth-Academy ${ }^{\circledR} \quad\left(\right.$ TBA $\left.^{\circledR}\right)$ and INCORE, (International Consortium of Research Excellence) of the $\left(\mathrm{TBA}^{\circledR}\right)$. We express our gratitude to the discussions on the web group of the Theodor-BillrothAcademy ${ }^{\circledR}\left(\mathrm{TBA}^{\circledR}\right)$ on LinkedIn, the exchange with scientists at Researchgate.com, as well as personal exchanges with distinguished colleagues who stimulated our thinking all named individually earlier in publications - we thank each one. We further gratefully acknowledge the support of Florian Lang, PhD, Professor of Physiology, Institute of Physiology, University of Tübingen, Grmany and Marjan S. Rupnik, PhD, Professor of Physiology, Institute of Physiology, Center for Physiology and Pharmacology, Medical University of Vienna, Austria, for pre-submission review of the literature and our fruitful discussions. The authors highly acknowledge the extreme helpful and professional peer-review process of the handling Editor as well as of the excellent peer-reviewers.

\section{Conflict of interest}

The author reports the following conflict of interest: Björn LDM Brücher is Editor-in-Chief in Life SciencesMedicine of 4open by EDP Sciences. Ijaz S. Jamall is Senior Editorial Board member in Life Sciences-Medicine of 4open by EDP Sciences. The authors, of their own initiative, suggested to the Managing Editorial to perform a transparent peer-review of their submittals. Neither author took any action to influence the standard submission and peer-review process, and report no conflict of interest. The authors alone are responsible for the content and writing of the manuscript of this Special Issue. This manuscript contains original material that has not previously been published. Both authors contributed to the discussion on its contents and approved the manuscript.

\section{References}

1. Hanna VS, Hafez EAA (2018), Synopsis of arachidonic acid metabolism: a review. J Adv Res 11, 23-32.

2. Bergström S, Danielsson H, Samuelsson B (1964), The enzymatic formation of prostaglandin E2 from arachidonic acid prostaglandins and related cofactors 32 . Biochim Biophys Acta 90, 207-210.

3. Leskanich CO, Noble RC (1997), Manipulation of the n-3 polyunsaturated fatty acid composition of avian eggs and meat. Poultry Sci 53, 155-183.
4. Taber L, Chiu CH, Whelan J (1998), Assessment of the arachidonic acid content in foods commonly consumed in the American diet. Lipids 33, 1151-1157.

5. Martin SA, Brash AR, Murphy RC (2016), The discovery and early structural studies of arachidonic acid. J Lipid Res 57, 1126-1132.

6. Shanab SMM, Hafez RM, Fouad AS (2018), A review on algae and plants as potential source of arachidonic acid. J Adv Res 11, 3-13.

7. Liebermann L (1888), Embryochemische Untersuchungen: Über einige weniger bekannte Bestandteile des Hühnereies, Untersuchungen zur Dotterhülle. Pfugers Arch 43, 71-155.

8. Kitt M (1897), Zur Kenntniss des Eieröles. ChemikerZeitung 21, 303.

9. Serono C, Palozzi A (1911), Im Eidotter enthaltene Lipoide. Chem Zentr 82, 772.

10. Serono C, Palozzi A (1911), Im Eidotter enthaltene Lipoide. Arch d Farm sperim 11, 553-570.

11. Eibner A (1927), Die Ei-Tempera, 8. Stück der Monographien zur Maltechnik (Hrsg.: Deutsche Ges für rationelle Malverfahren), München 1927.

12. Romanoff AL (1932), Fat metabolism of the chick embryo under standard concitions of artificial incubation. Biol Bull 62, 54-62.

13. Cruikshank EM (1934), Studies in fat metabolism in the fowl: the composition of the egg fat and depot fat of the fowl as affected by the ingestion of large amounts of different fats. Biochem J 28, 965-977.

14. Müller A (1927), An X-ray investigation of certain longchain compounds. Proc R Soc A 114, 542-562.

15. Hazura K, Grüssner A (1888), Über die Oxydation ungesättigter Fettsäuren mit Kaliumpermanganat. Monatsh Chem 9, 944-955.

16. Bull H (1899), Über die Bestimmung Stark Ungesättigter Fettsäuren in den Thranen. Chemiker-Zeitung 23, 10431044.

17. Tsujimoto M (1906), On a new unsaturated fatty acid in japanese sardine oil. J College Eng Tokyo 4, 1-10.

18. Hartley P (1909), On the nature of the fat contained in the liver, kidney, and heart, Part II. J Physiol 38, 353-374.

19. Dale HH (1957), Percival Hartley 1881-1957. Biogr Mem Fellows R Soc 3, 80-100.

20. Lewkowitsch J (1913), Chemical Technology and Analysis of Oils, Fats and Waxes, 5th ed. Macmillan, London, 1913-1915. https://searchworks.stanford.edu/ view $/ 10916818$

21. Kurzrok R, Lieb CC (1930), Biochemical studies of human semen; the action of semen on the human uterus. Proc Soc Exp Biol Med 28, 268-272.

22. Ouwendijk RJT (1985), Eicosanoids, endotoxins and liver disease, Erasmus University Rotterdam. Retrieved from http://hdl.handle.net/1765/38751

23. Goldblatt MW (1933), A depressor substance in seminal fluid. J Soc Chem Ind (London) 52, 1056-1057.

24. Von Euler US (1935), Über die spezifische blutdrucksenkende Substanz des menschlichen Prostata-und Samenblasensekretes. Klin Wochschr 14, 1182-1183.

25. Bergström S, Sjövall J (1957), The isolation of prostaglandin. Acta Chem Scand 11, 1086.

26. Van Dorp DA, Beerthuis RK, Nugteren DR, Vonkeman H (1964), The biosynthesis of prostaglandins. Biochim Biophys Acta 90, 204-207.

27. Bergström S, Danielsson H, Samuelsson B (1964), The enzymatic formation of prostaglandin E2 from arachidonic acid, prostaglandins and related factors 32. Biochim Biophys Acta 90, 207-210. 
28. Vane JR (1971), Inhibition of prostaglandin synthesis as a mechanism of action for aspirin-like drugs. Nat New Biol 231, 232-235.

29. Raz A, Schwartzman M, Kenig-Wakshal R (1976), Chemical and enzymatic transformations of prostaglandin endoperoxides: evidence for the predominance of the 15-hydroperoxy pathway. Eur J Biochem 70, 89-96.

30. Egan RW, Paxton J, Kuehl FA Jr (1976), Mechanism for irreversible self-deactivation of prostaglandin synthetase. J Biol Chem 251, 7329-7335.

31. Hitchcock M (1978), Effect of inhibitors of prostaglandin synthesis and prostaglandins E2 and F2alpha on the immunologic release of mediators of inflammation from actively sensitized guinea-pig lung. J Pharmacol Exp Ther 207, 630-640.

32. Marcus AJ, Broekman MJ, Safier LB, Ullman HL, Islam N, Serhan CN, Weissmann G (1984), Production of arachidonic acid lipoxygenase products during plateletneutrophil interactions. Clin Physiol Biochem 2, 78-83.

33. Arthur S, Singh S, Sundaram U (2018), Cyclooxygenase pathway mediates the inhibition of Na-glutamine cotransporter B0AT1 in rabbit villus cells during chronic intestinal inflammation. PLoS ONE 13, e0203552.

34. Galliard T, Phillips DR (1972), The enzymic conversion of linoleic acid into 9-(nona-1',3'-dienoxy)non-8-enoic acid, a novel unsaturated ether derivative isolated from homogenates of Solanum tuberosum tubers. Biochem J 129, $743-753$.

35. Siegel MI, McConnell RT, Cuatrecasas P (1979), Aspirinlike drugs interfere with arachidonate metabolism by inhibition of the 12-hydroperoxy-5,8,10,14-eicosatetraenoic acid peroxidase activity of the lipoxygenase pathway. Proc Natl Acad Sci USA 76, 3774-3778.

36. Siegel MI, McConnell RT, Porter NA, Cuatrecasas P (1980), Arachidonate metabolism via lipoxygenase and 12L-hydroperoxy-5,8,10,14-icosatetraenoic acid peroxidase sensitive to anti-inflammatory drugs. Proc Natl Acad Sci USA 77, 308-312.

37. Kühn H, Banthiya S, van Leyen K (2015), Mammalian lipoxygenases and their biological relevance. Biochim Biophys Acta 1851, 308-330.

38. Kühn H, Saam J, Eibach S, Holzhütter HG, Ivanov I, Walther M (2005), Structural biology of mammalian lipoxygenases: enzymatic consequences of targeted alterations of the protein structure. Biochem Biophys Res Commun 338, 93-101.

39. Oliw EH, Moldéus P (1982), Metabolism of arachidonic acid by isolated rat hepatocytes, renal cells and by some rabbit tissues. Detection of vicinal diols by mass fragmentography. Biochim Biophys Acta 721, $135-143$.

40. Sivarajah K, Jones KG, Fouts JR, Devereux T, Shirley JE, Eling TE (1983), Prostaglandin synthetase and cytochrome P-450-dependent metabolism of $(+/-)$ benzo(a) pyrene 7,8-dihydrodiol by enriched populations of rat Clara cells and alveolar type II cells. Cancer Res 43 , 2632-2636.

41. Lutton JD, Schwartzman ML, Abraham NG (1989), Cytochrome P450 dependent arachidonic acid metabolism in hemopoietic cells. Adv Exp Med Biol 271, $115-121$.

42. Laethem RM, Laethem CL, Koop DR (1992), Purification and properties of a cytochrome $\mathrm{P} 450$ arachidonic acid epoxygenase from rabbit renal cortex. J Biol Chem 267, $5552-5559$.
43. Bisogno T, Melck D, De Petrocellis L, Di Marzo V (1999), Phosphatidic acid as the biosynthetic precursor of the endocannabinoid 2-arachidonoylglycerol in intact mouse neuroblastoma cells stimulated with ionomycin. J Neurochem 72, 2113-2119.

44. Hada M, Edin ML, Hartge P, Lih FB, Wentzensen N, Zeldin DC, Trabert B (2018), Pre-diagnostic serum levels of fatty acid metabolites and risk of ovarian cancer in the Prostate, Lung, Colorectal, and Ovarian Cancer (PLCO) Screening Trial. Cancer Epidemiol Biomarkers Prev 2018. DOI: 10.1158/1055-9965.EPI-18-0392

45. Walker IC, Jones RL, Wilson NH (1979), The identification of an epoxy-hydroxy acid as a product from the incubation of arachidonic acid with washed blood platelets. Prostaglandins 18, 173-178.

46. Pace-Asciak CR, Granström E, Samuelsson B (1983), Arachidonic acid epoxides. Isolation and structure of two hydroxy epoxide intermediates in the formation of 8,11,12- and 10,11,12-trihydroxyeicosatrienoic acids. J Biol Chem 258, 6835-6840.

47. Gross GJ, Hsu A, Falck JR, Nithipatikom K (2007), Mechanisms by which epoxyeicosatrienoic acids (EETs) elicit cardioprotection in rat hearts. J Mol Cell Cardiol 42, 687-691.

48. Liu L, Chen C, Gong W, Li Y, Edin ML, Zeldin DC, Wang DW (2011), Epoxyeicosatrienoic acids attenuate reactive oxygen species level, mitochondrial dysfunction, caspase activation, and apoptosis in carcinoma cells treated with arsenic trioxide. J Pharmacol Exp Ther 339, 451-463.

49. Yu G, Zeng X, Wang H, Hou Q, Tan C, Xu Q, Wang H (2015), 14, 15-epoxyeicosatrienoic Acid suppresses cigarette smoke extract-induced apoptosis in lung epithelial cells by inhibiting endoplasmic reticulum stress. Cell Physiol Biochem 36, 474-486.

50. Dong R, Hu D, Yang Y, Chen Z, Fu M, Wang DW, Xu X, Tu L (2017), EETs reduces LPS-induced hyperpermeability by targeting GRP78 mediated Src activation and subsequent Rho/ROCK signaling pathway. Oncotarget 8, 50958-50971.

51. Deng BQ, Luo Y, Kang X, Li CB, Morisseau C, Yang J, Lee KSS, Huang J, Hu DY, Wu MY, Peng A, Hammock BD, Liu JY (2017), Epoxide metabolites of arachidonate and docosahexaenoate function conversely in acute kidney injury involved in GSK3 $\beta$ signaling. Proc Natl Acad Sci USA 114, 12608-12613.

52. Williams ED, Karim SM, Sandler M (1968), Prostaglandin secretion by medullary carcinoma of the thyroid, a possible cause of the associated idarrhoea. Lancet $1,22-23$.

53. Willis AL (1969), Parallel assay of prostaglandinlike activity in rat inflammatory exudate by means of cascade superfusion. J Pharm Pharmacol 21, $126-1280$

54. Levine L, Hinkle PM, Voelkel EF, Tashjian Jr AH (1972), Prostaglandin production by mouse fibrosarcoma cells in culture: inhibition by indomethacin and aspirin. Biochem Biophys Res Commun 47, 888-896.

55. Arora S, Lahiri PK, Sanyal RK (1970), The role of prostaglandin E1 in inflammatory process in the rat. Int Arch Allergy Appl Immunol 39, 186-191.

56. Tolone G, Bonasera L, Tolone C (1978), Biosynthesis and release of prostaglandins by mast cells. Br J Exp Pathol 59, 105-109.

57. Higgs GA, Youlten LJ (1972), Proceedings: prostaglandin production by rabbit peritoneal polymorphonuclear leukocytes in vitro. Br J Pharmacol 44, 330P. 
58. Gordon D, Bray MA, Morley J (1976), Control of lymphokine secretion by prostaglandins. Nature 262, 401-402.

59. Weissmann G, Dukor P, Zurier RB (1971), Effect of cyclic AMP on release of lysosomal enzymes from phagocytes. Nat New Biol 231, 131-135.

60. Lichtenstein LM, Gillespie E, Bourne HR, Henney CS (1972), The effects of a series of prostaglandins on in vitro models of the allergic response and cellular immunity. Prostaglandins 2, 519-528.

61. Bourne HR, Lichtenstein LM, Melmon KL, Henney CS, Weinstein Y, Shearer GM (1974), Modulation of inflammation and immunity by cyclic AMP. Science $184,19-28$.

62. Morley J (1974), Prostaglandins and lymphokines in arthritis. Prostaglandins 8, 315-326.

63. Delori PJ (1971), Isolation, purification and study of a toxic phospholipase A2 from the venom of Vipera berus. Biochimie 53, 941-942.

64. Kramer RM, Hession C, Johansen B, Hayes G, McGray P, Chow EP, Tizard R, Pepinsky RB (1989), Structure and properties of a human non-pancreatic phospholipase A2. J Biol Chem 264, 5768-5775.

65. Seilhamer JJ, Pruzanski W, Vadas P, Plant S, Miller JA, Kloss J, Johnson LK (1989), Cloning and recombinant expression of phospholipase A2 present in rheumatoid arthritic synovial fluid. J Biol Chem 264 , 5335-5338.

66. Dennis EA, Cao J, Hsu YH, Magrioti V, Kokotos G (2011), Phospholipase A2 enzymes: physical structure, biological function, disease implication, chemical inhibition, and therapeutic intervention. Chem Rev 111, 61306185 .

67. Gilroy DW, Newson J, Sawmynaden P, Willoughby DA, Croxtall JD (2004), A novel role for phospholipase A2 isoforms in the checkpoint control of acute inflammation. FASEB J 18, 489-498.

68. Xu W, Yi L, Feng Y, Chen L, Liu J (2009), Structural insight into the activation mechanism of human pancreatic prophospholipase A2. J Biol Chem 284, $16659-16666$.

69. Harwig SS, Tan L, Qu XD, Cho Y, Eisenhauer PB, Lehrer RI (1995), Bactericidal properties of murine intestinal phospholipase A2. J Clin Invest 95, 603-610.

70. Fenard D, Lambeau G, Valentin E, Lefebvre JC, Lazdunski M, Doglio A (1999), Secreted phospholipases $\mathrm{A}(2)$, a new class of HIV inhibitors that block virus entry into host cells. J Clin Invest 104, 611-618.

71. Triggiani M, Granata F, Frattini A, Marone G (2006), Activation of human inflammatory cells by secreted phospholipases A2. Biochim Biophys Acta 1761, 1289 1300 .

72. Giannattasio G, Lai Y, Granata F, Mounier CM, Nallan L, Oslund R, Leslie CC, Marone G, Lambeau G, Gelb MH, Triggiani M (2009), Expression of phospholipases A2 in primary human lung macrophages: role of cytosolic phospholipase A2-alpha in arachidonic acid release and platelet activating factor synthesis. Biochim Biophys Acta 1791, 92-102.

73. Meyer AM, Dwyer-Nield LD, Hurteau GJ, Keith RL, O'Leary E, You M, Bonventre JV, Nemenoff RA, Malkinson AM (2004), Decreased lung tumorigenesis in mice genetically deficient in cytosolic phospholipase A2. Carcinogenesis 25, 1517-1524.

74. Ferrer X, Moreno JJ (1992), Effects of copper, iron and zinc on oedema formation induced by phospholipase A2. Comp Biochem Physiol C 102, 325-327.
75. Vernhet L, Petit JY, Lang F (1997), An anti-inflammatory benzamide derivative inhibits the protein kinase $\mathrm{C}$ (PKC)-dependent pathway of ERK2 phosphorylation in murine macrophages. J Pharmacol Exp Ther 283, 358-365.

76. Eberhart CE, Coffey RJ, Radhika A, Giardiello FM, Ferrenbach S, DuBois RN (1994), Up-regulation of cyclooxygenase 2 gene expression in human colorectal adenomas and adenocarcinomas. Gastroenterology 107, $1183-1188$.

77. Michaluart P, Masferrer JL, Carothers AM, Subbaramaiah K, Zweifel BS, Koboldt C, Mestre JR, Grunberger D, Sacks PG, Tanabe T, Dannenberg AJ (1999), Inhibitory effects of caffeic acid phenethyl ester on the activity and expression of cyclooxygenase- 2 in human oral epithelial cells and in a rat model of inflammation. Cancer Res 59, 2347-2352.

78. Wang D, Dubois RN (2010), Eicosanoids and cancer. Nat Rev Cancer 10, 181-193.

79. Greene ER, Huang S, Serhan CN, Panigrahy D (2011), Regulation of inflammation in cancer by eicosanoids. Prostaglandins Other Lipid Mediat 96, 27-36.

80. Yoshimoto A, Kasahara K, Kawashima A, Fujimura M, Nakao S (2005), Characterization of the prostaglandine biosynthetic pathway in non-small cell lung cancer: a comparison with small cell lung cancer and correlation with angiogenesis, angiogenic factors and metastases. Oncol Rep 13, 1049-1057.

81. Zheng BY, Fang XF, Zou LY, Huang YH, Chen ZX, Li D, Zhou LY, Chen H, Wang XZ (2014), The co-localization of $\mathrm{HBx}$ and COXIII upregulates COX-2 promoting HepG2 cell growth. Int J Oncol 45, 1143-1150.

82. Bult H (1977), Prostaglandins and acute inflammatory reactions. Study on rat platelets and carrgeenin-induced paw edema, University of Rotterdam.

83. Moncada S, Vane JR (1979), Pharmacology and endogenous roles of prostaglandin endoperoxides thromboxane A 2 and prostacyclin. Pharmacol Rev 30, 293-331.

84. Harlan JM, Harker LA (1981), Hemostasis and trombo embolic disorders: the role of arachidonic acid metabolites in platelet-vessel wall interactions, in: RP Robertson (Ed.), Prostaglandins in health and disease in medical clinics of North America, W.B. Saunders Company, London 65, pp. 855-881.

85. Hyman AL, Mathe AA, Lippton HL, Kadowitz PJ (1981), Prostagl and ins and the lung, in: RP Robertson (Ed.), Prostaglandins in health and disease. The medical clinics of North America, W.B. Saunders Company, London 65, pp. 789-809.

86. Robertson RP (1981), Prostagl and ins and hypercalcemia of cancer, in: RP Robertson (Ed.), Prostaglandins in health and disease in medical clinics of North America, W.B. Saunders Company, London 65, pp. 845-855.

87. Editorial (1981), Prostaglandins in the kidney. Lancet 2, 343-345.

88. Weiss JW, Drazen JM, Coles N, McFadden ER, Weller PF, Corey EJ, Lewis RA, Austen KF (1982), Bronchoconstrictor effects of leukotriene C in humans. Science 216 , 196-198.

89. Bennett A (1983), Prostaglandins and their synthesis inhibitors in cancer, in: F Berti, G Folco, GP Velo (Eds.), Leukotrienes and prostacyclin, Plenum Press, New York, pp. 237-249.

90. Ney RL, Hochella NJ, Grahame-Smith DG, Dexter RN, Butcher RW (1969), Abnormal regulation of adenosine 3',5'-monophosphate and corticosterone formation in an adrenocortical carcinoma. J Clin Invest 48, 1733-1739. 
91. Taunton OD, Roth J, Pastan I (1969), Studies on the adrenocorticotropic hormone-activated adenyl cyclase of a functional adrenal tumor. J Biol Chem 244, $247-253$

92. Otten J, Johnson GS, Pastan I (1971), Cyclic AMP levels in fibroblasts: relationship to growth rate and contact inhibition of growth. Biochem Biophys Res Commun 44, 1192-1198.

93. Matusik RJ, Hilf R (1976), Relationship of adenosine 3',5'cyclic monophosphate and guanosine 3',5'-cyclic monophosphate to growth of dimethylbenz(a)anthraceneinduced mammary tumors in rats. J Natl Cancer Inst $56,659-661$.

94. Anderson WB, Russell TR, Carchman RA, Pastan I (1973), Interrelationship between adenylate cyclase activity, adenosine 3':5' cyclic monophosphate phosphodiesterase activity, adenosine 3':5' cyclic monophosphate levels, and growth of cells in culture. Proc Natl Acad Sci USA 70, 3802-3805.

95. Peery CV, Johnson GS, Pastan I (1971), Adenyl cyclase in normal and transformed fibroblasts in tissue culture, activation by prostaglandins. J Biol Chem 246, 57855790 .

96. Tashjian Jr AH, Voelkel EF, Levine L, Goldhaber P (1972), Evidence that the bone resorption-stimulating factor produced by mouse fibrosarcoma cells is prostaglandin E 2. A new model for the hypercalcemia of cancer. J Exp Med 136, 1329-1343.

97. Sykes JA, Moddox IS (1972), Prostaglandin production by experimental tumours and effects of anti-inflammatory compounds. Nat New Biol 237, 59-61.

98. Zor U, Kaneko T, Schneider HP, McCann SM, Lowe IP, Bloom G, Borland B, Field JB (1969), Stimulation of anterior pituitary adenyl cyclase activity and adenosine 3':5'-cyclic phosphate by hypothalamic extract and prostaglandin E1. Proc Natl Acad Sci USA 63, 918-925.

99. Burstein S, Gagnon G, Hunter SA, Maudsley DV (1977), Elevation of prostaglandin and cyclic AMP levels by arachidonic acid in primary epithelial cell cultures of C3H mouse mammary tumors. Prostaglandins 13, 41-53.

100. Brønstad GO, Christoffersen T, Johansen EJ, Oye I (1978), Effect of prostaglandins and hormones on cyclic AMP formation in rat hepatomas and liver tissue. Br $\mathrm{J}$ Cancer 38, 737-744.

101. Bhattacharyya A, Chattopadhyay R, Mitra S, Crowe SE (2014), Oxidative stress: an essential factor in the pathogenesis of gastrointestinal mucosal diseases. Physiol Rev 94, 329-354.

102. Arias-Negrete S, Keller K, Chadee K (1995), Proinflammatory cytokines regulate cyclooxygenase- 2 mRNA expression in human macrophages. Biochem Biophys Res Commun 208, 582-589.

103. Seibert K, Masferrer JL (1994), Role of inducible cyclooxygenase (Cox-2) in inflammation. Receptor 4, $17-23$.

104. Moreno J, Krishnan AV, Swami S, Nonn L, Peehl DM, Feldman D (2005), Regulation of prostaglandin metabolism by calcitriol attenuates growth stimulation in prostate cancer cells. Cancer Res 65, 7917-7925.

105. Mitchell JA, Belvisi MG, Akarasereenont P, Robbins RA, Kwon OJ, Croxtall J, Barnes PJ, Vane JR (1994), Induction of cyclo-oxygenase- 2 by cytokines in human pulmonary epithelial cells: regulation by dexamethasone. Br J Pharmacol 113, 1008-1014.

106. Krishnan AV, Feldman D (2010), Molecular pathways mediating the anti-inflammatory effects of calcitriol: implications for prostate cancer chemoprevention and treatment. Endocr Relat Cancer 17, R19-R38.

107. Kukreja RC, Kontos HA, Hess ML, Ellis EF (1986), PGH synthase and lipoxygenase generate superoxide in the presence of NADH or NADPH. Circ Res 59, $612-619$.

108. Simmons DL, Botting RM, Hla T (2004), Cyclooxygenase isozymes: the biology of prostaglandin synthesis and inhibition. Pharmacol Rev 56, 387-437.

109. Föller M, Kasinathan RS, Duranton C, Wieder T, Huber SM, Lang F (2006), PGE2-induced apoptotic cell death in K562 human leukaemia cells. Cell Physiol Biochem 17, 201-210.

110. Chen L, Cheng B, Jiang C (2015), Cyclic mechanical stretching induces autophagic cell death in tenofibroblasts through activation of prostaglandin E2 production. Cell Physiol Biochem 36, 24-33.

111. Baranski W, ukasik K, Skarzynski D, Sztachanska M, Zdunczyk S, Janowski T (2013), Secretion of prostaglandins and leukotrienes by endometrial cells in cows with subclinical and clinical endometritis. Theriogenology 80, 766-772.

112. Piotrowska-Tomala KK, Bah MM, Jankowska K, Lukasik K, Warmowski P, Galvao AM, Skarzynski DJ (2015), Lipopolysaccharides, cytokines, and nitric oxide affect secretion of prostaglandins and leukotrienes by bovine mammary gland during experimentally induced mastitis in vivo and in vitro. Domest Anim Endocrinol $52,90-99$.

113. von Rahden BHA, Brücher BLDM, Langner C, Hartl S, Theisen J, Siewert JR, Stein HJ, Sarbia M (2006), Expression of COX-1 and 2, mPGES and TGF-Beta1 and their link with proangiogenetic factors VEGF-A and VEGF-A C in Primary Adenocarcinomas of the Small Intestine. Br J Surg 93, 1424-1432.

114. Woclawek-Potocka I, Kondraciuk K, Skarzynski DJ (2009), Lysophosphatidic acid stimulates prostaglandin E2 production in cultured stromal endometrial cells through LPA1 receptor. Exp Biol Med (Maywood) 234, 986-993.

115. Wocławek-Potocka I, Rawinska P, Kowalczyk-Zieba I, Boruszewska D, Sinderewicz E, Was niewski T, Skarzynski DJ (2014), Lysophosphatidic acid (LPA) signaling in human and ruminant reproductive tract. Mediators Inflamm 2014, 649-702.

116. Papadimitriou A, King AJ, Jones PM, Persaud SJ (2007), Anti-apoptotic effects of arachidonic acid and prostaglandin E2 in pancreatic beta-cells. Cell Physiol Biochem 20, 607-616.

117. Simmons DL, Levy DB, Yannoni Y, Erikson RL (1989), Identification of a phorbol ester-repressible v-src-inducible gene. Proc Natl Acad Sci USA 86, 1178-1182.

118. Snipes JA, Kis B, Shelness GS, Hewett JA, Busija DW (2005), Cloning and characterization of cyclooxygenase1b (putative COX-3) in rat. J Pharmacol Exp Ther 313, 668-676.

119. Davies NM, Good RL, Roupe KA, Yáñez JA (2004), Cyclooxygenase-3: axiom, dogma, anomaly, enigma or splice error? Not as easy as 1, 2, 3. J Pharm Pharm Sci 7, 217-226. Erratum in: J Pharm Pharm Sci 2006, 9, following 433 .

120. Chandrasekharan NV, Dai H, Roos KL, Evanson NK, Tomsik J, Elton TS, Simmons DL (2002), COX-3, a cyclooxygenase-1 variant inhibited by acetaminophen and other analgesic/antipyretic drugs: cloning, structure, and expression. Proc Natl Acad Sci USA 99, 13926-13931. 
121. Schwab JM, Schluesener HJ, Meyermann R, Serhan CN (2003), COX-3 the enzyme and the concept: steps towards highly specialized pathways and precision therapeutics? Prostaglandins Leukot Essent Fatty Acids 69, 339-343.

122. Ayoub SS, Botting RM, Goorha S, Colville-Nash PR, Willoughby DA, Ballou LR (2004), Acetaminopheninduced hypothermia in mice is mediated by a prostaglandin endoperoxide synthase 1 gene-derived protein. Proc Natl Acad Sci USA 101, 11165-11169.

123. Simmons DL, Chandrasekharan NV, Hu D, Roos KL, Tomsik J (2005), Comments on "acetaminophen and the cyclooxygenase-3 puzzle: sorting out facts, fictions, and uncertainties". J Pharmacol Exp Ther 315, 1412-1414. Author reply 1415-1416.

124. Foegh ML, Ramwell PW (2001), The eicosanoids: prostagl and ins, thromboxanes, leukotrienes, and related compounds, in: BG Kartzung (Ed.), Basic and Clinical Pharmacology, 8th edn. Lange Medical Books, McGrawHill, New York, pp. 325.

125. Moerse HN (1878), Über eine neue Darstellungsmethode der Acetylamidophenole. Ber Deutscher Chem Ges 11, 232-233.

126. Roberts LJ, II, Morrow JD (2001), Analgesic-antipyretic and anti-inflammatory agents and drugs employed in the treatment of gout, in: JG Hardman, LE Limbird, AG Gilman (Eds.), The Pharmacological Basis of Therapeutics, 10th edn., McGraw-Hill, New York, pp. 687-731.

127. Kis B, Snipes JA, Isse T, Nagy K, Busija DW (2003), Putative cyclooxygenase-3 expression in rat brain cells. J Cereb Blood Flow Metab 23, 1287-1292.

128. Erol K, Sirmagul B, Kilic FS, Yigitaslan S, Dogan AE (2012), The role of inflammation and COX-derived prostanoids in the effects of bradykinin on isolated rat aorta and urinary bladder. Inflammation 35, 420-428.

129. Kis B, Snipes JA, Busija DW (2005), Acetaminophen and the cyclooxygenase-3 puzzle: sorting out facts, fictions, and uncertainties. J Pharmacol Exp Ther 315, 1-7.

130. Ozatik FY, Kaygisiz B, Erol K (2017), The role of cyclooxygenase enzymes in the effects of losartan and lisinopril on the contractions of rat thoracic aorta. Eurasian J Med 49, 16-21.

131. Oksuz E, Atalar F, Tanırverdi G, Bilir A, Shahzadi A, Yazici Z (2016), Therapeutic potential of cyclooxygenase3 inhibitors in the management of glioblastoma. J Neurooncol 126, 271-278.

132. Kuhnert N (2000), A century of aspirin. The history of themost successful drug of the last ry. Pharm Unserer Zeit 29, 32-39.

133. Gerhardt CF (1853), Untersuchungen über die wasserfrei organischen Saüren. Ann Chem Pharm 87, 149-179.

134. Eichengrün A (1949), 50 Jahre Aspirin. Die Pharmazie 4, $582-584$.

135. Sneader W (1997), The discovery of Aspirin. Pharmaceutical J 259, 614-617.

136. Sneader W (2000), The discovery of aspirin: a reappraisal. BMJ 321, 1591-1594.

137. Schwarcz J (2015), Monkeys, Myths and Molecules: Separating Fact from Fiction in the Science of Everyday Life, ECW Press.

138. Paul-Clark MJ, Van Cao T, Moradi-Bidhendi N, Cooper D, Gilroy DW (2004), 15-epi-lipoxin A4-mediated induction of nitric oxide explains how aspirin inhibits acute inflammation. J Exp Med 200, 69-78.

139. McCarty MF, Block KI (2006), Preadministration of highdose salicylates, suppressors of NF-kappaB activation, may increase the chemosensitivity of many cancers: an example of proapoptotic signal modulation therapy. Integr Cancer Ther 5, 252-268.
140. Somasundaram, et al. (2000), Uncoupling of intestinal mitochondrial oxidative phosphorylation and inhibition of cyclooxygenase are required for the development of NSAID-enteropathy in the rat. Aliment Pharmacol Ther 14, 639-650.

141. Jacobs EJ, Thun MJ, Bain EB, Rodriguez C, Henley SJ, Calle EE (2007), A large cohort study of long-term daily use of adult-strength aspirin and cancer incidence. J Natl Cancer Inst 99, 608-615.

142. Rothwell PM, Wilson M, Price JF, Belch JF, Meade TW, Mehta Z (2012), Effect of daily aspirin on risk of cancer metastasis: a study of incident cancers during randomised controlled trials. Lancet 379, 1591-1601.

143. Sutcliffe P, Connock M, Gurung T, Freeman K, Johnson S, Kandala NB, Grove A, Gurung B, Morrow S, Clarke A (2013), Aspirin for prophylactic use in the primary prevention of cardiovascular disease and cancer: a systematic review and overview of reviews. Health Technol Assess 17, 1-253.

144. Cao Y, Nishihara R, Wu K, Wang M, Ogino S, Willett WC, Spiegelman D, Fuchs CS, Giovannucci EL, Chan AT (2016), Population-wide impact of long-term use of aspirin and the risk for cancer. JAMA Oncol 2, $762-769$.

145. Brusselaers N, Lagergren J (2018), Maintenance use of non-steroidal anti-inflammatory drugs and risk of gastrointestinal cancer in a nationwide population-based cohort study in Sweden. BMJ Open 8, e021869.

146. Rostom A, Dube C, Lewin G (2007), Use of Aspirin and NSAIDs to Prevent Colorectal Cancer [Internet]. Agency for Healthcare Research and Quality (US), Rockville, MD. https://www.ncbi.nlm.nih.gov/books/NBK33464/

147. Algra AM, Rothwell PM (2012), Effects of regular aspirin on long-term cancer incidence and metastasis: a systematic comparison of evidence from observational studies versus randomised trials. Lancet Oncol 13, $518-527$.

148. Huang WK, Chiou MJ, Yu KH, Lin YC, Yang TS, Chen JS, Kuo CF, See LC (2013), The association between lowdose aspirin use and the incidence of colorectal cancer: a nationwide cohort study. Aliment Pharmacol Ther 38, 432-439.

149. Kunzmann AT, Murray LJ, Cardwell CR, McShane CM, McMenamin UC, Cantwell MM (2013), PTGS2 (Cyclooxygenase-2) expression and survival among colorectal cancer patients: a systematic review. Cancer Epidemiol Biomarkers Prev 22, 1490-1497.

150. Watt DG, Park JH, Ng SK, Horgan PG, McMillan DC (2016), Does pre-operative aspirin and statin prescription modulate the post-operative systemic inflammatory response following surgery for colorectal cancer? ASCO Gastrointestinal Cancers Symposium. J Clin Oncol 34, Suppl 4S, Abstract 596.

151. Restivo A, Cocco IM, Casula G, Scintu F, Cabras F, Scartozzi M, Zorcolo L (2015), Aspirin as a neoadjuvant agent during preoperative chemoradiation for rectal cancer. Br J Cancer 113, 1133-1139.

152. Ashida N, Kishihata M, Tien DN, Kamei K, Kimura T, Yokode M (2014), Aspirin augments the expression of Adenomatous Polyposis Coli protein by suppression of IKK $\beta$. Biochem Biophys Res Commun 446, 460-464.

153. Lee HS, Kim SB, Lee HJ, Park SJ, Hong SP, Cheon JH, Kim WH, Kim TI (2018), Postoperative adjuvant chemotherapy is associated with a lower incidence of colorectal adenomas in patients with previous colorectal cancer. Gastrointest Endosc 87, 688-694. 
154. Hada M, Edin ML, Hartge P, Lih FB, Wentzensen N, Zeldin DC, Trabert B (2017), Pre-diagnostic serum levels of fatty acid metabolites and risk of ovarian cancer in the Prostate, Lung, Colorectal, and Ovarian Cancer (PLCO) Screening Trial. Cancer Epidemiol Biomarkers Prev. DOI: 10.1158/1055-9965.EPI-18-0392

155. Merritt MA, Rice MS, Barnard ME, Hankinson SE, Matulonis UA, Poole EM, Tworoger SS (2018), Prediagnosis and post-diagnosis use of common analgesics and ovarian cancer prognosis (NHS/NHSII): a cohort study. Lancet Oncol 19, 1107-1116.

156. Cheung KS, Chan EW, Wong AYS, Chen L, Seto WK, Wong ICK, Leung WK (2018), Aspirin and risk of gastric cancer after Helicobacter pylori eradication: a territorywide study. J Natl Cancer Inst 110, 743-749.

157. Kim MH, Chang J, Kim WJ, Banerjee S, Park SM (2018), Cumulative dose threshold for the chemopreventive effect of aspirin against gastric cancer. Am J Gastroenterol 113, 845-854.

158. Niikura R, Hayakawa Y, Hirata Y, Konishi M, Suzuki N, Ihara S, Yamada A, Ushiku T, Fujishiro M, Fukayama M, Koike K (2018), Distinct chemopreventive effects of aspirin in diffuse and intestinal-type gastric cancer. Cancer Prev Res (Phila) 11, 279-286.

159. Streicher SA, Yu H, Lu L, Kidd MS, Risch HA (2014), Case-control study of aspirin use and risk of pancreatic cancer. Cancer Epidemiol Biomarkers Prev 23, 1254-1263.

160. Risch HA, Lu L, Streicher SA, Wang J, Zhang W, Ni Q, Kidd MS, Yu H, Gao YT (2017), Aspirin use and reduced risk of pancreatic cancer. Cancer Epidemiol Biomarkers Prev 26, 68-74.

161. Hwang IC, Chang J, Kim K, Park SM (2018), Aspirin use and risk of hepatocellular carcinoma in a national cohort study of Korean adults. Sci Rep 8, 4968.

162. Fraser DM, Sullivan FM, Thompson AM, McCowan C (2014), Aspirin use and survival after the diagnosis of breast cancer: a population-based cohort study. Br J Cancer 111, 623-627.

163. Wood ME, Sprague BL, Oustimov A, Synnstvedt MB, Cuke M, Conant EF, Kontos D (2017), Aspirin use is associated with lower mammographic density in a large screening cohort. Breast Cancer Res Treat 162, 419425.

164. Downer MK, Allard CB, Preston MA, Gaziano JM, Stampfer MJ, Mucci LA, Batista JL (2017), Regular aspirin use and the risk of lethal prostate cancer in the physicians' health study. Eur Urol 72, 821-827.

165. Ma Y, Brusselaers N (2018), Maintenance use of aspirin or other non-steroidal anti-inflammatory drugs (NSAIDs) and prostate cancer risk. Prostate Cancer Prostatic Dis 21, 147-152.

166. Pinsky PF, Miller E, Prorok P, Grubb R, Crawford ED, Andriole G (2018), Extended follow-up for prostate cancer incidence and mortality in the PLCO randomized cancer screening trial. BJU Int. DOI: 10.1111/bju.14580

167. Gamba CA, Swetter SM, Stefanick ML, Kubo J, Desai M, Spaunhurst KM, Sinha AA, Asgari MM, Sturgeon S, Tang JY (2013), Aspirin is associated with lower melanoma risk among postmenopausal Caucasian women: the Women's Health Initiative. Cancer 119, 1562-1569.

168. Yang H, Pellegrini L, Napolitano A, Giorgi C, Jube S, Preti A, Jennings CJ, De Marchis F, Flores EG, Larson D, Pagano I, Tanji M, Powers A, Kanodia S, Gaudino G, Pastorino S, Pass HI, Pinton P, Bianchi ME, Carbone M (2015), Aspirin delays mesothelioma growth by inhibiting HMGB1-mediated tumor progression. Cell Death Dis 6, e1786.
169. Chandra S, Jana M, Pahan K (2018), Aspirin induces lysosomal biogenesis and attenuates amyloid plaque pathology in a mouse model of Alzheimer's disease via PPAR $\alpha$. J Neurosci 38, 6682-6699.

170. Movahedi M, Bishop DT, Macrae F, Mecklin JP, Moeslein G, Olschwang S, Eccles D, Evans DG, Maher ER, Bertario L, Bisgaard ML, Dunlop MG, Ho JW, Hodgson SV, Lindblom A, Lubinski J, Morrison PJ, Murday V, Ramesar RS, Side L, Scott RJ, Thomas HJ, Vasen HF, Burn J, Mathers JC (2015), Obesity, aspirin, and risk of colorectal cancer in carriers of hereditary colorectal cancer: a prospective investigation in the CAPP2 study. J Clin Oncol 33, 3591-3597.

171. Tosoco P (2013), A mechanistic hypothesis for the aspirininduced switch in lipid mediator production by cyclooxygenase-2. J Am Chem Soc 135, 10404-10410.

172. Truitt EB Jr, Morgan M (1964), Gastrointestinal factors in aspirin absorption, a quantitative study. J Pharm Sci 53, 129-134.

173. Levitt DG (2013), Quantitation of small intestinal permeability during normal human drug absorption. BMC Pharmacol Toxicol 14, 34.

174. Takai E, Tsukimoto M, Kojima S (2013), TGF- $\beta 1$ downregulates Cox-2 expression leading to decrease of PGE2 production in human lung cancer A549 cells, which is involved in fibrotic response to TGF- $\beta 1$. PLoS ONE 8, e76346.

175. Zhang A, Wang MH, Dong Z, Yang T (2006), Prostaglandin E2 is a potent inhibitor of epithelial-to-mesenchymal transition: interaction with hepatocyte growth factor. Am J Physiol Renal Physiol 291, F1323- F1331.

176. Che D, Zhang S, Jing Z, Shang L, Jin S, Liu F, Shen J, Li Y, Hu J, Meng Q, Yu Y (2017), Macrophages induce EMT to promote invasion of lung cancer cells through the IL-6mediated Cox-2/PGE2/ $\beta$-catenin signalling pathway. Mol Immunol 90, 197-210.

177. Oner-Iyidogan Y, Oner P, Kocak H, Gurdol F, Bekpinar S, Unlucerci Y, Caliskan Y, Cetinalp-Demircan P, Kocak T, Turkmen A (2009), Dimethylarginines and inflammation markers in patients with chronic kidney disease undergoing dialysis. Clin Exp Med 9, 235-241.

178. Ricciotti E, FitzGerald GA (2011), Prostaglandins and inflammation. Arterioscler Thromb Vasc Biol 31, 9861000.

179. Kawahara K, Hohjoh H, Inazumi T, Tsuchiya S, Sugimoto Y (2015), Prostaglandin E2-induced inflammation: relevance of prostaglandin E receptors. Biochim Biophys Acta $1851,414-421$.

180. Brash AR (1999), Lipoxygenases: occurrence, functions, catalysis, and acquisition of substrate. J Biol Chem 274, 23679-23682.

181. Shureiqi I, Lippman SM (2001), Lipoxygenase modulation to reverse carcinogenesis. Cancer Res 61, 6307-6312.

182. Moore GY, Pidgeon GP (2017), Cross-talk between cancer cells and the tumour microenvironment: the role of the 5lipoxygenase pathway. Int J Mol Sci 18, E236.

183. Sanak M (2016), Eicosanoid mediators in the airway inflammation of asthmatic patients: what is new? Allergy Asthma Immunol Res 8, 481-490.

184. Cornejo-García JA, Perkins JR, Jurado-Escobar R, García-Martín E, Agúndez JA, Viguera E, Pérez-Sánchez N, Blanca-López N (2016), Pharmacogenomics of prostaglandin and leukotriene receptors. Front Pharmacol 7, 316.

185. Lee TH, Sethi T, Crea AE, Peters W, Arm JP, Horton CE, Walport MJ, Spur BW (1988), Characterization of leukotriene B3: comparison of its biological activities 
with leukotriene B4 and leukotriene B5 in complement receptor enhancement, lysozyme release and chemotaxis of human neutrophils. Clin Sci (Lond) 74, 467-475.

186. Jones T, Denis D, Hall R, Ethier D (1983), Pharmacological study of the effects of leukotrienes C4, D4, E4 \& F4 on guinea pig trachealis: interaction with FPL-55712. Prostaglandins 26, 833-843.

187. Smith MJ, Ford-Hutchinson AW, Bray MA (1980), Leukotriene B: a potential mediator of inflammation. J Pharm Pharmacol 32, 517-518.

188. Lee W, Su Kim HL Lee GR (2015), Leukotrienes induce the migration of Th17 cells. Immunol Cell Biol 93, 472479 .

189. Borgeat $P$, Sirois $P$ (1981), Leukotrienes: a major step in the understanding of immediate hypersensitivity reactions. J Med Chem 24, 121-126.

190. Gür ZT, Çalıskan B, Banoglu E (2017), Drug discovery approaches targeting 5-lipoxygenase-activating protein (FLAP) for inhibition of cellular leukotriene biosynthesis. Eur J Med Chem. DOI: 10.1016/j.ejmech.2017.07.019

191. Paris D, Town T, Parker TA, Tan J, Humphrey J, Crawford F, Mullan M (1999), Inhibition of Alzheimer's beta-amyloid induced vasoactivity and proinflammatory response in microglia by a cGMP-dependent mechanism. Exp Neurol 157, 211-221.

192. Dembinska-Kieć A, Korbut R, Zmuda A, Kostka-Trabka E, Simmet T, Peskar BA (1984), Formation of lipoxygenase and cyclooxygenase metabolites of arachidonic acid by brain tissue. Biomed Biochim Acta 43, S222-226.

193. Shi QJ, Wang H, Liu ZX, Fang SH, Song XM, Lu YB, Zhang WP, Sa XY, Ying HZ, Wei EQ (2015), HAMI 3379, a CysLT2R antagonist, dose- and time-dependently attenuates brain injury and inhibits microglial inflammation after focal cerebral ischemia in rats. Neuroscience 291, 53-69.

194. Prosiegel M, Neu I, Wildfeuer A, Mehlber L, Mallinger J, Ruhenstroth-Bauer G (1987), Leukotrienes B4 and C4 in MS. Acta Neurol Scand 75, 361-363.

195. Mirshafiey A, Jadidi-Niaragh F (2010), Immunopharmacological role of the leukotriene receptor antagonists and inhibitors of leukotrienes generating enzymes in multiple sclerosis. Immunopharmacol Immunotoxicol 32, 219-227.

196. Murphy RC, Hammarström S, Samuelsson B (1979), Leukotriene C: a slow-reacting substance from murine mastocytoma cells. Proc Natl Acad Sci USA 76, 42754279.

197. Nozaki M1, Yoshikawa M, Ishitani K, Kobayashi H, Houkin K, Imai K, Ito Y, Muraki T (2010), Cysteinyl leukotriene receptor antagonists inhibit tumor metastasis by inhibiting capillary permeability. Keio J Med 59, 1018.

198. Galdiero MR, Varricchi G, Seaf M, Marone G, LeviSchaffer F, Marone G (2017), Bidirectional mast celleosinophil interactions in inflammatory disorders and cancer. Front Med (Lausanne) 4, 103.

199. Zamarron BF, Chen W (2011), Dual roles of immune cells and their factors in cancer development and progression. Int J Biol Sci 7, 651-658.

200. Adel S, Heydeck D, Kuhn H, Ufer C (2016), The lipoxygenase pathway in zebrafish. Expression and characterization of zebrafish ALOX5 and comparison with its human ortholog. Biochim Biophys Acta 1861, 111. Erratum in: Biochim Biophys Acta 2017, 1862, 282.

201. Avis IM, Jett M, Boyle T, Vos MD, Moody T, Treston AM, Martínez A, Mulshine JL (1996), Growth control of lung cancer by interruption of 5-lipoxygenase-mediated growth factor signaling. J Clin Invest 97, 806-613.
202. Bai CY, Zhang JY, Shi TW, Bai YQ, Wu BL, Du ZP, Wu ZY, Xu XE, Wang SH, Wu JY, Te RY, Zhang JY, Xu LY, Li EM (2018), Association between 5-lipoxygenase expression, and malignant behaviors and poor prognosis in esophageal squamous cell carcinoma. Oncol Lett 15, 9353-9360.

203. Wasilewicz MP, Kołodziej B, Bojułko T, Kaczmarczyk M, Sulzyc-Bielicka V, Bielicki D, Ciepiela K (2010), Overexpression of 5-lipoxygenase in sporadic colonic adenomas and a possible new aspect of colon carcinogenesis. Int J Colorectal Dis 25, 1079-1085.

204. Ding XZ, Iversen P, Cluck MW, Knezetic JA, Adrian TE (1999), Lipoxygenase inhibitors abolish proliferation of human pancreatic cancer cells. Biochem Biophys Res Commun 261, 218-223.

205. Hennig R, Ding XZ, Tong WG, Schneider MB, Standop J, Friess H, Büchler MW, Pour PM, Adrian TE (2002), 5Lipoxygenase and leukotriene $\mathrm{B}(4)$ receptor are expressed in human pancreatic cancers but not in pancreatic ducts in normal tissue. Am J Pathol 161, 421-428.

206. Tong WG, Ding XZ, Hennig R, Witt RC, Standop J, Pour PM, Adrian TE (2002), Leukotriene B4 receptor antagonist LY293111 inhibits proliferation and induces apoptosis in human pancreatic cancer cells. Clin Cancer Res 8, 32323242 .

207. Anderson KM, Seed T, Vos M, Mulshine J, Meng J, Alrefai W, Ou D, Harris JE (1998), 5-Lipoxygenase inhibitors reduce $\mathrm{PC}-3$ cell proliferation and initiate nonnecrotic cell death. Prostate 37, 161-173.

208. Gupta S, Srivastava M, Ahmad N, Sakamoto K, Bostwick DG, Mukhtar H (2001), Lipoxygenase-5 is overexpressed in prostate adenocarcinoma. Cancer 91, 737-743.

209. Tong WG, Ding XZ, Adrian TE (2002), The mechanisms of lipoxygenase inhibitor-induced apoptosis in human breast cancer cells. Biochem Biophys Res Commun 296, 942-948.

210. Boado RJ, Pardridge WM, Vinters HV, Black KL (1992), Differential expression of arachidonate 5-lipoxygenase transcripts in human brain tumors: evidence for the expression of a multitranscript family. Proc Natl Acad Sci USA 89, 9044-9048.

211. Kargman S, Vickers PJ, Evans JF (1992), A23187 induces translocation of 5 -lipoxygenase in osteosarcoma cells. J Cell Biol 119, 1701-1709.

212. Romano M, Catalano A, Nutini M, D'Urbano E, Crescenzi C, Claria J, Libner R, Davi G, Procopio A (2001), 5lipoxygenase regulates malignant mesothelial cell survival: involvement of vascular endothelial growth factor. FASEB J 15, 2326-2336.

213. Shureiqi I, Wu Y, Chen D, Yang XL, Guan B, Morris JS, Yang P, Newman RA, Broaddus R, Hamilton SR, Lynch P, Levin B, Fischer SM, Lippman SM (2005), The critical role of 15-lipoxygenase-1 in colorectal epithelial cell terminal differentiation and tumorigenesis. Cancer Res 65, 11486-11492.

214. Cheon EC, Khazaie K, Khan MW, Strouch MJ, Krantz SB, Phillips J, Blatner NR, Hix LM, Zhang M, Dennis KL, Salabat MR, Heiferman M, Grippo PJ, Munshi HG, Gounaris E, Bentrem DJ (2011), Mast cell 5-lipoxygenase activity promotes intestinal polyposis in APCDelta468 mice. Cancer Res 71, 1627-1636.

215. Wculek SK, Malanchi I (2015), Neutrophils support lung colonization of metastasis-initiating breast cancer cells. Nature 528, 413-417.

216. Poczobutt JM, Nguyen TT, Hanson D, Li H, Sippel TR, Weiser-Evans MC, Gijon M, Murphy RC, Nemenoff RA (2016), Deletion of 5-lipoxygenase in the tumor microen- 
vironment promotes lung cancer progression and metastasis through regulating $\mathrm{T}$ cell recruitment. J Immunol 196, 891-901.

217. Xu XM, Deng JJ, Yuan GJ, Yang F, Guo HT, Xiang M, Ge W, Wu YG (2011), 5-Lipoxygenase contributes to the progression of hepatocellular carcinoma. Mol Med Rep 4, 1195-1200.

218. Roffeis J, Hornung D, Kuhn H, Walther M (2007), 15Lipoxygenase-2 is differentially expressed in normal and neoplastic ovary. Eur J Cancer Prev 16, 568-575.

219. Wen Z, Liu H, Li M, Li B, Gao W, Shao Q, Fan B, Zhao F, Wang Q, Xie Q, Yang Y, Yu J, Qu X (2015), Increased metabolites of 5-lipoxygenase from hypoxic ovarian cancer cells promote tumor-associated macrophage infiltration. Oncogene 34, 1241-1252.

220. Kummer NT, Nowicki TS, Azzi JP, Reyes I, Iacob C, Xie S, Swati I, Darzynkiewicz Z, Gotlinger KH, Suslina N, Schantz S, Tiwari RK, Geliebter J (2012), Arachidonate 5 lipoxygenase expression in papillary thyroid carcinoma promotes invasion via MMP-9 induction. J Cell Biochem 113, 1998-2008.

221. Shureiqi I, Chen D, Lee JJ, Yang P, Newman RA, Brenner DE, Lotan R, Fischer SM, Lippman SM (2000), 15-LOX1: a novel molecular target of nonsteroidal anti-inflammatory drug-induced apoptosis in colorectal cancer cells. J Natl Cancer Inst 92, 1136-1142.

222. Wu J, Xia HH, Tu SP, Fan DM, Lin MC, Kung HF, Lam SK, Wong BC (2003), 15-Lipoxygenase-1 mediates cyclooxygenase-2 inhibitor-induced apoptosis in gastric cancer. Carcinogenesis 24, 243-247.

223. Saul MJ, Groher F, Hegewald AB, Müller-McNicoll M, Marschalek R, Suess B, Steinhilber D (2017), TGFß/ SMAD signalling modulates MLL and MLL-AF4 mediated 5-lipoxygenase promoter activation. Prostaglandins Other Lipid Mediat 133, 60-67.

224. Yoshimura R, Matsuyama M, Tsuchida K, Kawahito Y, Sano H, Nakatani T (2003), Expression of lipoxygenase in human bladder carcinoma and growth inhibition by its inhibitors. J Urol 170, 1994-1999.

225. Hayashi T, Nishiyama K, Shirahama T (2006), Inhibition of 5-lipoxygenase pathway suppresses the growth of bladder cancer cells. Int J Urol 13, 1086-1091.

226. Goupil RC, Bushey JJ, Peters-Kennedy J, Wakshlag JJ (2012), Prevalence of 5-lipoxygenase expression in canine osteosarcoma and the effects of a dual 5-lipoxygenase/ cyclooxygenase inhibitor on osteosarcoma cells in vitro and in vivo. Vet Pathol 49, 802-810.

227. Nardone PA, Slotman GJ, Vezeridis MP (1988), Ketoconazole: a thromboxane synthetase and 5-lipoxygenase inhibitor with antimetastatic activity in B16-F10 melanoma. J Surg Res 44, 425-429.

228. Kuhnert R, Sárosi MB, George S, Lönnecke P, Hofmann B, Steinhilber D, Murganic B, Mijatovic S, Maksimovic-Ivanic D, Hey-Hawkins E (2017), CarbORev-5901: The First Carborane-Based Inhibitor of the 5-Lipoxygenase Pathway. ChemMedChem 12, 1081-1086.

229. Wilborn J, Bailie M, Coffey M, Burdick M, Strieter R, Peters-Golden M (1996), Constitutive activation of 5-lipoxygenase in the lungs of patients with idiopathic pulmonary fibrosis. J Clin Invest 97, 1827-1836.

230. Kamitani H, Geller M, Eling T (1998), Expression of 15lipoxygenase by human colorectal carcinoma Caco-2 cells during apoptosis and cell differentiation. J Biol Chem 273, 21569-21577.

231. Che XH, Chen CL, Ye XL, Weng GB, Guo XZ, Yu WY, Tao J, Chen YC, Chen X (2016), Dual inhibition of
COX-2/5-LOX blocks colon cancer proliferation, migration and invasion in vitro. Oncol Rep 35, 1680-1688.

232. DuBois RN, Giardiello FM, Smalley WE (1996), Nonsteroidal anti-inflammatory drugs, eicosanoids, and colorectal cancer prevention. Gastroenterol Clin North Am 25, 773-791.

233. Harris RE (2009), Cyclooxygenase-2 (cox-2) blockade in the chemoprevention of cancers of the colon, breast, prostate, and lung. Inflammopharmacology 17, $55-67$.

234. Jensen TSR, Mahmood B, Damm MB, Backe MB, Dahllöf MS, Poulsen SS, Hansen MB, Bindslev N (2018), Combined activity of COX-1 and COX-2 is increased in non-neoplastic colonic mucosa from colorectal neoplasia patients. BMC Gastroenterol 18, 31.

235. Gerbe F, van Es JH, Makrini L, Brulin B, Mellitzer G, Robine S, Romagnolo B, Shroyer NF, Bourgaux JF, Pignodel C, Clevers H, Jay P (2011), Distinct ATOH1 and Neurog3 requirements define tuft cells as a new secretory cell type in the intestinal epithelium. J Cell Biol 192, 767780 .

236. Rhodin J, Dalhamn T (1956), Electron microscopy of the tracheal ciliated mucosa in rat. Z Zellforsch Mikrosk Anat $44,345-412$.

237. Jarvi O, Keyrilainen O (1956), On the cellular structures of the epithelial invasions in the glandular stomach of mice caused by intramural application of 20-methylcholantren. Acta Pathol Microbiol Scand Suppl 39 (Suppl 111), 72-73.

238. Rioux N, Castonguay A (1998), Inhibitors of lipoxygenase: a new class of cancer chemopreventive agents. Carcinogenesis 19, 1393-1400.

239. Venerito M, Kuester D, Harms C, Schubert D, Wex T, Malfertheiner P (2011), Upregulation of leukotriene receptors in gastric cancer. Cancers (Basel) 3, 3156-3168.

240. Yoshimi N, Ino N, Suzui M, Tanaka T, Nakashima S, Nakamura M, Nozawa Y, Mori H (1995), The mRNA overexpression of inflammatory enzymes, phospholipase A2 and cyclooxygenase, in the large bowel mucosa and neoplasms of F344 rats treated with naturally occurring carcinogen, 1-hydroxyanthraquinone. Cancer Lett 97, 75-82.

241. Chen GY, Shu YC, Chuang DY, Wang YC (2016), Inflammatory and apoptotic regulatory activity of tanshinone IIA in Helicobacter pylori-infected cells. Am J Chin Med 44, 1187-1206.

242. Mao F, Xu M, Zuo X, Yu J, Xu W, Moussalli MJ, Elias E, Li HS, Watowich SS, Shureiqi I (2015), 15-Lipoxygenase-1 suppression of colitis-associated colon cancer through inhibition of the IL-6/STAT3 signaling pathway. FASEB J 29, 2359-2370.

243. Kroschwald S, Chiu CY, Heydeck D, Rohwer N, Gehring T, Seifert U, Lux A, Rothe M, Weylandt KH, Kuhn H (2018), Female mice carrying a defective Alox15 gene are protected from experimental colitis via sustained maintenance of the intestinal epithelial barrier function. Biochim Biophys Acta Mol Cell Biol Lipids 1863, 866-880.

244. Schwartzman ML, Falck JR, Yadagiri P, Escalante B (1989), Metabolism of 20-hydroxyeicosatetraenoic acid by cyclooxygenase. Formation and identification of novel endothelium-dependent vasoconstrictor metabolites. J Biol Chem 264, 11658-11662.

245. Omata K, Abe K, Sheu HL, Yoshida K, Tsutsumi E, Yoshinaga K, Abraham NG, Laniado-Schwartzman M (1992), Roles of renal cytochrome P450-dependent arachidonic acid metabolites in hypertension. Tohoku J Exp Med 166, 93-106. 
246. Sohlenius AK, Wigren J, Bäckström K, Andersson K, DePierre JW (1995), Synergistic induction of acyl-CoA oxidase activity, an indicator of peroxisome proliferation, by arachidonic acid and retinoic acid in Morris hepatoma 7800C1 cells. Biochim Biophys Acta 1258, 257-264.

247. Goodman AI, Choudhury M, da Silva JL, Schwartzman ML, Abraham NG (1997), Overexpression of the heme oxygenase gene in renal cell carcinoma. Proc Soc Exp Biol Med 214, 54-61.

248. Alexanian A, Rufanova VA, Miller B, Flasch A, Roman RJ, Sorokin A (2009), Down-regulation of 20-HETE synthesis and signaling inhibits renal adenocarcinoma cell proliferation and tumor growth. Anticancer Res 29, 38193824 .

249. Alexanian A, Miller B, Roman RJ, Sorokin A (2012), 20HETE-producing enzymes are up-regulated in human cancers. Cancer Genomics Proteomics 9, 163-169.

250. Chen C, Wei X, Rao X, Wu J, Yang S, Chen F, Ma D, Zhou J, Dackor RT, Zeldin DC, Wang DW (2011), Cytochrome P450 2J2 is highly expressed in hematologic malignant diseases and promotes tumor cell growth. J Pharmacol Exp Ther 336, 344-355.

251. Garcia V, Shkolnik B, Milhau L, Falck JR, Schwartzman ML (2016), 20-HETE activates the transcription of angiotensin-convertingenzyme via nuclear factor-kappaB translocation and promoter binding. J Pharmacol Exp Ther $356,525-533$.

252. Norwood S, Liao J, Hammock BD, Yang GY (2010), Epoxyeicosatrienoic acids and soluble epoxide hydrolase: potential therapeutic targets for inflammation and its induced carcinogenesis. Am J Transl Res 2, 447-457.

253. Wang D, Dubois RN (2012), Epoxyeicosatrienoic acids: a double-edged sword in cardiovascular diseases and cancer. J Clin Invest 122, 19-22.

254. Mizuno D, Soma GI (1988), Endogenous and exogenous TNF therapy (EET therapy): conceptual and experimental grounds. Ann Inst Pasteur Immunol 139, 282285.

255. Inagawa H, Oshima H, Soma G, Mizuno D (1988), TNF induces endogenous TNF in vivo: the basis of EET therapy as a combination of rTNF together with endogenous TNF. J Biol Response Mod 7, 596-607.

256. Jiang JG, Chen CL, Card JW, Yang S, Chen JX, Fu XN, Ning YG, Xiao X, Zeldin DC, Wang DW (2005), Cytochrome P450 2J2 is highly expressed in hematologic malignant diseases and promotes tumor cell growth. Cancer Res 65, 4707-4715.

257. Xu X, Zhang XA, Wang DW (2011), The roles of CYP450 epoxygenases and metabolites, epoxyeicosatrienoic acids, in cardiovascular and malignant diseases. Adv Drug Deliv Rev 63, 597-609.

258. Kim J, Yoon SP, Toews ML, Imig JD, Hwang SH, Hammock BD, Padanilam BJ (2015), Pharmacological inhibition of soluble epoxide hydrolase prevents renal interstitial fibrogenesis in obstructive nephropathy. Am J Physiol Renal Physiol 308, F131-F139.

259. Mitra R, Guo Z, Milani M, Mesaros C, Rodriguez M, Nguyen J, Luo X, Clarke D, Lamba J, Schuetz E, Donner DB, Puli N, Falck JR, Capdevila J, Gupta K, Blair IA, Potter DA (2011), CYP3A4 mediates growth of estrogen receptor-positive breast cancer cells in part by inducing nuclear translocation of phospho-Stat3 through biosynthesis of $( \pm)-14,15$-epoxyeicosatrienoic acid (EET). J Biol Chem 286, 17543-17559.

260. Tacconelli S, Patrignani P (2014), Inside epoxyeicosatrienoic acids and cardiovascular disease. Front Pharmacol 5, 239 .
261. Lakkappa N, Krishnamurthy PT, Hammock BD, Velmurugan D, Bharath MM (2016), Possible role of Epoxyeicosatrienoic acid in prevention of oxidative stress mediated neuroinflammation in Parkinson disorders. Med Hypotheses 93, 161-165.

262. Li P, Lahvic JL, Binder V, Pugach EK, Riley EB, Tamplin OJ, Panigrahy D, Bowman TV, Barrett FG, Heffner GC, McKinney-Freeman S, Schlaeger TM, Daley GQ, Zeldin DC, Zon LI (2015), Epoxyeicosatrienoic acids enhance embryonic haematopoiesis and adult marrow engraftment. Nature 523, 468-471.

263. Zhang W, Liao J, Li H, Dong H, Bai H, Yang A, Hammock BD, Yang GY (2013), Reduction of inflammatory bowel disease-induced tumor development in IL-10 knockout mice with soluble epoxide hydrolase gene deficiency. Mol Carcinog 52, 726-738.

264. Shao J, Wang H, Yuan G, Chen Z, Li Q (2016), Involvement of the arachidonic acid cytochrome P450 epoxygenase pathway in the proliferation and invasion of human multiple myeloma cells. PeerJ 4, e1925.

265. Wei X, Zhang D, Dou X, Niu N, Huang W, Bai J, Zhang G (2014), Elevated 14,15-epoxyeicosatrienoic acid by increasing of cytochrome $\mathrm{P} 4502 \mathrm{C} 8,2 \mathrm{C} 9$ and $2 \mathrm{~J} 2$ and decreasing of soluble epoxide hydrolase associated with aggressiveness of human breast cancer. BMC Cancer 14, 841.

266. Amaral A, Fernandes C, Lukasik K, Szóstek-Mioduchowska A, Baclawska A, Rebordão MR, Aguiar-Silva J, PintoBravo P, Skarzynski DJ, Ferreira-Dias G (2018), Elastase inhibition affects collagen transcription and prostaglandin secretion in mare endometrium during the estrous cycle. Reprod Domest Anim 53 (Suppl 2), 66-69.

267. Sakairi Y, Jacobson HR, Noland TD, Capdevila JH, Falck JR, Breyer MD (1995), 5, 6-EET inhibits ion transport in collecting duct by stimulating endogenous prostaglandin synthesis. Am J Physiol 268(5 Pt 2), F931-F939.

268. Liao J, Hwang SH, Li H, Liu JY, Hammock BD, Yang GY (2016), Inhibition of chronic pancreatitis and murine pancreatic intraepithelial neoplasia by a dual inhibitor of c-RAF and soluble epoxide hydrolase in LSL-KrasG ${ }^{12} \mathrm{D} /$ Pdx-1-Cre mice. Anticancer Res 36, 27-37.

269. Panigrahy D, Greene ER, Pozzi A, Wang DW, Zeldin DC (2011), EET signaling in cancer. Cancer Metastasis Rev $30,525-540$.

270. Jiang H, Harrison FE, Jain K, Benjamin S, May JM, Graves JP, Zeldin DC, Falck JR, Hammock BD, McGiff JC (2012), Vitamin C activation of the biosynthesis of epoxyeicosatrienoic acids. Adv Biosci Biotechnol 3, 204218.

271. Davis BB, Liu JY, Tancredi DJ, Wang L, Simon SI, Hammock BD, Pinkerton KE (2011), The anti-inflammatory effects of soluble epoxide hydrolase inhibitors are independent of leukocyte recruitment. Biochem Biophys Res Commun 410, 494-500.

272. Johnson N, De Ieso P, Migliorini G, Orr N, Broderick P, Catovsky D, Matakidou A, Eisen T, Goldsmith C, Dudbridge F, Peto J, Dos-Santos-Silva I, Ashworth A, Ross G, Houlston RS, Fletcher O (2016), Cytochrome P450 allele CYP3A $7 * 1 \mathrm{C}$ associates with adverse outcomes in chronic lymphocytic leukemia, breast, and lung cancer. Cancer Res 76, 1485-1493.

273. Guo Z, Sevrioukova IF, Denisov IG, Zhang X, Chiu TL, Thomas DG, Hanse EA, Cuellar RAD, Grinkova YV, Langenfeld VW, Swedien DS, Stamschror JD, Alvarez J, Luna F, Galván A, Bae YK, Wulfkuhle JD, Gallagher RI, Petricoin EF Rd, Norris B, Flory CM, Schumacher RJ, O'Sullivan MG, Cao Q, Chu H, Lipscomb JD, Atkins WM, 
Gupta K, Kelekar A6, Blair IA, Capdevila JH, Falck JR, Sligar SG, Poulos TL, Georg GI Ambrose E, Potter DA (2017), Heme binding biguanides target cytochrome P450dependent cancer cell mitochondria. Cell Chem Biol 24, 1259-1275.

274. Anderson KM, Harris JE (1990), 5, 8, 11, 14-eicosatetraynoic acid inhibits PC3 DNA synthesis and cellular proliferation, in part due to its 5'-lipoxygenase activity. Clin Physiol Biochem 8, 308-313.

275. Node K, Huo Y, Ruan X, Yang B, Spiecker M, Ley K, Zeldin DC, Liao JK (1999), Anti-inflammatory properties of cytochrome P450 epoxygenase-derived eicosanoids. Science 285, 1276-1279.

276. Chen C, Wei X, Rao X, Wu J, Yang S, Chen F, Ma D, Zhou J, Dackor RT, Zeldin DC, Wang DW (2011), Cytochrome P450 2J2 is highly expressed in hematologic malignant diseases and promotes tumor cell growth. J Pharmacol Exp Ther 336, 344-355.

277. Zhao G, Wang J, Xu X, Jing Y, Tu L, Li X, Chen C, Cianflone K, Wang P, Dackor RT, Zeldin DC, Wang DW (2012), Epoxyeicosatrienoic acids protect rat hearts against tumor necrosis factor-alpha-induced injury. J Lipid Res 53, 456-466.

278. Zhao G, Tu L, Li X, Yang S, Chen C, Xu X, Wang P, Wang DW (2012), Delivery of AAV2-CYP2J2 protects remnant kidney in the 5/6-nephrectomized rat via inhibition of apoptosis and fibrosis. Hum Gene Ther 23, 688-699.

279. Cai Z, Zhao G, Yan J, Liu W, Feng W, Ma B, Yang L, Wang JA, Tu L, Wang DW (2013), CYP2J2 overexpression increases EETs and protects against angiotensin II-induced abdominal aortic aneurysm in mice. J Lipid Res 54, 1448-1456.

280. Chen W, Zheng G, Yang S, Ping W, Fu X, Zhang N, Wang DW, Wang J (2014), CYP2J2 and EETs protect against oxidative stress and apoptosis in vivo and in vitro following lung ischemia/reperfusion. Cell Physiol Biochem 33, 1663-1680.

281. Chen W, Yang S, Ping W, Fu X, Xu Q, Wang J (2015), CYP2J2 and EETs protect against lung ischemia/ reperfusion injury via anti-inflammatory effects in vivo and in vitro. Cell Physiol Biochem 35, 2043-2054.

282. Wei Y, Lin DH, Kemp R, Yaddanapudi GS, Nasjletti A, Falck JR, Wang WH (2004), Arachidonic acid inhibits epithelial $\mathrm{Na}$ channel via cytochrome P450 (CYP) epoxygenase-dependent metabolic pathways. J Gen Physiol 124, 719-727.

283. Nüsing RM, Schweer H, Fleming I, Zeldin DC, Wegmann M (2007), Epoxyeicosatrienoic acids affect electrolyte transport in renal tubular epithelial cells: dependence on cyclooxygenase and cell polarity. Am J Physiol Renal Physiol 293, F288-F298.

284. Ren Q, Ma M, Yang J, Nonaka R, Yamaguchi A, Ishikawa KI, Kobayashi K, Murayama S, Hwang SH, Saiki S, Akamatsu W, Hattori N, Hammock BD, Hashimoto K (2018), Soluble epoxide hydrolase plays a key role in the pathogenesis of Parkinson's disease. Proc Natl Acad Sci USA 115, E5815-E5823.

285. Wang W, Yang J, Zhang J, Wang Y, Hwang SH, Qi W, Wan D, Kim D, Sun J, Sanidad KZ, Yang H, Park Y, Liu JY, Zhao X, Zheng X, Liu Z, Hammock BD, Zhang G (2018), Lipidomic profiling reveals soluble epoxide hydrolase as a therapeutic target of obesity-induced colonic inflammation. Proc Natl Acad Sci USA 115, $5283-5288$.

286. Kühn B, Brat C, Fettel J, Hellmuth N, Maucher IV, Bulut U, Hock KJ, Grimmer J, Manolikakes G, Rühl M, Kühn A, Zacharowski K, Matrone C, Urbschat A, Roos J,
Steinhilber D, Maier TJ (2018), Anti-inflammatory nitro-fatty acids suppress tumor growth by triggering mitochondrial dysfunction and activation of the intrinsic apoptotic pathway in colorectal cancer cells. Biochem Pharmacol 155, 48-60.

287. Commoner B, Townsend J, Pake GE (1954), Free radicals in biological materials. Nature 174, 689-691.

288. Gerschman R, Gilbert DL, Nye SW, Dwyer P, Fenn WO (1954), Oxygen poisoning and X-irradiation: a mechanism in common. Science 119, 623-626.

289. Rhodin JAG (1954), Correlation of ultrastructural organization and function in normal and experimentally changed proximal tubule cells of the mouse kidney, Doctorate Thesis, Karolinska Institutet, Stockholm.

290. Bernhrad W, Rouiller C (1956), Microbodies and the problem of mitochondrial regeneration in liver cells. J Biophys Biochem Cytol 2(4 Suppl), 355-360.

291. Bonetta L (2005), Seeing perioxisomes. J Cell Biol 169, 705 .

292. Wolf J, Schliebs W, Erdmann R (2010), Peroxisomes as dynamic organelles: peroxisomal matrix protein import. FEBS J 277, 3268-3278.

293. Sabatini DD, Adesnik M (2013), Christian de Duve: explorer of the cell who discovered new organelles by using a centrifuge. Proc Natl Acad Sci USA 110, 13234-13235.

294. De Duve C, Baudhuin P (1966), Peroxisomes (microbodies and related particles). Physiol Rev 46, 323-357.

295. McCord JM, Fridovich I (1969), An enzymatic function for erythrocuprein. J Biol Chem 244, 6049-6044.

296. Beem KM, Rich WE, Rajagopalan KV (1974), Total reconstitution of copper-zinc superoxide dismutase. J Biol Chem 249, 7298-7305.

297. Saito T, Ito K, Kurasaki M, Fujimoto S, Kaji H, Saito K (1982), Determination of true specific activity of superoxide dismutase in human erythrocytes. Clin Sci (Lond) 63, 251-255.

298. Sprote P, Brakhage AA, Hynes MJ (2009), Contribution of peroxisomes to penicillin biosynthesis in Aspergillus nidulans. Eukaryot Cell 8, 421-423.

299. Imazaki A, Tanaka A, Harimoto Y, Yamamoto M, Akimitsu K, Park P, Tsuge T (2010), Contribution of peroxisomes to secondary metabolism and pathogenicity in the fungal plant pathogen Alternaria alternate. Eukaryot Cell 9, 682-694.

300. Nyathi Y, Baker A (2006), Plant peroxisomes as a source of signalling molecules. Biochim Biophys Acta 1763, 14781495 .

301. Blum JJ (1973), Localization of some enzymes of betaoxidation of fatty acids in the peroxisomes of Tetrahymena. J Protozool 20, 688-692.

302. Lazarow PB (1978), Rat liver peroxisomes catalyze the beta oxidation of fatty acids. J Biol Chem 253, 15221528.

303. Yamada J, Ogawa S, Horie S, Watanabe T, Suga T (1987), Participation of peroxisomes in the metabolism of xenobiotic acyl compounds: comparison between peroxisomal and mitochondrial beta-oxidation of omega-phenyl fatty acids in rat liver. Biochim Biophys Acta 921, 292301 .

304. Watkins PA, Ferrell EV Jr, Pedersen JI, Hoefler G (1991), Peroxisomal fatty acid beta-oxidation in HepG2 cells. Arch Biochem Biophys 289, 329-336.

305. Perry JJ, Shin DS, Getzoff ED, Tainer JA (2010), The structural biochemistry of the superoxide dismutases. Biochim Biophys Acta 1804, 245-262.

306. Chillemi G, Falconi M, Amadei A, Zimatore G, Desideri A, Di Nola A (1997), The essential dynamics of $\mathrm{Cu}, \mathrm{Zn}$ 
superoxide dismutase: suggestion of intersubunit communication. Biophys J 73, 1007-1018.

307. Bedard K, Krause KH (2007), The NOX family of ROSgenerating NADPH oxidases: physiology and pathophysiology. Physiol Rev 87, 245-313.

308. Dickinson BC, Chang CJ (2011), Chemistry and biology of reactive oxygen species in signaling or stress responses. Nat Chem Biol 7, 504-511.

309. Sies H (1985), Oxidative Stress, Academic Press, London, UK, pp. 1-507.

310. Sies H (2015), Oxidative stress: a concept in redox biology and medicine. Redox Biol 4, 180-183.

311. Niki E (2016), Oxidative stress and antioxidants: distress or eustress? Arch Biochem Biophys 595, 19-24.

312. Fridovich I (1997), Superoxide anion radical (O2-.), superoxide dismutases, and related matters. J Biol Chem $272,18515-18517$.

313. Lambeth JD (2004), NOX enzymes and the biology of reactive oxygen. Nat Rev Immunol 4, 181-189.

314. Steinbacher P, Eckl P (2015), Impact of oxidative stress on exercising skeletal muscle. Biomolecules 5, $356-377$.

315. Schieber M, Chandel NS (2014), ROS function in redox signaling and oxidative stress. Curr Biol 24, R453R462.

316. Hsieh HJ, Liu CA, Huang B, Tseng AH, Wang DL (2014), Shear-induced endothelial mechanotransduction: the interplay between reactive oxygen species (ROS) and nitric oxide (NO) and the pathophysiological implications. J Biomed Sci 21, 3.

317. Radi R (2018), Oxygen radicals, nitric oxide, and peroxynitrite: redox pathways in molecular medicine. Proc Natl Acad Sci USA 115, 5839-5848.

318. Groß F, Durner J, Gaupels F (2013), Nitric oxide, antioxidants and prooxidants in plant defence responses. Front Plant Sci 4, 419.

319. Chen Y, Azad MB, Gibson SB (2009), Superoxide is the major reactive oxygen species regulating autophagy. Cell Death Differ 16, 1040-1052.

320. Weinberg F, Hamanaka R, Wheaton W, Weinberg S, Joseph J, Lopez M, Kalyanaraman B, Mutlu G, Budinger G, Chandel N (2010), Mitochondrial metabolism and ROS generation are essential for Kras mediated tumorigenicity. Proc Natl Acad Sci USA 107, 8788-8793.

321. Fruehauf JP, Meyskens FL Jr (2007), Reactive oxygen species: a breath of life or death? Clin Cancer Res 13, 789794.

322. Cho KJ, Seo JM, Kim JH (2011), Bioactive lipoxygenase metabolites stimulation of NADPH oxidases and reactive oxygen species. Mol Cells 32, 1-5.

323. Lassègue B, San Martín A, Griendling KK (2012), Biochemistry, physiology, and pathophysiology of NADPH oxidases in the cardiovascular system. Circ Res 110, 1364-1390.

324. Roy J, Galano JM, Durand T, Le Guennec JY, Lee JC (2017), Physiological role of reactive oxygen species as promoters of natural defenses. FASEB J 31, 3729-3745.

325. Onodera Y, Teramura T, Takehara T, Shigi K, Fukuda K (2015), Reactive oxygen species induce Cox-2 expression via TAK1 activation in synovial fibroblast cells. FEBS Open Bio 5, 492-501.

326. Hsu HH, Lin YM, Shen CY, Shibu MA, Li SY, Chang SH, Lin CC, Chen RJ, Viswanadha VP, Shih HN, Huang CY (2017), Prostaglandin E2-induced COX-2 expressions via EP2 and EP4 signaling pathways in human LoVo colon cancer cells. Int J Mol Sci 18, E1132.
327. Araldi RP, Módolo DG, de Sá Júnior PL, Consonni SR, de Carvalho RF, Roperto FP, Beçak W, de Cassia Stocco R (2016), Genetics and metabolic deregulation following cancer initiation: a world to explore. Biomed Pharmacother 82, 449-458.

328. Aversa I, Zolea F, Ieranò C, Bulotta S, Trotta AM, Faniello MC, De Marco C, Malanga D, Biamonte F, Viglietto G, Cuda G, Scala S, Costanzo F (2017), Epithelial-to-mesenchymal transition in FHC-silenced cells: the role of CXCR4/CXCL12 axis. J Exp Clin Cancer Res 36, 104.

329. Jackson LM, Wu KC, Mahida YR, Jenkins D, Hawkey CJ (2000), Cyclooxygenase (Cox) 1 and 2 in normal, inflamed, and ulcerated human gastric mucosa. Gut 47, $762-770$.

330. Konturek SJ, Konturek PC, Plonka A, Duda A, Sito E, Zuchowicz M, Hahn EG (2001), Implication of gastrin in cyclooxygenase-2 expression in Helicobacter pylori infected gastric ulceration. Prostaglandins Other Lipid Mediat 66, 39-51.

331. O'Connor PM, Lapointe TK, Beck PL, Buret AG (2010), Mechanisms by which inflammation may increase intestinal cancer risk in inflammatory bowel disease. Inflamm Bowel Dis 16, 1411-1420.

332. Surowiak P, Gansukh T, Donizy P, Halon A, Rybak Z (2014), Increase in cyclooxygenase-2 (Cox-2) expression in keratinocytes and dermal fibroblasts in photoaged skin. J Cosmet Dermatol 13, 195-201.

333. (2018) Global Dietary Supplements Market Size Will Grow USD 220.3 Billion by 2022According to the report, global dietary supplements market valued at USD 132.8 billion in2016 and is expected to reach USD, Apr 12, 2018, https://markets.businessinsider.com/news/stocks/globaldietary-supplements-market-size-will-grow-usd-220-3-bil lion-by-2022according-to-the-report-global-dietary-supple ments-market-valued-at-usd-132-8-billion-in-2016-and-isexpected-to-reach-usd-1021297252

334. Boveris A, Oshino N, Chance B (1972), The cellular production of hydrogen peroxide. Biochem J 128, 617-630.

335. Simko M (2007), Cell type specific redox status is responsible for diverse electromagnetic field effects. Curr Med Chem 14, 1141-1152.

336. Martino CF, Castello PR (2011), Modulation of hydrogen peroxide production in cellular systems by low level magnetic fields. PLoS ONE 6, e22753.

337. Valko M, Leibfritz D, Moncol J, Cronin MT, Mazur M, Telser J (2007), Free radicals and antioxidants in normal physiological functions and human disease. Int J Biochem Cell Biol 39, 44-84.

338. Giorgio M, Trinei M, Migliaccio E, Pelicci PG (2007), Hydrogen peroxide: a metabolic by-product or a common mediator of ageing signals? Nat Rev Mol Cell Biol 8, 722728.

339. Forkink M, Smeitink JA, Brock R, Willems PH, Koopman WJ (2010), Detection and manipulation of mitochondrial reactive oxygen species in mammalian cells. Biochim Biophys Acta 1797, 1034-1044.

340. Cockbain AJ, Toogood GJ, Hull MA (2012), Omega-3 polyunsaturated fatty acids for the treatment and prevention of colorectal cancer. Gut 61, 135-149.

341. Azrad M, Turgeon C, Demark-Wahnefried W (2013), Current evidence linking polyunsaturated Fatty acids with cancer risk and progression. Front Oncol 3, 224.

342. Vaughan VC, Hassing MR, Lewandowski PA (2013), Marine polyunsaturated fatty acids and cancer therapy. Br J Cancer 108, 486-492. 
343. Nabavi SF, Bilotto S, Russo GL, Orhan IE, Habtemariam S, Daglia M, Devi KP, Loizzo MR, Tundis R, Nabavi SM (2015), Omega-3 polyunsaturated fatty acids and cancer: lessons learned from clinical trials. Cancer Metastasis Rev 34, 359-380.

344. Huerta-Yépez S, Tirado-Rodriguez AB, Hankinson O (2016), Role of diets rich in omega-3 and omega-6 in the development of cancer. Bol Med Hosp Infant Mex 73, 446-456.

345. Garg A (1998), High-monounsaturated-fat diets for patients with diabetes mellitus: a meta-analysis. Am J Clin Nutr 67(3 Suppl), 577S-582S.

346. Finucane OM, Lyons CL, Murphy AM, Reynolds CM, Klinger R, Healy NP, Cooke AA, Coll RC, McAllan L, Nilaweera KN, O'Reilly ME, Tierney AC, Morine MJ, Alcala-Diaz JF, Lopez-Miranda J, O'Connor DP, O'Neill LA, McGillicuddy FC, Roche HM (2015), Monounsaturated fatty acid-enriched high-fat diets impede adipose NLRP3 inflammasome-mediated IL-1 $\beta$ secretion and insulin resistance despite obesity. Diabetes 64, 2116-2128.

347. Gonçalves-de-Albuquerque CF, Medeiros-de-Moraes IM, Oliveira FM, Burth P, Bozza PT, Castro Faria MV, Silva AR, Castro-Faria-Neto HC (2016), Omega-9 oleic acid induces fatty acid oxidation and decreases organ dysfunction and mortality in experimental sepsis. PLoS ONE 11, e0153607.

348. Delgado GE, Krämer BK, Lorkowski S, März W, von Schacky C, Kleber ME (2017), Individual omega-9 monounsaturated fatty acids and mortality - The Ludwigshafen Risk and Cardiovascular Health Study. J Clin Lipidol 11, 126-135, e5.

349. Melo RB, de Barros Silva PG, Oriá RB, Melo JU, da Silva Martins C, Cunha AM, Vasconcelos PR (2017), Antiinflammatory effect of a fatty acid mixture with high $\omega-9: \omega-6$ ratio and low $\omega-6: \omega-3$ ratio on rats submitted to dental extraction. Arch Oral Biol 74, 63-68.

350. Lee HC, Liang A, Lin YH, Guo YR, Huang SY (2017), Low dietary $n-6 / n-3$ polyunsaturated fatty acid ratio prevents induced oral carcinoma in a hamster pouch model. Prostaglandins Leukot Essent Fatty Acids. DOI: 10.1016/j.plefa.2017.03.003

351. Otto C, Kaemmerer U, Illert B, Muehling B, Pfetzer N, Wittig R, Voelker HU, Thiede A, Coy JF (2008), Growth of human gastric cancer cells in nude mice is delayed by a ketogenic diet supplemented with omega-3 fatty acids and medium-chain triglycerides. BMC Cancer 8, 122.

352. Lee S, Lee J, Choi IJ, Kim YW, Ryu KW, Kim YI, Kim J (2018), Dietary n-3 and n-6 polyunsaturated fatty acids, the FADS gene, and the risk of gastric cancer in a Korean population. Sci Rep 8, 3823.

353. Calviello G, Di Nicuolo F, Gragnoli S, Piccioni E, Serini S, Maggiano N, Tringali G, Navarra P, Ranelletti FO, Palozza P (2004), n-3 PUFAs reduce VEGF expression in human colon cancer cells modulating the COX-2/PGE2 induced ERK-1 and -2 and HIF-1alpha induction pathway. Carcinogenesis 25, 2303-2310.

354. Kim S, Sandler DP, Galanko J, Martin C, Sandler RS (2010), Intake of polyunsaturated fatty acids and distal large bowel cancer risk in whites and African Americans. Am J Epidemiol 171, 969-979.

355. Hawcroft G, Volpato M, Marston G, Ingram N, Perry SL, Cockbain AJ, Race AD, Munarini A, Belluzzi A, Loadman PM, Coletta PL, Hull MA (2012), The omega-3 polyunsaturated fatty acid eicosapentaenoic acid inhibits mouse MC-26 colorectal cancer cell liver metastasis via inhibition of PGE2-dependent cell motility. Br J Pharmacol 166, 1724-1737.
356. Calviello G, Palozza P, Piccioni E, Maggiano N, Frattucci A, Franceschelli P, Bartoli GM (1998), Dietary supplementation with eicosapentaenoic and docosahexaenoic acid inhibits growth of Morris hepatocarcinoma 3924A in rats: effects on proliferation and apoptosis. Int J Cancer 75, 699-705.

357. Lim K, Han C, Dai Y, Shen M, Wu T (2009), Omega-3 polyunsaturated fatty acids inhibit hepatocellular carcinoma cell growth through blocking beta-catenin and cyclooxygenase-2. Mol Cancer Ther 8, 3046-3055.

358. Hughes-Fulford M, Chen Y, Tjandrawinata RR (2001), Fatty acid regulates gene expression and growth of human prostate cancer PC-3 cells. Carcinogenesis 22, 701-707.

359. Hughes-Fulford M, Tjandrawinata RR, Li CF, Sayyah S (2005), Arachidonic acid, an omega-6 fatty acid, induces cytoplasmic phospholipase A2 in prostate carcinoma cells. Carcinogenesis 26, 1520-1526.

360. Sasaki T, Kobayashi Y, Shimizu J, Wada M, In'nami S, Kanke Y, Takita T (1998), Effects of dietary n-3-to-n-6 polyunsaturated fatty acid ratio on mammary carcinogenesis in rats. Nutr Cancer 30, 137-143. Erratum in: Nutr Cancer 1998, 31, 151.

361. Horia E, Watkins BA (2007), Complementary actions of docosahexaenoic acid and genistein on COX-2, PGE2 and invasiveness in MDA-MB-231 breast cancer cells. Carcinogenesis 28, 809-815.

362. Yang B, Ren XL, Fu YQ, Gao JL, Li D (2014), Ratio of n3/n-6 PUFAs and risk of breast cancer: a meta-analysis of 274135 adult females from 11 independent prospective studies. BMC Cancer 14, 105.

363. Huang LH, Chung HY, Su HM (2017), Docosahexaenoic acid reduces sterol regulatory element binding protein-1 and fatty acid synthase expression and inhibits cell proliferation by inhibiting pAkt signaling in a human breast cancer MCF-7 cell line. BMC Cancer 17, 890.

364. Liu J, Abdelmagid SA, Pinelli CJ, Monk JM, Liddle DM, Hillyer LM, Hucik B, Silva A, Subedi S, Wood GA, Robinson LE, Muller WJ, Ma DWL (2018), Marine fish oil is more potent than plant-based n-3 polyunsaturated fatty acids in the prevention of mammary tumors. J Nutr Biochem 55, 41-52.

365. Lu XY, Zeng T (2014), Effects of polyunsaturated fatty acids on endometrial carcinoma Ishikawa cells. Eur Rev Med Pharmacol Sci 18, 3311-3314.

366. Funahashi H, Satake M, Hasan S, Sawai H, Newman RA, Reber HA, Hines OJ, Eibl G (2008), Opposing effects of n6 and n-3 polyunsaturated fatty acids on pancreatic cancer growth. Pancreas 36, 353-362.

367. Mohammed A, Janakiram NB, Brewer M, Duff A, Lightfoot S, Brush RS, Anderson RE, Rao CV (2012), Endogenous n-3 polyunsaturated fatty acids delay progression of pancreatic ductal adenocarcinoma in Fat1-p48(Cre/+)-LSL-Kras(G12D/+) mice. Neoplasia 14, 1249-1259.

368. Ben Fradj MK, Ouanes Y, Hadj-Taieb S, Sallemi A, Kallel A, Jemaa R, Kaabachi N, Nouira Y, Feki M (2018), Decreased oleic acid and marine n-3 polyunsaturated fatty acids in Tunisian patients with urothelial bladder cancer. Nutr Cancer 2018, 1-8.

369. Cremonezzi DC, Silva RA, del Pilar Díaz M, Valentich MA, Eynard AR (2001), Dietary polyunsatured fatty acids (PUFA) differentially modulate melamine-induced preneoplastic urothelial proliferation and apoptosis in mice. Prostaglandins Leukot Essent Fatty Acids 64, 151-159. 
370. Luu HN, Cai H, Murff HJ, Xiang YB, Cai Q, Li H, Gao J, Yang G, Lan Q, Gao YT, Zheng W, Shu XO (2018), A prospective study of dietary polyunsaturated fatty acids intake and lung cancer risk. Int J Cancer. DOI: 10.1002/ ijc.31608

371. Albino AP, Juan G, Traganos F, Reinhart L, Connolly J, Rose DP, Darzynkiewicz Z (2000), Cell cycle arrest and apoptosis of melanoma cells by docosahexaenoic acid: association with decreased $\mathrm{pRb}$ phosphorylation. Cancer Res 60, 4139-4145.

372. Denkins Y, Kempf D, Ferniz M, Nileshwar S, Marchetti D (2005), Role of omega-3 polyunsaturated fatty acids on cyclooxygenase- 2 metabolism in brain-metastatic melanoma. J Lipid Res 46, 1278-1284.

373. Black HS, Rhodes LE (2016), Potential benefits of omega3 fatty acids in non-melanoma skin cancer. J Clin Med 5, E23.

374. Li J, Chen CY, Arita M, Kim K, Li X, Zhang H, Kang JX (2018), An omega-3 polyunsaturated fatty acid derivative, 18-HEPE, protects against CXCR4-associated melanoma metastasis. Carcinogenesis. DOI: 10.1093/carcin/bgy117

375. Latham P, Lund EK, Johnson IT (1999), Dietary n-3 PUFA increases the apoptotic response to 1,2-dimethylhydrazine, reduces mitosis and suppresses the induction of carcinogenesis in the rat colon. Carcinogenesis 20, 645650.

376. West NJ, Clark SK, Phillips RK, Hutchinson JM, Leicester RJ, Belluzzi A, Hull MA (2010), Eicosapentaenoic acid reduces rectal polyp number and size in familial adenomatous polyposis. Gut 59, 918-925.

377. Correia M, Michel V, Matos AA, Carvalho P, Oliveira MJ, Ferreira RM, Dillies MA, Huerre M, Seruca R, Figueiredo C, Machado JC, Touati E (2012), Docosahexaenoic acid inhibits Helicobacter pylori growth in vitro and mice gastric mucosa colonization. PLoS ONE 7, e35072.

378. Wiese DM, Horst SN, Brown CT, Allaman MM, Hodges ME, Slaughter JC, Druce JP, Beaulieu DB, Schwartz DA, Wilson KT, Coburn LA (2016), Serum fatty acids are correlated with inflammatory cytokines in ulcerative colitis. PLoS ONE 11, e0156387.

379. Pickens CA, Albuquerque Pereira MF, Fenton JI (2017), Long-chain $\omega-6$ plasma phospholipid polyunsaturated fatty acids and association with colon adenomas in adult men: a cross-sectional study. Eur J Cancer Prev 26, 497505.

380. Patterson WL 3rd, Georgel PT (2014), Breaking the cycle: the role of omega-3 polyunsaturated fatty acids in inflammation-driven cancers. Biochem Cell Biol 92, $321-328$.

381. Taguchi A, Kawana K, Tomio K, Yamashita A, Isobe Y, Nagasaka K, et al. (2014), Matrix metalloproteinase (MMP)-9 incancer-associated fibroblasts (CAFs) is suppressed by omega-3 polyunsaturated fatty acids in vitro and in vivo. PLoS ONE 9, e89605.

382. Qiu X, Cheng JC, Chang HM, Leung PC (2014), COX2 and PGE2 mediate EGF-induced E-cadherin-independent human ovarian cancer cell invasion. Endocr Relat Cancer 21, 533-543.

383. Hong MY, Chang WC, Chapkin RS, Lupton JR (1997), Relationship among colonocyte proliferation, differentiation, and apo-ptosis as a function of diet and carcinogen. Nutr Cancer 28, 20-29.

384. Brock TG, McNish RW, Coffey MJ, Ojo TC, Phare SM, Peters-Golden M (1996), Effects of granulocyte-macrophage colony-stimulating factor on eicosanoid production by mononuclear phagocytes. J Immunol 156, 25222527 .
385. Das UN (2018), Ageing: is there a role for arachidonic acid and other bioactive lipids? A review. J Adv Res 11, $67-79$.

386. Takano T, Clish CB, Gronert K, Petasis N, Serhan CN (1998), Neutrophil-mediated changes in vascular permeability are inhibited by topical application of aspirintriggered 15-epi-lipoxin A4 and novel lipoxin B4 stable analogues. J Clin Invest 101, 819-826.

387. Serhan CN, Clish CB, Brannon J, Colgan SP, Chiang N, Gronert K (2000), Novel functional sets of lipid-derived mediators with antiinflammatory actions generated from omega-3 fatty acids via cyclooxygenase 2-nonsteroidal antiinflammatory drugs and transcellular processing. J Exp Med 192, 1197-1204.

388. Levy BD, Clish CB, Schmidt B, Gronert K, Serhan CN (2001), Lipid mediator class switching during acute inflammation: signals in resolution. Nat Immunol 2, 612-619.

389. Serhan CN, Hong S, Gronert K, Colgan SP, Devchand PR, Mirick G, Moussignac RL (2002), Resolvins: a family of bioactive products of omega-3 fatty acid transformation circuits initiated by aspirin treatment that counter proinflammation signals. J Exp Med 196, 1025-1037.

390. Hong S, Gronert K, Devchand PR, Moussignac RL, Serhan CN (2003), Novel docosatrienes and 17S-resolvins generated from docosahexaenoic acid in murine brain, human blood, and glial cells. Autacoids in anti-inflammation. J Biol Chem 278, 14677-14687.

391. Marcheselli VL, Hong S, Lukiw WJ, Tian XH, Gronert K, Musto A, Hardy M, Gimenez JM, Chiang N, Serhan CN, Bazan NG (2003), Novel docosanoids inhibit brain ischemia-reperfusion-mediated leukocyte infiltration and pro-inflammatory gene expression. J Biol Chem 278, 43807-43817. Erratum in: J Biol Chem 2003, 278, 51974.

392. Serhan CN (2004), A search for endogenous mechanisms of anti-inflammation uncovers novel chemical mediators: missing links to resolution. Histochem Cell Biol 122, 305-321.

393. Bannenberg GL, Chiang N, Ariel A, Arita M, Tjonahen E, Gotlinger KH, Hong S, Serhan CN (2005), Molecular circuits of resolution: formation and actions of resolvins and protectins. J Immunol 174, 4345-4355. Erratum in: J Immunol 2005, 174, 5884 .

394. Serhan CN (2005), Novel omega - 3-derived local mediators in anti-inflammation and resolution. Pharmacol Ther 105, 7-21.

395. Serhan CN, Petasis NA (2011), Resolvins and protectins in inflammation-resolution. Chem Rev 111, 5922-5943.

396. Dalli J, Winkler JW, Colas RA, Arnardottir H, Cheng CY, Chiang N, Petasis NA, Serhan CN (2013), Resolvin D3 and aspirin-triggered resolvin D3 are potent immunoresolvents. Chem Biol 20, 188-201.

397. Serhan CN (2017), Treating inflammation and infection in the 21st century: new hints from decoding resolution mediators and mechanisms. FASEB J 31, 1273-1288.

398. Serhan CN, Hamberg M, Samuelsson B (1984), Lipoxins: novel series of biologically active compounds formed from arachidonic acid in human leukocytes. Proc Natl Acad Sci USA $81,5335-5339$.

399. Serhan CN, Hamberg M, Samuelsson B (1984), Trihydroxytetraenes: a novel series of compounds formed from arachidonic acid in human leukocytes. Biochem Biophys Res Commun 118, 943-949.

400. Bannenberg G, Moussignac RL, Gronert K, Devchand PR, Schmidt BA, Guilford WJ, Bauman JG, Subramanyam B, Perez HD, Parkinson JF, Serhan CN (2004), 
Lipoxins and novel 15-epi-lipoxin analogs display potent anti-inflammatory actions after oral administration. Br J Pharmacol 143, 43-52.

401. Bannenberg G, Serhan CN (2010), Specialized proresolving lipid mediators in the inflammatory response: an update. Biochim Biophys Acta 1801, 1260-1273.

402. Norling LV, Serhan CN (2010), Profiling in resolving inflammatory exudates identifies novel anti-inflammatory and pro-resolving mediators and signals for termination. $\mathrm{J}$ Intern Med 268, 15-24.

403. Spite M, Serhan CN (2010), Novel lipid mediators promote resolution of acute inflammation: impact of aspirin and statins. Circ Res 107, 1170-1184.

404. Serhan CN (2014), Pro-resolving lipid mediators are leads for resolution physiology. Nature 510, 92-101.

405. Serhan CN, Chiang N, Dalli J, Levy BD (2014), Lipid mediators in the resolution of inflammation. Cold Spring Harb Perspect Biol 7, a016311.

406. Maddox JF, Serhan CN (1996), Lipoxin A4 and B4 are potent stimuli for human monocyte migration and adhesion: selective inactivation by dehydrogenation and reduction. J Exp Med 183, 137-146.

407. Maddox JF, Colgan SP, Clish CB, Petasis NA, Fokin VV, Serhan CN (1998), Lipoxin B4 regulates human monocyte/neutrophil adherence and motility: design of stable lipoxin B4 analogs with increased biologic activity. FASEB J 12, 487-494.

408. Badr KF (1992), 15-Lipoxygenase products as leukotriene antagonists: therapeutic potential in glomerulonephritis. Kidney Int Suppl 38, S101-S108.

409. Das U (2014), HLA-DR expression, cytokines and bioactive lipids in sepsis. Arch Med Sci 10, 325-335.

410. Papayianni A, Serhan CN, Brady HR (1996), Lipoxin A4 and B4 inhibit leukotriene-stimulated interactions of human neutrophils and endothelial cells. J Immunol 156, 2264-2272.

411. Serhan CN, Gotlinger K, Hong S, Arita M (2004), Resolvins, docosatrienes, and neuroprotectins, novel omega-3-derived mediators, and their aspirin-triggered endogenous epimers: an overview of their protective roles in catabasis. Prostaglandins Other Lipid Mediat 73, 155-172.

412. Isobe $\mathrm{Y}$, Arita M, Matsueda S, Iwamoto R, Fujihara T, Nakanishi H, Taguchi R, Masuda K, Sasaki K, Urabe D, Inoue M, Arai H (2012), Identification and structure determination of novel anti-inflammatory mediator resolvin E3, 17, 18-dihydroxyeicosapentaenoic acid. J Biol Chem 287, 10525-10534

413. Hong S, Lu Y, Yang R, Gotlinger KH, Petasis NA, Serhan CN (2007), Resolvin D1, protectin D1, and related docosahexaenoic acid-derived products: analysis via electrospray/low energy tandem mass spectrometry based on spectra and fragmentation mechanisms. J Am Soc Mass Spectrom 18, 128-144.

414. Sun YP, Oh SF, Uddin J, Yang R, Gotlinger K, Campbell E, Colgan SP, Petasis NA, Serhan CN (2007), Resolvin D1 and its aspirin-triggered $17 \mathrm{R}$ epimer. Stereochemical assignments, anti-inflammatory properties, and enzymatic inactivation. J Biol Chem 282, 9323-9334.

415. Bento AF, Claudino RF, Dutra RC, Marcon R, Calixto JB (2011), Omega-3 fatty acid-derived mediators 17(R)hydroxy docosahexaenoic acid, aspirin-triggered resolvin D1 and resolvin D2 prevent experimental colitis in mice. J Immunol 187, 1957-1969.

416. Mas E, Croft KD, Zahra P, Barden A, Mori TA (2012), Resolvins D1, D2, and other mediators of self-limited resolution of inflammation in human blood following n-3 fatty acid supplementation. Clin Chem 58, 1476-1484.
417. Spite M, Norling LV, Summers L, Yang R, Cooper D, Petasis NA, Flower RJ, Perretti M, Serhan CN (2009), Resolvin D2 is a potent regulator of leukocytes and controls microbial sepsis. Nature 461, 1287-1291.

418. Clària J, Dalli J, Yacoubian S, Gao F, Serhan CN (2012), Resolvin D1 and resolvin D2 govern local inflammatory tone in obese fat. J Immunol 189, 2597-2605.

419. Chiang N, Fredman G, Bäckhed F, Oh SF, Vickery T, Schmidt BA, Serhan CN (2012), Infection regulates proresolving mediators that lower antibiotic requirements. Nature 484, 524-528.

420. Clària J, Serhan CN (1995), Aspirin triggers previously undescribed bioactive eicosanoids by human endothelial cell-leukocyte interactions. Proc Natl Acad Sci USA 92, 9475-9479.

421. Chiang N, Fierro IM, Gronert K, Serhan CN (2000), Activation of lipoxin A(4) receptors by aspirintriggered lipoxins and select peptides evokes ligandspecific responses in inflammation. J Exp Med 191, 1197-1208.

422. Clish CB, O'Brien JA, Gronert K, Stahl GL, Petasis NA, Serhan CN (1999), Local and systemic delivery of a stable aspirin-triggered lipoxin prevents neutrophil recruitment in vivo. Proc Natl Acad Sci USA 96, 8247-8252.

423. Mitchell S, Thomas G, Harvey K, Cottell D, Reville K, Berlasconi G, Petasis NA, Erwig L, Rees AJ, Savill J, Brady HR, Godson C (2002), Lipoxins, aspirin-triggered epi-lipoxins, lipoxin stable analogues, and the resolution of inflammation: stimulation of macrophage phagocytosis of apoptotic neutrophils in vivo. J Am Soc Nephrol 13, 2497-2507.

424. Winkler JW, Uddin J, Serhan CN, Petasis NA (2013), Stereocontrolled total synthesis of the potent antiinflammatory and pro-resolving lipid mediator resolvin D3 and its aspirin-triggered 17R-epimer. Org Lett 15, 1424-1427.

425. Colby JK, Abdulnour RE, Sham HP, Dalli J, Colas RA, Winkler JW, Hellmann J, Wong B, Cui Y, El-Chemaly S, Petasis NA, Spite M, Serhan CN, Levy BD (2016), Resolvin D3 and aspirin-triggered resolvin D3 are protective for injured epithelia. Am J Pathol 186, 18011813.

426. Bazan NG (2005), Neuroprotectin D1 (NPD1): a DHAderived mediator that protects brain and retina against cell injury-induced oxidative stress. Brain Pathol 15, 159166.

427. Mukherjee PK, Marcheselli VL, Serhan CN, Bazan NG (2004), Neuroprotectin D1: a docosahexaenoic acidderived docosatriene protects human retinal pigment epithelial cells from oxidative stress. Proc Natl Acad Sci USA 101, 8491-8496.

428. Ariel A, Li PL, Wang W, Tang WX, Fredman G, Hong S, Gotlinger KH, Serhan CN (2005), The docosatriene protectin D1 is produced by $\mathrm{TH} 2$ skewing and promotes human $\mathrm{T}$ cell apoptosis via lipid raft clustering. J Biol Chem 280, 43079-43086.

429. Duffield JS, Hong S, Vaidya VS, Lu Y, Fredman G, Serhan CN, Bonventre JV (2006), Resolvin D series and protectin D1 mitigate acute kidney injury. J Immunol 177, 59025911.

430. Gronert K, Maheshwari N, Khan N, Hassan IR, Dunn M, Laniado Schwartzman M (2005), A role for the mouse 12/ 15-lipoxygenase pathway in promoting epithelial wound healing and host defense. J Biol Chem 280, 15267-15278.

431. Serhan CN, Gotlinger K, Hong S, Lu Y, Siegelman J, Baer T, Yang R, Colgan SP, Petasis NA (2006), Antiinflammatory actions of neuroprotectin D1/protectin D1 
and its natural stereoisomers: assignments of dihydroxycontaining docosatrienes. J Immunol 176, 1848-1859. Erratum in: J Immunol 2006, 176, 3843.

432. Levy BD, Kohli P, Gotlinger K, Haworth O, Hong S, Kazani S, Israel E, Haley KJ, Serhan CN (2007), Protectin D1 is generated in asthma and dampens airway inflammation and hyperresponsiveness. J Immunol 178, 496502.

433. Yanes O, Clark J, Wong DM, Patti GJ, Sánchez-Ruiz A, Benton HP, Trauger SA, Desponts C, Ding S, Siuzdak G (2010), Metabolic oxidation regulates embryonic stem cell differentiation. Nat Chem Biol 6, 411-417.

434. Lukiw WJ, Cui JG, Marcheselli VL, Bodker M, Botkjaer A, Gotlinger K, Serhan CN, Bazan NG (2005), A role for docosahexaenoic acid-derived neuroprotectin D1 in neural cell survival and Alzheimer disease. J Clin Invest 115, 2774-2783.

435. Serhan CN, Dalli J, Colas RA, Winkler JW, Chiang N (2015), Protectins and maresins: new pro-resolving families of mediators in acute inflammation and resolution bioactive metabolome. Biochim Biophys Acta 1851, 397413.

436. Chen P, Fenet B, Michaud S, Tomczyk N, Véricel E, Lagarde M, Guichardant M (2009), Full characterization of PDX, a neuroprotectin/protectin D1 isomer, which inhibits blood platelet aggregation. FEBS Lett 583, 34783484 .

437. Serhan CN, Yang R, Martinod K, Kasuga K, Pillai PS, Porter TF, Oh SF, Spite M (2009), Maresins: novel macrophage mediators with potent antiinflammatory and proresolving actions. J Exp Med 206, 15-23.

438. Hong S, Lu Y, Tian H, Alapure BV, Wang Q, Bunnell BA, Laborde JM (2014), Maresin-like lipid mediators are produced by leukocytes and platelets and rescue reparative function of diabetes-impaired macrophages. Chem Biol 21, 1318-1329.

439. Xian W, Wu Y, Xiong W, Li L, Li T, Pan S, Song L, Hu L, Pei L, Yao S, Shang Y (2016), The pro-resolving lipid mediator Maresin 1 protects against cerebral ischemia/ reperfusion injury by attenuating the pro-inflammatory response. Biochem Biophys Res Commun 472, 175-181.

440. Sasaki K, Urabe D, Arai H, Arita M, Inoue M (2011), Total synthesis and bioactivities of two proposed structures of maresin. Chem Asian J 6, 534-543.

441. Serhan CN, Dalli J, Karamnov S, Choi A, Park CK, Xu ZZ, Ji RR, Zhu M, Petasis NA (2012), Macrophage proresolving mediator maresin 1 stimulates tissue regeneration and controls pain. FASEB J 26, 1755-1765.

442. Gao J, Tang C, Tai LW, Ouyang Y, Li N, Hu Z, Chen X (2018), Pro-resolving mediator maresin 1 ameliorates pain hypersensitivity in a rat spinal nerve ligation model of neuropathic pain. J Pain Res 11, 1511-1519.

443. Dalli J, Zhu M, Vlasenko NA, Deng B, Haeggström JZ, Petasis NA, Serhan CN (2013), The novel 13S,14S-epoxymaresin is converted by human macrophages to maresin 1 (MaR1), inhibits leukotriene A4 hydrolase (LTA4H), and shifts macrophage phenotype. FASEB J 27, 2573-2783.

444. Dalli J, Vlasakov I, Riley IR, Rodriguez AR, Spur BW, Petasis NA, Chiang N, Serhan CN (2016), Maresin conjugates in tissue regeneration biosynthesis enzymes in human macrophages. Proc Natl Acad Sci USA 113, $12232-12237$.

445. Li R, Wang Y, Zhao E, Wu K, Li W, Shi L, Wang D, Xie G, Yin Y, Deng M, Zhang P, Tao K (2016), Maresin 1, a proresolving lipid mediator, mitigates carbon tetrachloride-induced liver injury in mice. Oxid Med Cell Longev $2016,9203716$.
446. Nordgren TM, Heires AJ, Wyatt TA, Poole JA, LeVan TD, Cerutis DR, Romberger DJ (2013), Maresin-1 reduces the pro-inflammatory response of bronchial epithelial cells to organic dust. Respir Res 14, 51 .

447. Marcon R, Bento AF, Dutra RC, Bicca MA, Leite DF, Calixto JB (2013), Maresin 1, a proresolving lipid mediator derived from omega-3 polyunsaturated fatty acids, exerts protective actions in murine models of colitis. J Immunol 191, 4288-4298.

448. Wang CW, Colas RA, Dalli J, Arnardottir HH, Nguyen D, Hasturk H, Chiang N, Van Dyke TE, Serhan CN (2015), Maresin 1 biosynthesis and proresolving anti-infective functions with human-localized aggressive periodontitis leukocytes. Infect Immun 84, 658-665.

449. Sun Q, Wu Y, Zhao F, Wang J (2017), Maresin 1 inhibits transforming growth factor- $\beta 1$-induced proliferation, migration and differentiation in human lung fibroblasts. Mol Med Rep 16, 1523-1529.

450. Wang Y, Li R, Chen L, Tan W, Sun Z, Xia H, Li B, Yu Y, Gong J, Tang M, Ji Y, Yuan S, Shanglong Y, Shang Y (2015), Maresin 1 inhibits epithelial-to-mesenchymal transition in vitro and attenuates bleomycin induced lung fibrosis in vivo. Shock 44, 496-502.

451. Akagi D, Chen M, Toy R, Chatterjee A, Conte MS (2015), Systemic delivery of proresolving lipid mediators resolvin D2 and maresin 1 attenuates intimal hyperplasia in mice. FASEB J 29, 2504-2513.

452. Deng B, Wang CW, Arnardottir HH, Li Y, Cheng CY, Dalli J, Serhan CN (2014), Maresin biosynthesis and identification of maresin 2, a new anti-inflammatory and pro-resolving mediator from human macrophages. PLoS ONE 9, e102362.

453. Gu Z, Lamont GJ, Lamont RJ, Uriarte SM, Wang H, Scott DA (2016), Resolvin D1, resolvin D2 and maresin 1 activate the GSK3 $\beta$ anti-inflammatory axis in TLR4engaged human monocytes. Innate Immun 22, 186-195.

454. Wallace JL (2018), Eicosanoids in the gastrointestinal tract. Br J Pharmacol. DOI: 10.1111/bph.14178

455. Chandrasekharan JA, Huang XM, Hwang AC, SharmaWalia N (2016), Altering the anti-inflammatory lipoxin microenvironment: a new insight into Kaposi's sarcomaassociated herpesvirus pathogenesis. J Virol 90, 1102011031.

456. Kirkby NS, Chan MV, Zaiss AK, Garcia-Vaz E, Jiao J, Berglund LM, Verdu EF, Ahmetaj-Shala B, Wallace JL, Herschman HR, Gomez MF, Mitchell JA (2016), Systematic study of constitutive cyclooxygenase-2 expression: role of NF-кB and NFAT transcriptional pathways. Proc Natl Acad Sci USA 113, 434-439.

457. Mensing H, Czarnetzki BM (1984), Leukotriene B4 induces in vitro fibroblast chemotaxis. J Invest Dermatol 82, 9-12.

458. Baud L, Perez J, Denis M, Ardaillou R (1987), Modulation of fibroblast proliferation by sulfidopeptide leukotrienes: effect of indomethacin. J Immunol 138, 1190-1195.

459. Pannunzio A, Coluccia M (2018), Cyclooxygenase-1 (COX-1) and COX-1 inhibitors in cancer: a review of oncology and medicinal chemistry literature. Pharmaceuticals (Basel) 11, E101.

460. Chatterjee K, Jana S, Choudhary P, Swarnakar S (2018), Triumph and tumult of matrix metalloproteinases and their crosstalk with eicosanoids in cancer. Cancer Metastasis Rev 37, 279-288.

461. Gomes RN, Felipe da Costa S, Colquhoun A (2018), Eicosanoids and cancer. Clinics (Sao Paulo) 73 (suppl 1), e530s. 
462. Kühn H, Humeniuk L, Kozlov N, Roigas S, Adel S, Heydeck D (2018), The evolutionary hypothesis of reaction specificity of mammalian ALOX15 orthologs. Prog Lipid Res 72, 55-74.

463. Yang W, Wang X, Xu L, Li H, Wang R (2018), LOX inhibitor HOEC interfered arachidonic acid metabolic flux in collagen-induced arthritis rats. Am J Transl Res 10, 2542-2554.

464. Brücher BLDM, Jamall IS (2019), Undervalued ubiquitous proteins. 4open 2, 7, 1-13, https://doi.org/10.1051/ fopen $/ 2019002$

465. Brücher BLDM, Jamall IS (2019), Chronic inflammation evoked by pathogenic stimulus during carcinogenesis. 4open 2, 8, 1-22, https://doi.org/10.1051/fopen/2018006

466. Brücher BLDM, Jamall IS (2019), Precancerous niche (PCN), a product of fibrosis with remodeling by incessant chronic inflammation. 4open 2, 11, 1-21, https://doi.org/ $10.1051 /$ fopen/2018009

467. Brücher BLDM, Jamall IS (2019), Microbiome and morbid obesity increase pathogenic stimulus diversity. 4open 2, 10, 1-16, https://doi.org/10.1051/fopen/2018007
468. Brücher BLDM, Jamall IS (2019), Transition from normal to cancerous cell by precancerous niche (PCN) induced chronic cell-matrix stress. 4open 2, https://doi.org/ $10.1051 /$ fopen $/ 2018996$

469. Morteau O (2000), Prostaglandins and inflammation: the cyclooxygenase controversy. Arch Immunol Ther Exp (Warsz) 48, 473-480.

470. Hawkey CJ (2001), Nonsteroidal anti-inflammatory drugs and the gastrointestinal tract: consensus and controversy. Introduction. Am J Med 110, 1S-3S.

471. Bonner GF (2002), Using COX-2 inhibitors in IBD: antiinflammatories inflame a controversy. Am J Gastroenterol 97, 783-785.

472. Khanna D, Khanna PP, Furst DE (2005), COX-2 controversy: where are we and where do we go from here? Inflammopharmacology 13, 395-402.

473. Brücher BLDM, Jamall IS (2014), Epistemology of the origin of cancer: a new paradigm. BMC Cancer 14, 1-15.

474. Brücher BLDM, Jamall IS (2014), Cell-cell communication in tumor microenvironment, carcinogenesis and anticancer treatment. Cell Physiol Biochem 34, 213-243.

Cite this article as: Brücher BLDM, Jamall IS. (2019), Eicosanoids in carcinogenesis. 4open, 2, 9. 